Trans. zool. Soc. Lond. (1978) 34, 347-416

\title{
The characteristics and affinities of the Amphisbaenia
}

\author{
CARL Gans \\ Division of Biological Sciences, The University of Michigan, \\ Ann Arbor, Michigan, U.S.A.
}

(Accepted 13 June 1978)

Published for

THE ZOOLOGICAL SOCIETY OF LONDON

by

ACADEMIC PRESS 
COPYRIGHT (C) 1978 THE ZOOLOGICAL SOCLETY OF LONDON, REGENT'S PARK, LONDON, NW1 4RY 


\section{The characteristics and affinities of the Amphisbaenia}

The amphisbaenians, to judge from the many changes of opinion regarding their appropriate position among the vertebrates, appear to have puzzled most students of herpetology. Reevaluation suggests that a case may now be made for classifying the amphisbaenians as an order, separate from the lizards and snakes, but included with them in a superorder Squamata. Evidence for such a position may be derived from several dozen systems in which amphisbaenians differ from lizards, from snakes, or from both. Although individual character states are occasionally equivalent to those shown by one or another family of lizards, there is no "closest" family. This suggests that the Amphisbaenia probably diverged from the remainder of the Squamata before the diversification of all present families of lizards. Unfortunately many of the character states are still known from only a limited number of amphisbaenians and information for other groupings of squamates is similarly inadequate. 


\section{Contents}

$\begin{array}{llllllllllllllll}\text { Introduction } & \ldots & \ldots & \ldots & \ldots & \ldots & \ldots & \ldots & \ldots & \ldots & \ldots & \ldots & 353\end{array}$

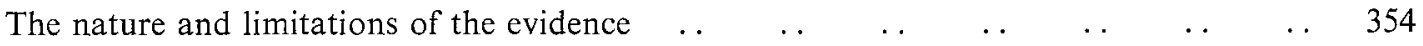

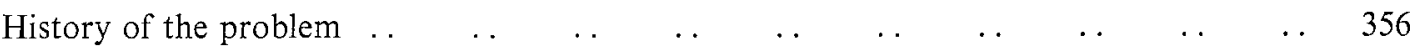

$\begin{array}{llllllllllllll}\text { Suprageneric status } & \ldots & \ldots & \ldots & \ldots & \ldots & \ldots & \ldots & \ldots & \ldots & \ldots & 361\end{array}$

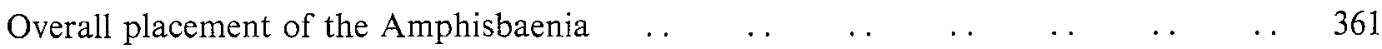

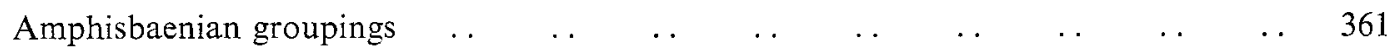

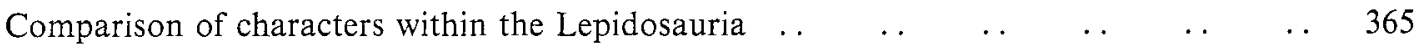

$\begin{array}{lllllllllllllll}\text { General } & \ldots & \ldots & \ldots & \ldots & \ldots & \ldots & \ldots & \ldots & \ldots & \ldots & \ldots & 365\end{array}$

$\begin{array}{llllllllllllll}\text { Locomotor pattern } & \ldots & \ldots & \ldots & \ldots & \ldots & \ldots & \ldots & \ldots & \ldots & \ldots & 365\end{array}$

$\begin{array}{lllllllllllll}\text { Burrowing patterns } & \ldots & \ldots & \ldots & \ldots & \ldots & \ldots & \ldots & \ldots & \ldots & \ldots & 366\end{array}$

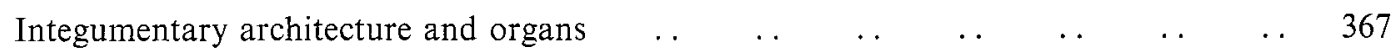

$\begin{array}{llllllllllllll}\text { Osteocranium } & \ldots & \ldots & \ldots & \ldots & \ldots & \ldots & \ldots & \ldots & \ldots & \ldots & \ldots & 369\end{array}$

$\begin{array}{llllllllllllll}\text { Chondrocranium } & \ldots & \ldots & \ldots & \ldots & \ldots & \ldots & \ldots & \ldots & \ldots & \ldots & 373\end{array}$

$\begin{array}{lllllllllllll}\text { Cranial kinesis } & \ldots & \ldots & \ldots & \ldots & \ldots & \ldots & \ldots & \ldots & \ldots & \ldots & 374\end{array}$

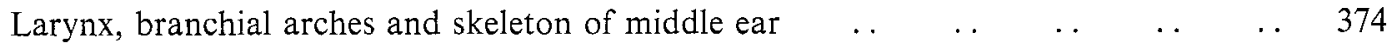

$\begin{array}{llllllllllllll}\text { Inner } \operatorname{ear} & \ldots & \ldots & \ldots & \ldots & \ldots & \ldots & \ldots & \ldots & \ldots & \ldots & \ldots & 377\end{array}$

$\begin{array}{lllllllllllllll}\text { Nasal system } & \ldots & \ldots & \ldots & \ldots & \ldots & \ldots & \ldots & \ldots & \ldots & \ldots & \ldots & 379\end{array}$

$\begin{array}{lllllllllllllll}\text { Teeth } & \ldots & \ldots & \ldots & \ldots & \ldots & \ldots & \ldots & \ldots & \ldots & \ldots & \ldots & \ldots & 380\end{array}$

$\begin{array}{lllllllllllllll}\text { Tongue } \ldots & \ldots & \ldots & \ldots & \ldots & \ldots & \ldots & \ldots & \ldots & \ldots & \ldots & \ldots & 380\end{array}$

$\begin{array}{llllllllllllllll}\text { Buccal glands } & \ldots & \ldots & \ldots & \ldots & \ldots & \ldots & \ldots & \ldots & \ldots & \ldots & \ldots & 381\end{array}$

$\begin{array}{llllllllllllll}\text { Head muscles } & \ldots & \ldots & \ldots & \ldots & \ldots & \ldots & \ldots & \ldots & \ldots & \ldots & \ldots & 381\end{array}$

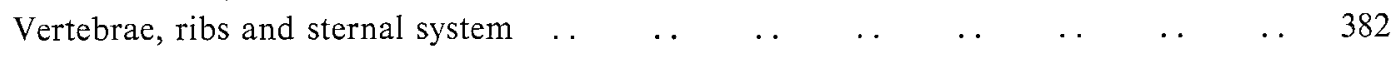

$\begin{array}{lllllllllllll}\text { Limb girdles and limbs } & \ldots & \ldots & \ldots & \ldots & \ldots & \ldots & \ldots & \ldots & \ldots & 383\end{array}$

$\begin{array}{llllllllllllll}\text { Trunk muscles } & \ldots & \ldots & \ldots & \ldots & \ldots & \ldots & \ldots & \ldots & \ldots & \ldots & 385\end{array}$

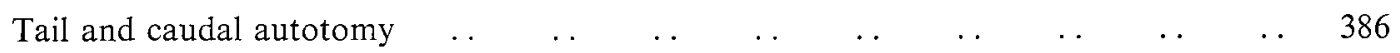

$\begin{array}{lllllllllllllll}\text { Hypophysis } & \ldots & \ldots & \ldots & \ldots & \ldots & \ldots & \ldots & \ldots & \ldots & \ldots & \ldots & 387\end{array}$

$\begin{array}{llllllllllllll}\text { Adrenal glands } & \ldots & \ldots & \ldots & \ldots & \ldots & \ldots & \ldots & \ldots & \ldots & \ldots & 387\end{array}$

$\begin{array}{lllllllllllllll}\text { Pancreas } & \ldots & \ldots & \ldots & \ldots & \ldots & \ldots & \ldots & \ldots & \ldots & \ldots & \ldots & 388\end{array}$

$\begin{array}{lllllllllllll}\text { Thyroid and parathyroid } & \ldots & \ldots & \ldots & \ldots & \ldots & \ldots & \ldots & \ldots & \ldots & 388\end{array}$

$\begin{array}{lllllllllllllll}\text { Thymus . } & \ldots & \ldots & \ldots & \ldots & \ldots & \ldots & \ldots & \ldots & \ldots & \ldots & \ldots & 388\end{array}$

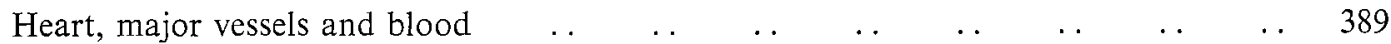

$\begin{array}{llllllllllllllll}\text { Lungs } & \ldots & \ldots & \ldots & \ldots & \ldots & \ldots & \ldots & \ldots & \ldots & \ldots & \ldots & \ldots & 391\end{array}$

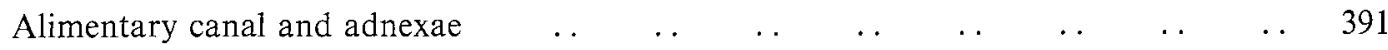

$\begin{array}{llllllllllllll}\text { Liver and bile ducts } & \ldots & \ldots & \ldots & \ldots & \ldots & \ldots & \ldots & \ldots & \ldots & \ldots & 393\end{array}$ 
$\begin{array}{lllllllllllllll}\text { Spleen } & \ldots & \ldots & \ldots & \ldots & \ldots & \ldots & \ldots & \ldots & \ldots & \ldots & \ldots & \ldots & 393\end{array}$

$\begin{array}{llllllllllllll}\text { Fat bodies } & \ldots & \ldots & \ldots & \ldots & \ldots & \ldots & \ldots & \ldots & \ldots & \ldots & \ldots & 393\end{array}$

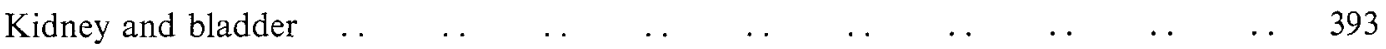

$\begin{array}{lllllllllllll}\text { Gonads } & \ldots & \ldots & \ldots & \ldots & \ldots & \ldots & \ldots & \ldots & \ldots & \ldots & \ldots & 394\end{array}$

$\begin{array}{llllllllllllll}\text { Hemipenes } & \ldots & \ldots & \ldots & \ldots & \ldots & \ldots & \ldots & \ldots & \ldots & \ldots & \ldots & 395\end{array}$

$\begin{array}{lllllllllllll}\text { Brain } & \ldots & \ldots & \ldots & \ldots & \ldots & \ldots & \ldots & \ldots & \ldots & \ldots & \ldots & \ldots\end{array}$

$\begin{array}{lllllllllllllll}\text { Cranial nerves } & . & \ldots & \ldots & \ldots & \ldots & \ldots & \ldots & \ldots & \ldots & \ldots & \ldots & 396\end{array}$

$\begin{array}{lllllllllllll}\text { Appendicular plexuses } & \ldots & \ldots & \ldots & \ldots & \ldots & \ldots & \ldots & \ldots & \ldots & 397\end{array}$

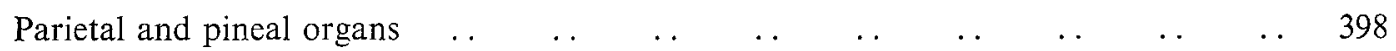

$\begin{array}{llllllllllllllll}\text { Eyes } & \ldots & \ldots & \ldots & \ldots & \ldots & \ldots & \ldots & \ldots & \ldots & \ldots & \ldots & \ldots & 398\end{array}$

$\begin{array}{lllllllllllllll}\text { Mast cells } & \ldots & \ldots & \ldots & \ldots & \ldots & \ldots & \ldots & \ldots & \ldots & \ldots & \ldots & 399\end{array}$

$\begin{array}{llllllllllllll}\text { Karyotypes } & \ldots & \ldots & \ldots & \ldots & \ldots & \ldots & \ldots & \ldots & \ldots & \ldots & \ldots & 399\end{array}$

$\begin{array}{llllllllllllll}\text { Discussion } & \ldots & \ldots & \ldots & \ldots & \ldots & \ldots & \ldots & \ldots & \ldots & \ldots & \ldots & 401\end{array}$

$\begin{array}{llllllllllllllll}\text { References } & \ldots & \ldots & \ldots & \ldots & \ldots & \ldots & \ldots & \ldots & \ldots & \ldots & \ldots & 404\end{array}$ 


\section{INTRODUCTION}

"Geminum caput Amphisbaenae, hoc est, et a cauda, tanquam, parum esset uno ore fundi venenum." [The amphisbaena has a pair of heads, that is another one on the tail; as if it were not enough for poison to pour forth from one only.] Pliny, Lib. 8, cap. 25.

"Phylogenetic schemes are always useful when constructed with proper discrimination and with due regard to the known and the unknown." Williston (1917: 411).

"This type of writing is not a joyous form of self-expression but the manifestation of a twitching at once cosmic and mundane." Thurber (1933: 10).

The Class Reptilia represents a most heterogeneous assemblage. Here traditionally have been placed all Recent amniotes that have neither hair nor feathers. It is not surprising that authors have suggested that certain reptilian categories, such as the turtles (Parsons, 1959; von Hofsten, 1941), may well represent lines of distinct origin, while arguments persist about the exact placement of other groups, such as the Crocodilia (Reig, 1967), birds (Ostrom, 1974, 1975) and dinosaurs (Bakker \& Galton, 1974; Charig, 1976; Thulborn, 1975).

Another group of reptiles whose origin and relationships pose some problems are the Amphisbaenia. Equal numbers of workers have placed them with the lizards or considered them distinct, and the consensus seems to have cycled from one position to the other. The uncertainty is at least partly due to the high degree of modification of their skulls, to the reduction or extreme modification ("degeneration" or "specialization") of their locomotor system, and to the scarcity of embryos available for anatomical study.

I have been concerned with this problem of probable assignment for more than a decade. As a by-product of a review of amphisbaenian systematics at the species level and reconsideration of their adaptive pattern, I have gradually collected information pertinent to the issue and have attempted to interest others in the question. Recently the level of information has become sufficient to reconsider the probable affinities of the Amphisbaenia* to other reptiles. In order to provide a basis for further discussion, I here present a summary of the data which have gradually led me to conclude that the Amphisbaenia probably merit recognition as a distinct order including four families (Table I) of the Reptilia, to be placed with the Sauria and Serpentes in the superorder Squamata. Rather than a definitive analysis, this paper represents a statement of the current level of information on amphisbaenian character states with incidental comments on the probable reliability

* Throughout this paper I use the term Amphisbaenia when I intend to include all species, and use the more restrictive term Amphisbaenidae for members of that subgroup (excluding the Trogonophidae, Bipedidae, and Rhineuridae) when this is all that the data mentioned imply. Generic and specific names are similarly modernized. Only in the historical section do I retain some of the exact terms used by authors, even when the terms are archaic. 
and generality of these data. It is hoped that further analyses of reptilian systematics may take this group into account.

I am grateful to all who have commented on the evidence or have provided me with summaries of their current investigation, though it is obvious that responsibility for opinions expressed and errors perpetrated is entirely my own. Many friends personally discussed these matters with me, and Drs A. d'A. Bellairs, D. L. Cundall, H. C. Dessauer, A. E. Greer, G. Haas, T. S. Parsons, P. J. Regal, O. Rieppel, A. P. Russell, H. Saint Girons, G. L. Underwood, E. G. Wever, and G. Zug reviewed various instars of the manuscript. Dr E. G. Wever let me refer to the amphisbaenian heads sectioned for our studies of reptilian ears. Drs A. d'A. Bellairs, T. S. Parsons and H. Saint Girons most kindly made available portions of unpublished manuscripts on related topics. I thank Drs I. R. Baird, A. d'A. Bellairs, H. Dundee, P. Hyde, E. May, M. Miller, R. G. Northcutt, T. S. Parsons, R. Platel, S. Renous-Léçuru, O. Rieppel, and H. Saint Girons for advice on specific issues raised herein. Grants, currently BMS 77 02602, from the U.S. National Science Foundation have supported these studies.

THE NATURE AND LIMITATIONS OF THE EVIDENCE

It might be argued that we need an overall re-evaluation of the subdivisions of the Squamata before we can start to analyze the position of the amphisbaenians. I desist from such re-evaluation and, for the moment, proceed on the implicit assumption that the Sauria and the Serpentes are each monophyletic, reasonably well defined categories (cf. Romer, 1956). The problems of their classification mainly concern the affinities and placement of their component families relative to each other (cf. Underwood, 1957b, 1967) rather than the question of which families are lizards and which are snakes.

The following analysis was initially based upon the literature; gradually, it has been expanded by data from current studies by myself and also by colleagues on materials assembled by me. Many of the earlier statements came from anatomical papers, and I was thus (and often still am) depending not only on the accuracy of each author's observations, but also on the correctness of specific and generic identifications or assignments. Beyond this, I am relying on those characteristics that have thus far been studied or considered useful for analysis. I have tried to offset possible bias by referring to every comparative study known to me in which even one amphisbaenian species was included. It is, of course, unfortunate that many more recent observations are still based on but a few (or a single) specimens of a single or at most a few species of amphisbaenians. This is regrettable as the more than 20 clearly defined genera of amphisbaenians are currently assigned to four families and consequently differ substantially in the expression of some of the characteristics here discussed. Furthermore, most amphisbaenian names and their current generic assignments date from the present century. Thus the old names Amphisbaena cinerea and $A$. brasiliana refer to species now placed more properly in the genera Blanus and Bronia. Therefore, Camp's (1923: 342) statement, that "Amphisbaena has been said to have a persistent connection of the hyoid arch with the skull", makes sense only when one realizes that the author cited (Versluys, 1903) referred to an earlier paper (Bedriaga, 1884) on $A$. cinerea (=Blanus).

Further difficulties derive from the scarcity of comparative information for the groups with which the amphisbaenians should be compared (cf. Gans, 1975). Thus, isolated studies in which the condition in an amphisbaenian is analyzed, relative only to the 
conditions in birds and mammals, inevitably pose difficulties in identifying the structural details to which reference is made. As long as the cochlea of a single species of amphisbaenian could be compared to those of only two teiids (Schmidt, 1964: 548), and these not of the group (gymnophthalmines, MacLean, 1974) perhaps most similar to amphisbaenians, incidental statements regarding phylogeny could have only low probability. Many systems and groups merit additional attention; the recent emphasis on the morphology of various pygopodids and gymnophthalmines is particularly welcome.

The procedure of tabulating multiple characters in order to determine the affinities of obscure groups is well established (cf. Camp, 1923; Underwood, 1957b; Kluge, 1976b). One must be cautious of the implication that all members of a monophyletic group need now share a single characteristic (or set of characteristics). Such single differentiating characters may be useful when one is constructing keys to groups; they are an unnecessary precondition for the conclusion that the group is indeed derived from a common ancestor. Though the ideal "key" character may mark the separation of the group from a sister stock, the characteristic may have become subsequently modified in some or all surviving members of the group. Furthermore, "derived" characteristics, though widely shared, may be lacking in the group's least modified members. Parallelism and convergence make reliance upon a single characteristic unsafe, whether one is dealing with bones or with chromosomes, scale counts or hair cell number. Only simultaneous comparison of the evidence from many systems and their assay on a wide spectrum of component species is apt to yield an acceptable estimate of relationships.

Even though the evidence derived from any one characteristic may be inadequate, some increase in probability may be obtained by increasing the number of characteristics examined, provided that these are indeed non-associated. When each of several parameters of two taxonomic groups indicates with a probability, $P$, that they are distinct, the overall probability that the groups are distinct is likely to be greater than $P$. In the present instance, the amphisbaenians are indeed found to differ from snakes, from lizards, or again from both for a significant portion of the characteristics thus far checked in detail. Consequently, it is probable that the three groups have long, separate histories. The aggregate probability must stand unless (1) the individual observations are proven invalid, (2) the statements from the literature have been misinterpreted, and/or (3) the species selected for comparison prove to incorporate an intrinsic, but unforeseen bias.

Another aspect needs emphasis. Some characteristics of the amphisbaenians show similarity to those of certain families of lizards. This observation would be suggestive of affinity as long as the same lizard family was always involved. When several characters, each suggesting affinity of the Amphisbaenia to a particular (but usually to a different) family of lizards, and when multiple, broadly shared similarities remain lacking, the pattern is probably due to a complex of parallelism and convergence. Many of the aspects for which similarity has been claimed (putative shared character states) are here included mainly to submit them to test. It appears illogical at this moment to cite their occurrence as indicating more than a general relationship between Amphisbaenia and Sauria.

The existence of the numerous differences tabulated below has often been overlooked. Many papers, reviewing the taxonomic variability of a single anatomical structure, region, or physiological system, present such new information in some phylogenetic or similar scheme. However, analysis suggests that these schemata are rarely generated de novo from the information derived from the new study. Rather, there seems to be a tendency 
to check the "new" information in order to see whether it forces a modification in one of the generally accepted phylogenies. Such an approach then incorporates a bias for the status quo, particularly when characteristics that do not fit the accepted pattern are downgraded. The paper of Richter (1933: 478) provides an excellent example of this. He observed that the hyoid and hyoid musculature of the Amphisbaenidae differed from those of all lizards seen by him. He nevertheless placed the Amphisbaenia adjacent to the teiids, (1) because Boulenger and Fürbringer had placed them there, and (2) as amphisbaenids (not their hyoids) had great (and presumably external) "Ähnlichkeit" (= similarity) to limbless teiids! Thus, such procedures can be as inadequate as attempts to modify a classification based only on a single anatomical characteristic.

\section{HISTORY OF THE PROBLEM}

The historical discussion that follows is purposely selective. It is not intended as an exhaustive compilation but is presented only to trace the development of present concepts of phylogeny, the change of the so-called "climate of opinion" with time. Papers dealing primarily with one or another structure are thus relegated to the discussion of the evidence.

Linné (1758: 229) mentioned only two species, ascribing them to Amphisbaena. His placement of the genus among the "Amphibia serpentes" was accepted by contemporary authors; only Bipes* was generally placed in some sort of relation to the lizards (cf. Lacépède, 1788, 1789; Sonnini \& Latreille, 1802; Oppel, 1811; Fleming, 1822).

Gray (1825) recognized five orders of Recent reptiles. Of these, the first (Sauri) and fifth (Saurophidii) contained lizards; the latter order was composed of skinks, anguids, cordylids, typhlopids and those amphisbaenians then known. A similarly complex arrangement is represented by Wagler's order Angues (1830); Merrem (1820) placed the limbless amphisbaenians among the snakes, with Bipes in the adjacent group Incendentia, between snakes and lizards. Fitzinger (1826) furnished the first classification in which Amphisbaena, Leposternon and Bipes are together in the "family" Amphisbaenoidea, which he placed next to the Typhlopoidea and included both under the lizards.

The famous biologist Johannes Müller (1831) furnished the first review of the skeleton and soft tissue morphology of these animals. In his broad review of the structure of amphibians and reptiles with reduced limbs, he commented on members of the amphisbaenian genera Amphisbaena, Blanus, Bipes, Leposternon and Trogonophis. He placed Bipes with the other amphisbaenians, and indicated that the composite group was quite distinct from most snakes and more similar to lizards. He nevertheless retained them in the family Amphisbaenoidea, which he placed in the group "Ophidia microstomata" together with various burrowing snakes. Wiegmann (1834) may have been moved by Müller's analysis to separate the amphisbaenians as the distinct [sub]order, Annulati [paralleling the Loricati (=Crocodilia) and Squamata ( $=$ Sauria) of his order Sauri], and probably leading Fitzinger (1843) to use the term as a "tribus" over the two families of amphisbaenians, which he included under the Leptoglossae.

In 1839 and again in 1840, Bonaparte, in two papers almost never cited in this connection, included the amphisbaenians in his distinct order Saurophidii, in parallel with his orders Saurii and Ophidii. Interestingly enough, he later abandoned this view, and in 1845 and 1850 , included the amphisbaenians among the lizards. It is unfortunately impossible to determine what prompted either of his decisions, unless it was the appearance

\footnotetext{
* Referred to as Bimanus and Chirotes, because Bipes was then used for a pygopodid.
} 
of the fifth volume of the Erpétologie générale (Duméril \& Bibron, 1839). The amphisbaenians were there placed among the lizards as a subfamily, "Cyclosaures glyptodermes", which was assigned to a group that included some teiids. Yet even these authors (or Bibron alone, cf. Gervais, 1853:297f) mentioned, in a generally overlooked paragraph in the introduction to their volume (1839: viii), that the assignment of the amphisbaenians to the "Cyclosaures" dated to the time when the initial scheme was drawn. At the time the introduction was written, they regarded the amphisbaenians as a distinct order that should be placed beside the lizards and the snakes, "particularly to Typhlops". The new scheme was to be included in a summary statement that never seems to have appeared in print.

In 1844, Gray placed the amphisbaenians in a distinct order, the Amphisbaenia, and his colleague Simon (1844) accepted this classification. Gray's paper is generally (and of course incorrectly) cited as presenting the first support for this view, and his diagnosis (1844: 68) hence merits attention:

Body elongate, cylindrical, naked, with square imbedded plates placed in cross rings, divided into two sets by a slight longitudinal groove on each side. Tail short, continuous, blunt. Tongue not sheathed, flat, enlarged and nicked at the end, ending in 2 smooth threads, the rest covered with large flat papillae or scales. Eyes small, under the skin; eyelid none. Ear hidden under the skin. Mouth small; jaws not extensile. Feet none, or rarely in front. Penis double. Vent rather transversely plaited. Skull very solid; orbits incomplete; tympanic bone inclosed in the skull, oblique; parietal bone simple; temporal and mastoid bones scarcely separate.

The following year Gray (1845: 1) repeated his diagnosis of the major reptilian groupings. He continued to place the amphisbaenians as an order of his Cataphracta or shielded reptiles, defined as having a solid skull, recessed ear bones, and solidly united jaws, and designed to include those reptiles (as turtles and crocodilians and contrasted with the Squamata or scaly forms) the head and body of which were covered with regular shields. He did not note that the Amphisbaenia disagreed with the group definition by possessing bifid rather than simple intromittent organs. He retained his fundamental classification (1865 when he recognized the families, Trogonophidae, Chirotidae, and Amphisbaenidae, $1872,1873)$, only modifying it by including Sphenodon in the Cataphracta.

Owen (1840-1845) included amphisbaenians in his ophisaurians (non Müller) with the anguians, which included a mixture of forms such as Dibamus, Anguis and Ablepharus. He provided neither argument nor much information and, in his "Comparative Anatomy" (1866), only recognized three groupings of lizards defined by the presence or absence of limbs and a sacrum.

In 1852, Duméril again argued for a separation of the Amphisbaenia as a distinct order between the lizards and "blind" snakes, basing this on such characteristics as the peculiar integument, and the absence of eyelids. In a review of the osteology of species of Amphisbaena, Blanus, Leposternon and Trogonophis, Gervais (1853) stated that there could be no doubt that the amphisbaenians belonged in a group distinct from the lizards; only its exact placement remained in question. In contrast, Stannius (1856) interpreted the morphological evidence differently: he noted the characteristics of the amphisbaenian hyoid, of the intestinal tract and of the kidneys, the lack of an epipterygoid, the presence of a bladder and the remnants of the shoulder girdle, as well as other characteristics, and used them as 
evidence that the amphisbaenians should be placed among the Sauria, but as a distinct suborder.

In 1864, Cope presented a perceptive reclassification of the Squamata, summarizing much osteological information. He placed the amphisbaenians into the lacertilian suborder "Ophiosauri", considered to lie adjacent to the "Pleurodonta" as the latter contained Anniella, which he claimed to be most similar to amphisbaenids. Cope conceived of the lizards as including a main group and three divergent lines leading respectively to the geckos, to Sphenodon and the chamaeleons, and lastly "toward the serpents by Amphisbaenia". He commented that the true hiatus lay between amphisbaenians and various burrowing snakes (his Tortricina). He added additional characteristics to this scheme in 1871 (cranial bones), 1892a (girdles), 1892b (general osteology; here he treated the Anniellidae as a very distinct family of the Amphisbaenia), $1896 a$ (mesenteries), $1896 b$ (hemipenes) and 1900 (summary, see below).

Boulenger initially (1878, at a time when only 30 species of amphisbaenians had been described) accepted the concept of a family Amphisbaenidae comprising the four tribes, Trogonophina, Chirotina, Amphisbaenina, and Lepidosternina. Six years later (1884: 117) he followed Schreiber (1875) and Strauch (1881, who had provided an excellent review of the Amphisbaenia on the specific level), in relegating the Amphisbaenia to family status and considering them to be degraded types of teiids. He argued that the absence of an interorbital septum also characterized the teiid Ophiognomon, as did the absence of a columella (epipterygoid). Both conditions were approached by other lizards. The aberrant lower jaw differed as much within the Amphisbaenia as among amphisbaenians and other groups. The condyle was not always divided, the naked skin was paralleled by that of geckos and some teiids, and the absence of arches on the skull was no more than a familial character. Characters common to teiids and amphisbaenians were the presence of precloacal pores, the tongue shape and scalation, and the reduction of pelvic before pectoral limbs. In the Catalogue of lizards (Boulenger, 1885) the amphisbaenians are listed as a single family in parallel with the various families of lizards. Only the chameleons among the lizards are accorded a suprafamilial status.

In 1884 also appeared the first (and the only published) portion of Bedriaga's extensive report on the morphology of Blanus. This author strongly concurred with Gray's view that the amphisbaenians represented an order, independent of the lizards, arguing his stand mainly on the basis of numerous cranial specializations. The parallel and most perceptive morphological report of Smalian (1884) derived multiple details from an analysis of the amphisbaenian musculature which he used to argue at length that the Amphisbaenia were neither snakes nor truly intermediate between snakes and lizards. By implication Smalian considered them to represent an independent group, as he mentioned snakes, amphisbaenians and skinks as all arising from "more or less differentiated lizard-like forms ... on the vertebrate trunk."

In the phylogenetic discussion appended to his account of the shoulder girdle, Fürbringer (1900: 606, expanding on an 1870 paper, and also in 1919, 1922) subdivided the Sauria (his Lacertilia) into five suborders, of which the amphisbaenians were one, characterized mainly by the reduction of the right lung and the curious extracolumella. His opinion was based essentially upon arguments from the literature, as he never had the opportunity of dissecting Bipes, the only form in which the pectoral apparatus remained functional. In general, Fürbringer disagreed with Boulenger's (1885) view that the amphis- 
baenians were only a family of lizards with teiid affinities, but maintained Boulenger's class fication. In contrast, Versluys (1898), whose detailed anatomical studies of the saurian middle ear included comparative material of Sphenodon and Amphisbaenia, noted that the latter group differed more from the lizards than these did among each other. He specifically rejected Boulenger's (1885) placement of the Amphisbaenia between the Teiidae and Lacertidae and argued that they were so distinct that direct comparisons were impossible.

In $1892 b$, and again in his posthumous monograph (1900), Cope summarized his views on squamate classification. He listed the evidence adduced earlier, added to it from the writing of later anatomists, and specifically rejected (1900:678) Boulenger's position on supposed teiid affinities of amphisbaenians, noting their resemblance to Anniella. He retained the amphisbaenians (plus Anniella) among the lizards in a position adjacent to the snakes, although he remarked that they "may have come off from the common ancestors of the Sauria and Ophidia". Baur (1894), in a short paper preliminary to a (never published) study of the amphisbaenian skull, noted that Anniella was more typical of lizards and differed profoundly from the Amphisbaenia. [It is interesting to note that Leonhard Stejneger had also started, but never completed, a review of the Amphisbaenia, to judge from a box of clippings and notes in the U.S. National Museum.]

In 1923, Camp presented the next and probably the most stimulating general review of lizard classification, basing this upon a review of some 35 sets of "paleotelic" characters, although he seems to have dissected but few amphisbaenians. He placed the amphisbaenians into his section Scincomorpha as a superfamily in parallel with the Lacertoidea, Scincoidea, and Xantusioidea and noted that the isolated position and morphological variation of the group, as well as its scattered geographical distribution, led one to expect its antiquity. His definition of the "superfamily" may be summarized as:

Vertebrae with broad, flat centra and wide condyles, sub-central arterial foramina present as in gekkonids and pygopodids; no neural spines, no intercentra; rectus superficialis present; rectus lateralis attached closely to the belly scales and greatly extended, reaching the dorsal mid-line in some forms; dorsal scales granular or tubercular where present; skin usually naked; no parasternum; preanal pores present. No osteoderms; no skull arches; no interorbital septum; no epipterygoids; pre-maxillaries single; extra-columella enormous.

He emphasized that the complexity of amphisbaenian body muscles was second among the Squamata only to that in the burrowing snakes, that they showed an enormous cervicomandibular muscle as in burrowing scincomorphs, and a series of "for the most part secondary" resemblances to degenerate Teiidae. The exceptional length of the anterior process of the basihyal was supposed to be indicative of ancestral relationship to that family.

Matthey $(1931,1932 a, b, c, 1933,1949,1951 a)$, in a series of papers, referred to the examination of the chromosomes of one acrodont (Trogonophis) and one pleurodont (Rhineura) species. He claimed that the differences between these were so profound that the group was clearly polyphyletic and that the former genus should be placed next to the agamids and the latter next to the teiids in the two major divisions of the Sauria shown by his scheme. Later $(1951 b, 1954)$ he obtained a third species (Blanus cinereus) and concluded that chromosome evolution had apparently proceeded independently within each family of lizards and that karyotypes did not simply reflect affinities on this level.

In 1944, Zangerl described the skulls of nine species of eight genera (from among the 
four families) of amphisbaenians, and in 1945 he commented extensively on their affinities. He suggested that the amphisbaenians apparently became fossorial much earlier than did the snakes and presented a summary characterization of the group (1945: 779). He noted structural similarities of the amphisbaenian skull to that of the Permian amphibian Lysorhophus, which he interpreted as the results of reduction and simplification, and stated that the amphisbaenians were "not clearly related to either lizards or the snakes and should occupy an order by themselves" (1944: 453). His viewpoint was accepted by Taylor (1951: 523) who, in the introduction to a paper on fossil rhineurids, presented nine, not always correct, reasons why amphisbaenians should be placed into a suborder or order of their own. Kritzinger (1946), on the basis of a detailed analysis of the skull of Monopeltis capensis, noted that these animals were "so specialized and at the same time so degenerate" that it was very difficult to connect them with any other group of the Lacertilia. He also suggested that resemblances to snakes represented the effect of parallel evolution rather than "direct relationship".

Bellairs alluded to amphisbaenian classification in a series of papers in which he furnished numerous new details regarding the structure of the squamate head (Bellairs \& Boyd, 1947; Bellairs, 1949b, and especially 1950). He tended to avoid the problem of the actual placement of the Amphisbaenia, agreed that they were distinct, but felt that they should be placed with lizards and snakes. In a popular book (1957: 130) he expressed a view reminiscent of Cope by stating that "there are ... many snake-like lizards and some rather lizard-like snakes, and the two suborders almost grade into one another". However, a more recent edition treats the Amphisbaenia as a separate suborder of the Squamata (Bellairs \& Attridge, 1975).

A doctoral dissertation by Vanzolini (1951a; of which only a key to and synopsis of the genera of amphisbaenians was published, 1951b) described many amphisbaenian skulls. He does not include an extended discussion of the major affinities of the group, but suggests that it be placed as an infraorder within the Sauria on the grounds that amphisbaenians differ from other lizards only in the possession of a large orbitosphenoid, in the absence of the interorbital septum, and in the reduction of the right lung. Though unpublished, this thesis is of importance in the present connection, because it may be reflected in Romer's (1956: 563) placement of these animals in the infraorder Annulata (Amphisbaenia) of the suborder Sauria.

Hoffstetter (1955: 637) expressed the opposite view by placing the Amphisbaenia as a full order between lizards and snakes and based this conclusion mainly on characters inherent in the skull. The classifications of Kuhn (1961) and some other recent authors (cf. Halstead Tarlo, 1968) also accept the Amphisbaenia as an order or suborder parallel to the snakes and lizards. The same view was also expressed by Kesteven (1957: 116), who sectioned the skulls and dissected the cranial muscles of some four species of Amphisbaena, Chirindia and Leposternon (his Amphisbaena sp.). He suggested that amphisbaenians showed close relationships neither to the snakes nor to the lizards, and might possibly represent relicts of a more primitive condition. For one reason or another, the group has recently been considered to be distinct in various books and papers that do not deal specifically with classification. Yet this view is far from unanimous; thus Underwood (1971), in the introduction to a new edition of Camp (1923), retains the Amphisbaenia as an infraorder within the Sauria, and Gorman (1973), in a summary of reptilian chromosomes, still notes that "for convenience I consider the amphisbaenians as a lizard family". 
SUPRAGENERIC STATUS

Overall placement of the Amphisbaenia

Amphisbaenians include both oviparous (Carr, 1949; Loveridge, 1920; Smalian, 1884) and ovoviviparous forms (Hediger, 1935; Loveridge, 1955; Visser, 1967). Embryos have been reported (Bellairs, 1949b; Bons \& Saint Girons, 1963; Broadley, Gans \& Visser, 1976; Carr, 1949; Gans, 1971; Goeldi, 1897; Loveridge, 1955; Smalian, 1884; Visser, 1967), but these are few and fewer have been sectioned and studied. Only the Goeldi material of Leposternon included early stages. It is now being sectioned and, thus far, it is in complete agreement with later stages (cf. May, In press).

The head joint (Zangerl, 1945; Gans, 1960) again maintains the amniote, indeed reptilian, condition (Williams, 1959). There is a well-differentiated atlas-axis complex of typical composition. The quadrate of all species shows strong attachment to the otic capsule; there is an undivided hypoglossal foramen, a parasphenoid ossification and a small posterior basicranial fenestra in the embryo (May, in press). The heart shows partial division of the ventricles, and the roots of the systemic aortae leave the heart as simple aortic trunks, of which the right may be the larger (Francis, 1977; Stannius, 1856: 224; van der Merwe, 1940), in an arrangement that represents a variant of the typical reptilian condition. There is then no reason to follow up hints (Kesteven, 1957; Zangerl, 1945) that amphisbaenians are not reptiles.

The amphisbaenian position within the reptiles is restricted by their possession of retractile hemipenes (Cope, 1896b; Gans \& Alexander, 1962; Rosenberg, 1967), organs that are otherwise known only in snakes and lizards. They also have the squamate characteristic of a sexual segment to the male kidney (Bons \& Saint Girons, 1963; Fox, 1977; Saint Girons, 1972). Of less biological importance, but also shared with these, are the true egg tooth (Fiorini, 1962; Schnabel, 1956; Smalian, 1884; Smith, Bellairs \& Miles, 1953) as opposed to a caruncle, the position of the cloacal slit at a right angle to the long axis of the trunk, separation of the telencephalic roof into three distinct cortices (Beckers, Platel \& Nieuwenhuys, 1972), and the smooth, relatively simple skin, consisting of keratinized scales that are mobile versus each other and the surface of which is regularly shed in its entirety. The organ of Jacobson is typical of that in the Squamata and quite different from that in other amniotes (Parsons, 1970).

All of these characters confirm that the Amphisbaenia belong with the snakes and lizards in the lepidosaurian grouping Squamata. In discussing these forms, I hence place the Amphisbaenia, Sauria and Serpentes as subordinate categories within the Squamata. For convenience, I treat the Squamata as a superorder (rather than an order, Dowling, 1975). This level of classification appears closer to, but probably not yet equivalent to, that accorded groups of birds and mammals, and seems appropriate in view of the astonishing and generally neglected variability of the squamates. However, and as noted in the Discussion, the status of the Squamata is a question beyond the limits of this study.

\section{Amphisbaenian groupings}

All of the amphisbaenians resemble each other in such aspects as the architecture of the skull, the curious extracolumellar system, and the nature of the integument. Consequently, there is no reason to assume that the Amphisbaenia are polyphyletic or that any of the several amphisbaenian families is more closely related to a particular group of Recent lizards than to each other. 
Vanzolini $(1951 a, b)$ presented the first approach to an acceptable arrangement of the amphisbaenians. He recognized the three subfamilies Amphisbaeninae, Rhineurinae and Trogonophinae within his family Amphisbaenidae. While (as already suggested by him) the Rhineurinae (sensu Vanzolini, 1951a,b) are clearly polyphyletic, and while certain of his other decisions have had to be modified (Gans, 1960; Gans \& Alexander, 1962; Gans \& Lynn, 1965), Vanzolini was certainly correct in claiming that Trogonophis is the most primitive acrodont, and that Blanus, Cadea and Bipes are the most primitive pleurodont forms. Comparison should then emphasize these genera.

There can be little question that the Amphisbaenia is an old group. Thus Rhineura, a genus exhibiting a highly derived set of burrowing modifications, shows up in the Paleocene (Estes, 1975) and has, by the Oligocene, already diversified into several species (Berman, 1973; Taylor, 1951); there seem to be some North American fossils with Rhineura-like characteristics, but these are often placed into different families (Berman, 1976; Vanzolini, 1951a). Chinese (Young, 1961) and Mongolian (Gilmore, 1943) records of fossil amphisbaenians are apparently based on misidentifications. A sudden appearance of a fully developed group is a commonly observed pattern in the Squamata and does not simplify the determination of affinities.

I here recognize the four mainly allopatric families, Trogonophidae, Bipedidae, Rhineuridae and Amphisbaenidae, of which only the Trogonophidae overlap part of the amphisbaenid geographical range (see Gans, 1967a, for species ranges, unless otherwise noted; see also Table I).

The definition of the south Mediterranean and Arabo-African Trogonophidae is that of Gans \& Lynn (1965). The six species, characterized by an oscillating excavating pattern (Gans, 1968), absence of caudal autotomy, and a non-circular cross-section of their trunk, are the only acrodont ones in the order. They show tendencies to shortening of the trunk (snout-vent length) and fusion of cervical vertebrae. Trogonophis is the most generalized, Pachycalamus is of uncertain affinities, and Agamodon and Diplometopon are the most derived genera (cf. Gans, 1960).

The Bipedidae are defined by the possession of forelimbs that are well-developed and show polyphalangy in one species (B. canaliculatus, Castañeda \& Alvarez, 1968). Their chromosomal formulae (Bipes biporus, Huang \& Gans, 1971; B. canaliculatus and $B$. tridactylus, Cole, pers. comm.) are also unique in the order. Electrophoretic study of about 22 genetic loci shows that the three species are very distinct and also show low levels of genetic variability (Kim, Gorman et al., 1976); indeed Cope (1894) considered each form to represent a monotypic genus. All three species show parieto-frontal fusion, lack an extracolumella but retain an epihyal attached to the hyoid (Wever \& Gans, 1972; pers. obs.), and have simple hemipenes (pers. obs.), and their relict range in Central Mexico (Guerrero and Michoacan) and Baja California is disjunct from that of any other Recent or fossil amphisbaenians.

The Rhineuridae includes a single Recent (Rhineura floridana, cf. Gans, 1967c) and a number of fossil forms (Gans, 1967b; Berman, 1972, 1973, 1976, 1977; Estes, 1965, 1970 [including record for "Amphisbaeninae", later, 1975, made the type of the family Oligodontosauridae]; MacDonald, 1970; Taylor, 1951; Yatkola, 1976). Rhineura was earlier included by Vanzolini (1951a; with some qualifications) and others as the nominal member of a group (subfamily) of spade-snouted species (also including the genera Aulura, Leposternon, Monopeltis and Dalophia, here considered to be amphisbaenids). The fossil 
TABLE I

Summary of amphisbaenian genera (with some distributional and character data)

\begin{tabular}{|c|c|c|}
\hline \multicolumn{2}{|l|}{ Trogonophidae } & [acrodont] \\
\hline Trogonophis & North(west) Africa & Generalized in family and order \\
\hline Pachycalamus & Socotra & \\
\hline Agamodon & Aden, Somalia (Africa) & Derived, oscillating digger \\
\hline Diplometopon & Arabia, Iran & Derived, oscillating digger \\
\hline Bipedidae & & [pleurodont] \\
\hline Bipes & Central Mexico, Baja California & Limbed \\
\hline Rhineuridae & & [pleurodont] \\
\hline Rhineura & Florida (U.S.A.) & Spade-snouted \\
\hline Amphisbaenidae & & [pleurodont] \\
\hline Blanus & $\begin{array}{l}\text { Iberian Peninsula, North Africa, } \\
\text { Turkey to Iraq, Lebanon }\end{array}$ & Generalized in family and order \\
\hline Amphisbaena & $\begin{array}{l}\text { Caribbean, South America } \\
\text { Panama to Peru and Argentina }\end{array}$ & $\begin{array}{l}\text { Round headed to slight lateral } \\
\text { compression, small to very large }\end{array}$ \\
\hline Cadea & Cuba & Slight lateral compression \\
\hline Bronia & Northern South America & Lateral compression \\
\hline Anops & South America & Keel-headed, small \\
\hline Aulura & Brazil & Slightly spade-headed, small \\
\hline Leposternon & South America & Spade-snouted, medium to large \\
\hline Zygaspis & Africa, south of Zaire & Round-headed, medium \\
\hline Chirindia & Eastern Africa, Tanzania to Natal & Round-headed, very thin \\
\hline Cynisca (Placogaster) & Western Africa, Senegal to Gabon & Round-headed, small to medium \\
\hline Geocalamus & East Africa, Kenya to Tanzania & Laterally compressed, small \\
\hline Baikia & West Africa, Nigeria & Keel-headed, small \\
\hline Ancylocranium & East Africa, Somalia to Tanzania & Keel-headed, small \\
\hline Monopeltis & Africa, Cameroon to Cape & Spade-snouted, small to very large \\
\hline Dalophia & Africa, Zaire, to northern South Africa & Spade-snouted, medium to very large \\
\hline
\end{tabular}

record suggests that the Rhineuridae (sensu strictu), and the apparently closely related fossil families Hyporhinidae and Oligodontosauridae, diversified in western North America and that they have clearly been isolated from the Amphisbaenidae sensu strictu since the Cretaceous.*

The Recent member of the family Rhineuridae is unique in the formation of its spatulate digging shield, in the exposure of the premaxilla on the face, in the absence of segmental modification of the pectoral integument, in various skeletal details (such as the absence of caudally directed ancillary (uncinate) processes of the ribs and loss of the third branchial arch), and in such characteristics as the chromosome formula and the curious and simple but paddle-shaped hemipenes (pers. obs.).

The family Amphisbaenidae includes more than 100 Recent species, as well as all prePleistocene fossils from outside of North America (cf. Hoffstetter, 1955; Charig \& Gans,

\footnotetext{
* I do not consider it appropriate to re-evaluate to status of these fossil families in a footnote; there is, furthermore, no absolute reason why "families" described in the fossil record need show degrees of difference equivalent to those seen in the Recent. However, the characteristics that are stated to be diagnostic for the Oligodontosauridae do not differ any more from those of Rhineura than do those of members of either the African or the South American radiations of the Amphisbaenidae among each other. Several of the aspects stressed, such as the high tooth count, the laterally exposed, falcate coronoid, notched posterior border of dentary, less "robust" symphysis, and greater exposure of semifused elements on the lingual surface of the mandible, would all be expected in a stage that preceded the shortening of the snout (facial aspect of the skull) and mandible seen, for instance, in Recent Rhineura.
} 
in press). The overall group occupies by far the largest range among all the families of Amphisbaenia. Besides variously round-headed species, it includes spade-snouted and keel-headed forms (Gans, 1968). The Mediterranean genus Blanus (two species) is clearly the most generalized; $B$. cinereus lacks a countersunk lower jaw and has a simple integumentary annulation (one dermal annulus, rather than two, per nerve and vertebra). Both species lack an extracolumella, but have elongate epihyals (Gans \& Wever, 1975), and retain paired and elongate lungs. The family is represented in the Greater Antilles and Virgin islands, as well as on Trinidad, Fernando Noronha, and on various islands just east of the continental coast. On the American continent, its range extends from Panama into the Colombian Choco, west of the Andes into north coastal Peru, and south across the Amazonian and La Plata lowlands into Patagonia. In Africa, the other members of the family range south and east of the Sahara and the central highlands, from Senegal in the west and Somalia in the east, south to the Cape Province of South Africa. Amphisbaenids are found on the island of Fernando Po off western Africa, but not on any coastal (or oceanic) islands off the east coast of Africa (though the trogonophid Pachycalamus does occur on the oceanic island of Socotra).

The head of most members of the Amphisbaenidae is more or less rounded (referred to as round-headed below), and specimens with this character state occur over most of the aggregate range of the family. The round-headed South American genus Amphisbaena includes some 45 species, including the largest and the smallest amphisbaenians found on that continent. It ranges from the Antilles to Patagonia. The genera Cadea (two species, Cuba), Bronia (two species, northern Amazon) and Mesobaena (one species, Colombia, Venezuela) combine various generalized character states but also show a tendency to keel formation and keratinization of the snout; the latter tendency reaches its peak in the southern genus Anops (two species, Mato Grosso, Brasil to Argentina). The genus Aulura (one species) of the Lower Amazon region presents a tendency to spade formation, a characteristic seen more highly developed in the genus Leposternon (seven or eight species; Gans, 1971), the species of which extend across the lowlands east of the Andes from south of the Amazon to central Argentina.

The relatively small, round-headed amphisbaenian species of Africa (cf. Gans, 1967a; Loveridge, 1941) are, at this moment, placed into the genera Cynisca (12 species, perhaps including two species of Placogaster; Laurent, 1947), Zygaspis (three species, Broadley \& Gans, 1978b), Chirindia (six species, Broadley \& Gans, 1978a), and Loveridgea (two species). The two species of the genus Geocalamus from eastern Kenya-Tanzania show some approaches to a keel-headed pattern, and the three species of Ancylocranium, occupying isolated ranges between Somalia and central Tanzania, show it at its most complex condition (Gans \& Kochva, 1966; Parker, 1942). A single keel-headed species from Nigeria (Baikia africana) seems to belong to a different radiation. The spade-snouted genera Monopeltis (16 species; Broadley, Gans \& Visser, 1976; Gans \& Lehman, 1973) and Dalophia (seven species; Broadley, Gans \& Visser, 1976) range south from Cameroon in the west and from Malawi and Mozambique in the east to the Cape Province of South Africa.

In contrast to the situation in the Americas, where (except for some localities on the south-eastern coast of Brazil) round-headed species are generally much more common than are the more modified ones, specimens of Monopeltis and Dalophia are by far the most common amphisbaenids in wide areas of south central Africa. Their character 
states and the scattered fossil record suggest that the African and American radiations of keel-headed and spade-snouted species each derived locally. Consequently, each of the superficially similar conditions of keel heads and spade snouts appears to have arisen at least three times in the radiation of the group.

\section{COMPARISON OF CHARACTERS WITHIN THE LEPIDOSAURIA General}

The characteristics discussed under these headings were either found to be useful by me, or have been mentioned by one or more authors dealing with the topic of amphisbaenian affinities. As physiological and behavioral topics have occasionally been referred to in such contexts, I intersperse their treatment with that of more purely morphological topics. In discussing characteristics, I emphasize similarity to and difference from the groups most often alluded to in a discussion of relationships, but desist from expanding these sections into a comparative anatomy of all the genera or families of the Squamata.

The personal observations derive from an external examination of preserved materials of almost all described forms, from skeletal material of most genera and from living specimens of some 14 amphisbaenian genera, including representatives of all the families, specifically of Trogonophidae: Trogonophis (one species), Agamodon (two species), Diplometopon (one species). Bipedidae: Bipes (three species). Rhineuridae: Rhineura (one species). Amphisbaenidae: Amphisbaena (nine species), Chirindia (two species), Cynisca (one species), Zygaspis (two species), Geocalamus (one species), Anops (one species), Mesobaena (one species), Leposternon (one species), Monopeltis (one species).

\section{Locomotor pattern}

When moving on the surface of the soil, amphisbaenians travel by lateral undulation, sometimes coupled with concertina movement; both mechanisms are widely distributed among other limbless squamates, indeed among other limbless vertebrates, and require only the morphological adaptations of elongation and concurrent increase of the number of axial segments (Gans, 1974). While progression by concertina and lateral undulation is possible in many "limbless" or "reduced-limb" lizards, its effectiveness is clearly dependent on the degree of elongation and the capacity for bending of the trunk as a whole (Gans, 1975). In many Scincidae, the tail is long, muscular and of constant diameter, and aids progression by increasing the number of reversing bends and permitting extension of the zone between points d'appui. Analysis of such systems requires films of the movement of multiple species on diverse substrates. Records for snakes and amphisbaenians differ markedly from those for skinks from southern Africa (C. Leonard, pers. comm.), anguids and Anniella; unfortunately, there are no analyses yet for gymnophthalmines and dibamids which are structurally most similar to amphisbaenians.

All amphisbaenian species, as far as is known, can utilize rectilinear locomotion. The Trogonophidae and stout-bodied members of the Amphisbaenidae do so on the surface of the soil; many other species only utilize this method within their tunnels. Rectilinear movement depends upon the liberation of the skin and upon its movement, relative to the underlying mass of the trunk, by special costocutaneous and vertebrocutaneous muscles (the scalares) that can bunch the skin when it is free and pull on the trunk when the skin is forced into tight contact with the ground (see Trunk Muscles, below). Rectilinear motion then requires a flexible integumentary covering that can telescope along part of 
the circumference; it also requires double or triple sets of muscles directed anteriorly and posteriorly inward from the integument. The vertical undulations, mentioned as an amphisbaenian characteristic by Taylor (1951), are superficial indications of rectilinear movement (cf. Gans, 1960); no amphisbaenian moves by vertical undulations of the vertebral column.

Rectilinear locomotion has also been reported in snakes, but apparently in no lizards (Gans, 1974). While their rectilinear pattern is analogous to that of amphisbaenians, snakes lack vertebrocutaneous muscles and generally restrict the telescoping ability to the lateroventral portions of the skin (Wiedemann, 1932); in amphisbaenians the skin is loose around most of the circumference so that the entire sleeve may telescope.

\section{Burrowing patterns}

Many squamates live beneath the surface of the ground and displace or compact the soil to generate temporary or permanent tunnels (Gans, 1974). In most instances, penetration involves only the forward push of the head and the reaction forces are transmitted to the soil by the lateral curves of the body, or by pushing the posterior part of the body against sections of the tunnel. Some typhlopids and leptotyphlopids have also developed a downward torsion, using pointed caudal spines to dig in and assist in the development of a reaction force base; the curiously modified tails of other snakes, such as the Uropeltidae, appear to serve different functions (Gans \& Baic, 1977), and few lizards are known to use the tail to provide a reaction site. Amphisbaenians may induce similar reaction forces with two significant differences. Many species of amphisbaenians use rectilinear locomotion in the tunnel, pushing against top, sides or bottom (and sometimes applying concertina forces simultaneously). Both the integumentary flexibility and musculature are modified to facilitate this (see below). When rectilinear movement is used, force transmission to the wall of the tunnel is via static friction and only the head will be forcibly slid past the soil. Consequently, this locomotor method reduces sliding friction during the penetrating stroke.

The caudal tip may form a protective tunnel plug, but does not appear to serve for propulsion in the Rhineuridae, Bipedidae and Amphisbaenidae. However, in the Trogonophidae the tails are short, downward-curved and non-autotomizing, and are used to apply the forces needed when the head is effecting initial penetration of the soil (the need for transmission of forces from tail to head, while rotating the skull on the vertebral column, appears also to be reflected in the unique fusion of the second and third vertebrae in Agamodon; Gans, 1960).

In lizards, morphological specialization for burrowing appears to be primarily concentrated on elongation of the trunk with increase of vertebral number (Hoffstetter \& Gasc, 1969), modifications of head shape and cranial architecture, and reduction of limbs (Essex, 1927). Most such burrowers or fossorial hunters utilize soft soils or are sand swimmers. In contrast, the amphisbaenians have not only utilized rectilinear movement as the basis for an internal penetrating stroke but have now combined this with three distinct tunnel-widening mechanisms. All derive from a sequence in which the head is first forced into the soil to form a tunnel that will be widened as the body penetrates further. In the first modified pattern (used by most spade-snouted forms), and apparently developed independently in three lines, the tunnel is widened by rotating the head dorsad, ramming the overburden toward the dorsal surface, and then smoothing the tunnel wall 
with the pectoral region. In the second pattern, used by the keel-headed forms and apparently developed at least twice, the tunnel is widened by driving the head alternately toward the left and right, in each case smoothing the walls by the pressure of the sides of the head and trunk. In the third (seen only in the Trogonophidae), an oscillating (rotating left and right alternately) stroke simultaneously shaves soil off the tunnel's end and compacts it into the walls (Gans, 1968, 1974).

None of these variously effective methods of tunnel formation is exhibited by any lizard or snake. The only other true tunnellers in hard soils are the uropeltid snakes. These drive their conical head into the soil and then pull the vertebral column into an undulant curve within the dermal envelope to widen the tunnel before the next penetrating stroke that derives its reaction force from concertina contact with the ground (Gans, 1973, 1976). Furthermore, most uropeltid tunnels are formed when the soil is moist and penetrable. It is interesting that a variant of the uropeltid pattern is shown by the ribbon-like $A g a-$ modon compressum, the member of the Trogonophidae with the most derived characteristics; the example represents a clear case of convergence.

At least two amphisbaenian lines have each developed a unique modification for initial penetration of the soil. The Trogonophidae use their convexly curved snout to build up a layer of soil particles across their dorsal surface (Gans, 1974), while the Bipedidae use their hands to generate the entry tunnel (Gans \& Shaw, 1963).

The mechanics of movement of a burrowing animal may be divided into three phases. The first involves the mechanics of travel over the surface or along an existing tunnel; the second involves true burrowing or extending existing tunnel systems; the third involves the initial penetration of the soil when leaving the surface. These three phases appear to represent a hierarchy of difficulty. The high degree of specialization of the amphisbaenians is particularly well expressed in the speed and effectiveness with which they are able to carry out the second and third tasks, even in fairly hard soils.

\section{Integumentary architecture and organs}

The skin of the amphisbaenian trunk is, in most cases, divided into annular sections, defined in their anterior and posterior portions by deep, bending grooves. Each annulus is further subdivided into more or less rectangular integumentary segments. The arrangement is roughly symmetrical, except in a few species where the intersection of the intersegmental raphes with the posteriorly positioned interannular raphe may involve a triangular wedge of irregular folding lines. Integumentary pigmentation shows some matching of colour to the substrate (Gans, 1968, 1969). In some amphisbaenian species, the annuli project further posteriorly than anteriorly. The projection may slightly overlap the deep interannular raphes, particularly when the annuli are contracted. However, the anterior and posterior halves of each annulus are roughly symmetrical in most species. In the advanced members of the Trogonophidae, the halves of each annulus run at angles to a plane normal to the midline of the trunk so that their segments are parallelogramic. The mid-dorsal integumentary segments of these species may be rounded, but granular or tubercular dorsal scales (mentioned by Camp, 1923) occur only in a few species, such as Amphisbaena spurrelli and $A$. rozei, and even here they are concentrated to the tip of the tail (cf. Gans, 1966). The entire skin is shed periodically.

The cephalic region of amphisbaenians transmits forces during locomotion. Its integument is subdivided into shields, with the intermediate hinges showing little flexibility. The 
generalized pattern appears to have been one of symmetrically paired shields, except for the rostral and mental/postmental shields, which are always unpaired. Trends within the group reflect burrowing modalities (Gans, 1974); in regions exposed to wear (force transmission), the shields are increased in size and may be more heavily keratinized, but no osteoderms occur. Increase in segmental size occurs, both by changes in the proportions of individual shields and by fusion of adjacent ones.

The Trogonophidae (except for members of the genus Trogonophis) and the Bipedidae (as well as the members of the amphisbaenid genus Cadea) are again distinguished in not showing a regular lateral sulcus (Gans, 1960). In most other forms, these lateral sulci (which normally start near the twenty-fifth vertebra, thus corresponding to the anterior tip of the lung) are clearly defined, and various species also show mid-dorsal and midventral sulci.

In almost all snakes, the skin is subdivided into lozenge-shaped free scales set on a parallelogramic pattern. The wide, free edges of the scales overlap and retain a shielding of $\beta$-keratin that protects the flexible interscalar skin. This overlapping pattern of scales provides for lower friction when the body is moved toward the head rather than toward the tail. Incidental to this set of characteristics, the hard external surface apparently provides some protection against the bites of certain arthropods; the skin of healthy snakes deflects penetration of their chelicerae.

The overlapping scales of snakes, though modified in a few groups of marine forms, are almost diagnostic for the order Serpentes (cf. Jackson \& Reno, 1975); however, similar arrangements are found in a few lizards (cf. Dibamidae), and variant arrangements, often reinforced by osteoderms, occur in a variety of skinks and pygopodids. In contrast, the amphisbaenian pattern, involving a more or less irregular subdivision into regular annular sections of the subcylindrical trunk and very slight overlap of the posterior annular edges in limited zones of certain species, has analogues only among the reducedlimbed cordylids and the gymnophthalmines (MacLean, 1974), such as Bachia and Ophiognomon. In both these groups, we recognize a superficial parallelism of integumentary architecture; however, their annular pattern apparently does not permit the skin to be folded and expanded in the concertina fashion, required for rectilinear locomotion and seen in amphisbaenians. The analogy here is roughly equivalent to that between the lateral sulci of anguids and those of amphisbaenians; the structural details are quite distinct in both cases.

Except for Blanus cinereus, in which the number of body annuli corresponds to that of vertebrae, all amphisbaenians appear to have a number of annular rings twice the number of vertebrae, though they show but a single series of costo- and vertebrocutaneous muscles and of integumentary nerves (Alexander, 1966a; Alexander \& Gans, 1966; Gans, 1960; Smalian, 1884). Exceptions to this generalization appear in Bipes and Cadea, but most clearly in the spade-snouted Leposternon (Gans, 1971) and Monopeltis (Broadley, Gans \& Visser, 1976), all of which show supernumerary partial or complete body annuli. As the tail, in which the integument is tied closely to the central mass, shows a $1: 1$ ratio, it appears as if this ratio is the primitive one in amphisbaenians, and the doubling of body annuli (and further intercalation of supernumeraries) represents a specialization (Gans, 1960). Camp (1923) felt that the $1: 1$ ratio represented an advanced characteristic. Like many other organs, the skin is under intense selective pressure, and there is little reason to suspect that selection always favoured either an arrangement of overlapping shields or 
one of imbricate tubercles, nor that departures from the $1: 1$ ratio were always favoured. Neither the evidence adduced by Camp nor that of subsequent studies (Kerfoot, 1970) forces the decision that either maintenance of or departure from the $1: 1$ ratio was necessarily favoured in all squamate groups.

Amphisbaenians are unique among all squamates (except for Heloderma) in apparently lacking such integumentary sense organs as scale pits and sensory pores (Underwood, 1967). Blanus and Trogonophis, the only amphisbaenians studied, also lack the alveolar cells found in the hinge regions of the cephalic integument of all other lepidosaurians (except for Sphenodon). This seems particularly significant as these cells are otherwise best developed in burrowing species (Gabe \& Saint Girons, 1967).

Amphisbaenians, except for a scattered number of forms and lines, commonly show precloacal pores which tend to be better expressed in males, while Blanus strauchi also shows possible remnants of pectoral pores (Alexander, 1966a). As far as studied, these precloacal pores (Whiting, 1967) show a histological appearance very similar to that in the femoral pores of various lizards (Cole, 1966; Gabe \& Saint Girons, 1965); no precloacal pores have been reported in any snake, nor in Sphenodon.

Bogert \& Cowles (1947) suggested that the amphisbaenian Rhineura was unique among reptiles in being able to gain weight by absorbing water through the skin. Further experiments indicated that the animals are not unique among the reptiles, but rather gain water by promoting capillary flow between their lips (Krakauer et al., 1968).

\section{Osteocranium}

The first modern description of the amphisbaenian skull is that of Zangerl (1944). Skulls of various groups of the Amphisbaenia have since been discussed and figured by Charig \& Gans (in press), Gans (1960), Jollie (1960), Kesteven (1957; the figures leave something to be desired and are mislabelled), Kritzinger (1946), and Vanzolini (1951a). Al-Nassar (1976) provides a detailed and useful description of the elements of the skull of Diplometopon.

The amphisbaenian skull reminds one of the skull of burrowing lizards, due to the elongation of the parietal downgrowths. Unlike that of lizards but like that of most snakes, the cranial cavity has completely bony walls. It is unique among those of the Squamata in its solid construction and particularly in the complex interdigitations of the anterior bones. The thin edges of the parietals, occipitals, sphenoid and otic elements interdigitate and overlap in three dimensions, so that joints form a sandwich-like lamellar layering. Consequently, the elements should be described on the basis of the disarticulated bones rather than only characterized in terms of their exposure on the surface of the intact skull. The layered bones show involved and curved flutings that keep them from slipping when the skull is subjected to alternating compressive, tensile, bending and torsional stresses, yet the pattern of articulation still permits relative growth (Gans, 1974). While the concept of solidity is somewhat subjective, it represents a quantum difference, even from such subterranean genera as Anniella (cf. Coe \& Kunkel, 1906), the microteiids Ophiognomon and Bachia, the skinks Acontias (Brock, 1941) and Feylinia, the dibamids Dibamus and Anelytropsis, and members of the Pygopodidae (Kluge, 1976b).

The facial portion of the amphisbaenian skull particularly shows marked interfamilial and intergeneric differences (Gans \& Kochva, 1966; Vanzolini, 1951a; Zangerl, 1944). In the Trogonophidae, the skull has become shortened, and the bend between facial and 
cranial portions is accentuated (Gans, 1960); in the amphisbaenid Chirindia (cf. Zangerl, 1944), the braincase is elongate as is the almost horizontally positioned quadrate, so that the anteriorly placed mandible occupies less than one half the total length of the skull. The external shape of the head is a poor overall predictor of the kinds of internal architecture or, more specifically, for the particular bone that contributes to the formation of one or another part of the face; there are obvious "generic" and "familial" trends (which have clearly been used in establishing the present taxonomy).

The amphisbaenian skull lacks arcades and palpebral elements. Vanzolini (1951a) discusses the possible occurrence of a jugal (cf. Jollie, 1960; Lakjer, 1927); however, reports on this element seem to be based on the interspecifically variable position of the ectopterygoid. Most forms lack a postfrontal and a postorbital; a single (postorbital) element occurs in such "rhineurid" fossils as Hyporhina and Dycticonastis (Berman, 1976; Hoffstetter, 1955). Williston (1918) and also Camp (1923) are wrong in their claim that a postorbital occurs in Amphisbaena alba. Williston's (1925) figure shows an arrow pointing to what is either the lachrymal or the frontal. All genera but Trogonophis lack an epipterygoid (Bellairs, 1950; Cope, 1892b), a characteristic shared with chameleons, Dibamus and snakes. Camp (1923; confirmed by Carroll, 1977) considered fusion of the median elements of the cranial roof a derived condition and, as only premaxilla and parietal showed this in amphisbaenians, he found them "relatively primitive" in this characteristic. Romer's (1956) remark that the "nasals may be fused" does not appear to reflect the condition of any species known to me. Zangerl (1944) does note the unique fusion of the facial edge of the anterior portion of the frontals in Chirindia ewerbecki.

The azygous premaxilla is generally large and solid and often retains an enormous facial process, although the posterior part may be variably excluded from facial exposure (cf. Amphisbaena caeca, Gans \& Alexander, 1962). Variable contributions from the facial process of the premaxilla may roof the snout, aided by parts of the nasals, frontals and maxillary edges, but major intergeneric differences occur. The nasals may or may not meet medially on the facial surface, they may form part of the anterior edge of the rostral spade or they may be isolated from this. The maxillae make an extensive contribution to the sides of the face and extend medially from the toothrow as palatine processes to which the vomers attach medially via cartilages. The vomers (prevomers, de Beer, 1937; Kesteven, 1957) lie ventromedially to the vomeronasal organ. They lie ventral to the internasal septum (Kritzinger, 1946; Lakjer, 1927).

The thin bony lamellae in the ventrolateral surface of the nasal openings have been interpreted as septomaxillae (Fischer, 1900; Jollie, 1960; Zangerl, 1944). They could not be seen in intact skulls of certain forms (Gans, 1960), although Al-Nassar (1976) saw them in disarticulated skulls and May (in press) noted them in sections. The palatines roof the posterior portion of the internal choanae. The ectopterygoids and pterygoids form an almost complete ventral shelf that extends from maxilla to quadrate. All palatal elements may overlap widely. Amphisbaenia (except for Chirindia ewerbecki, ?, Jollie, 1960; Zangerl, 1944) and Dibamidae are unique among the Squamata in lacking a palatal vacuity.

The posterior prolongation of the secondary palate in Monopeltis has been listed as analogous to the condition in burrowing Scincidae (Kritzinger, 1946). Lakjer (1927) considered the amphisbaenian palate the most primitive of all neochoanate ones. That of Trogonophis showed most primitive features, indicating some (convergent) similarity 
with microteiids (gymnopthalmids) rather than with skinks, but Amphisbaena and Leposternon were considered even more diverse.

There is some question about the identity of the bones on the anterior surface of the orbit. A lachrymal and a discrete prefrontal may occur, may be fused (Kesteven, 1957; Vanzolini, 1951a), or again neither may be present, as in Diplometopon (Al-Nassar, 1976). Bellairs \& Boyd (1947) note that in Monopeltis, Kritzinger's (1946) lachrymal is the prefrontal (see also de Beer, 1937; Gans, 1960; Jollie, 1960; Underwood, 1957b; Versluys, 1936). The orbitosphenoids (postoptics, Cope, 1900; presphenoids, Kesteven, 1957; orbitosphenoids plus laterosphenoids, Romer, 1956; laterosphenoids, Zangerl, 1944; perhaps pleurosphenoids, May, In press; or orbitosphenoids plus pleurosphenoids, Berman, 1976; Hoffstetter, 1955; see Jollie, 1960, for discussion) are enormous and lack equivalent ossified analogues in other squamates (Bellairs, 1949b; Jollie, 1960); indeed a slight anterior ossification of the cartilaginous precursors of these elements in Anniella led Cope $(1892 b)$ to consider the genus as closely related to the amphisbaenians. This region of the original cartilaginous braincase ossifies much earlier than in lizards; thus juveniles of Trogonophis show extensive ossification at a time when the orbitosphenoid region of lizards is totally uncalcified (Bellairs, 1949b).

The anterior part of the brain case of the Amphisbaenia is unique in its complete closure formed variably of parietals (Bellairs (1949b) Amphisbaena; Jollie (1960) Trogonophis), frontals, lachrymals (or prefrontals) and orbitosphenoids (Zangerl, 1944); these elements form a continuous tube from cranial cavity to nasal passages. The medial orbital wall is hence closed by ossifications, in contrast to that of lizards which remains largely unossified; that of snakes is formed by the frontal and parietal elements, although the ventral portion of this wall may be discontinuous between the sides. Adult amphisbaenians also lack the interorbital (but retain an internasal) septum found otherwise in all living reptiles, except for most snakes. In amphisbaenians the frontals rest on the trabecula communis, the posterior and ossified portion of which may fuse to the orbitosphenoids (in Rhineura, Bellairs, 1949b; Bellairs, pers. comm., reports a large unpaired bone here), whereas in snakes the frontals rest on the parasphenoid and paired trabeculae (Underwood, 1957a). These anterior skeletal elements of amphisbaenians are complexly folded about each other, thus strengthening the anterior braincase.

The enormous, azygous and partly multi-layered parietal roofs the braincase, being complexly joined to the sphenoids and occipitals. Anteriorly, it overlaps part of the frontals and may extend into contact with a process of the premaxilla (in Trogonophis) or parietal and frontals may fuse (in Bipes). The extent of the lateral downgrowths of the parietal exceeds even the magnitude of that seen in burrowing lizards (Underwood, 1957b). The stout and geometrically complex quadrate lies almost horizontally, particularly in the most slender species, and its head is locked into a joint on the poorly developed paroccipital process; Kritzinger notes a synovial capsule here in Monopeltis. Slightly posterodorsal to it lies what may be a remnant of the squamosal or supratemporal [See Brock, 1941, Jollie, 1960, and Versluys, 1936, for terminology; Zangerl, 1944 (Trogonophis, Rhineura); Lakjer, 1927, and Stannius, 1856]. It was not found by Jollie, 1960 (Amphisbaena), Bedriaga, 1884 (Blanus), Gervais, 1853 (Leposternon) and Kritzinger, 1946 (Monopeltis); this element is generally lost during the preparation of skulls but may be seen in sections of the head of some species (Zangerl, 1944). In some African forms, the extracolumella (see section on Larynx, branchial arches and skeleton of middle ear) passes through a deep groove in the 
lateral face of the quadrate (Vanzolini, 1951a,b); in other species, it crosses the lateral surface of the distal tip of the pterygoid and then the quadrate. Little can be said about the components of the otic capsules; they are almost always fused in adults, although sutural remnants sometimes remain. Authors (Bedriaga, 1884; Jollie, 1960; Kesteven, 1957; Zangerl, 1944) variably refer to fused prootics, opisthotics and epiotics. Among the Squamata, the sella turcica is least marked in Amphisbaenia, Leptotyphlopidae and Typhlopidae (Saint Girons, 1968).

The basioccipital and basisphenoid tend to fuse in adults, and the suture with the more ventral parasphenoid may close (Kesteven, 1957, argues that this element is part of the basisphenoid, but it appears clearly distinct in juvenile specimens). Lateral to the basioccipital-basisphenoid line of fusion, lie two pairs of small, independent bones, either pair of which may represent the so-called "elements X" of Zangerl (1944). Vanzolini (1951a), who discussed the literature, suggested that these bones are homologous with the basitemporal bones of birds and crocodilians, representing two of the three centres of parasphenoid ossification, while Kesteven (1957) considered one pair to be the prootics. Lakjer (1927, fig. 54; also Brühl, 1886) referred to them as sphenoccipital epiphyses, which makes sense as they represent the attachment sites for the very stout tendons that allow the hypaxial $M$. longus capitis to shift the skull in burrowing (cf. Jollie, 1960). Some tendency for separate ossification of elements in this region is also observed in specimens of Anelytropsis and Ophiognomon; apparently it represents a solution to a similar adaptive problem.

The occipital condyle of the Amphisbaenia is wide and differs from that of lizards by its tendency to be doubled (cf. Stannius, 1856), although the two halves are joined by a ventral shelf of bone. The U-shape may suggest that the basioccipital makes only a limited contribution and that most of the condyle is formed of exoccipitals. While the U-shape has been assumed to demonstrate similarities to the condition in amphibians (Zangerl, 1944), it is more likely that the modification is a function-associated change of the kind which led to the repeated loss of the atlantal intercentrum in various advanced amphisbaenians (Gans \& Alexander, 1962).

The generally short lower jaw (cf. Gans, 1960; Vanzolini, 1951a) is formed primarily of the extensive dentary, an often large, discrete coronoid, and a variably exposed or perhaps fused splenial (Jollie, 1960); this element was not recognized by Vanzolini (1951b), Zangerl (1944), or Romer (1956), but is apparently retained in Rhineura (Cope, 1892b) and various rhineurid fossils (Berman, 1976). The mandibular symphysis is quite solid (Gans, 1960; Kritzinger, 1946). The posteromedial aspect, in certain species, is formed by articular, (prearticular), angular and surangular, which may be variably exposed on the lingual side of the mandible, and tend to fuse partially or completely, except in Monopeltis and Dalophia (Vanzolini, 1951a). Meckel's canal closes anteriorly in some forms. The entire pattern is one of overlapping, multiple-layered construction. The homologies of the various slivers of bone surviving in the posterior region of the jaw are apt to remain uncertain until embryos become available. Enormous differences occur among amphisbaenian mandibles in shape, in the presence or absence of a retroarticular process, height of the coronoid, exposure of bony elements on the two faces of the mandible, and fusion of the posterior and lingual elements.

The pattern seen in the amphisbaenian skull presumably reflects adaptations to burrowing by methods that utilize the anterior portion of the skull as a spade and, more important. 
by methods that imposed major bending and torsional stresses upon the transition between face and posterior part of the braincase. This obviously explains the thickening and laminate reinforcement of the cranial wall and its complex and integral suturing to the facial portion of the skull. The second functional influence may be size dependent; absolute reduction of the diameter of the trunk is apparently advantageous to a burrowing species (Gans, 1974). Size dependence, plus the coupled disadvantage of reducing the absolute diameter of the skull (or of the otic capsules which form the widest portion), would explain the reduction of peripheral elements, such as the lateral arcades and the anterior position and forward slanting of the quadrate away from the zone of largest cranial diameter, particularly in advanced and in smaller species. Both permit the lateralmost extremes of the head to be occupied by the extreme aspects of the lateral semicircular canals, thus maintaining their width, which is critical for function of the canals (Jones \& Spells, 1963). Size dependence also suggests a basis for the multiple roles of many cephalic elements; the continuous tubular anterior prolongation of the cranial into the olfactory cavity fills the anterior digging spade, while the braincase and the palatopterygoid shelf reinforce each other.

\section{Chondrocranium}

The following comments rely heavily on the reconstruction of the chondrocranium of a single, one-third developed embryo of Leposternon by May (in press), who considered it generally reduced. The taeniae, pilae, and the sphenoidal region are poorly represented, while the interorbital region lacks a solum (planum) supraseptale, unless this has become ossified as the orbitosphenoid bone. This confirms Kritzinger's (1946) view (based on a juvenile Monopeltis), and notes of Bellairs (1949b; based mainly on juvenile Trogonophis) that the taenia and cartilaginous planum supraseptale are entirely absent.

The nasal portion of the (subadult) amphisbaenian chondrocranium has been described by Fischer (1900), Kritzinger (1946), May (in press) and Pratt (1948). It shows a small fenestra narina, a weak parietotectal cartilage and a large fenestra superior and, in contrast to the condition seen in lizards, reduced cartilaginous enclosure of the cavim nasi proprium which rather shows a bony enclosure (Fischer, 1900). Anteriorly, the trabeculae are fused and bear a nasal septum, but they remain separate for much of their length posterior to this level (Bellairs, 1949b). The short paraseptal cartilage is fused posteriorly with the planum antorbitale and sometimes shows a short posterior maxillary process. The reduction of the rostral elements and absence of a distinct foramen apicale are shared with burrowing lizards. The skull is hence intermediate between the typical platytrabic (Kritzinger, 1946) or tropitrabic conditions (Bellairs, 1949b, based on an adult specimen). Embryos have an undivided hypoglossal foramen and a small posterior basicranial fenestra. There are true basipterygoid processes in some forms while others show basipterygoid angles, on which the pterygoids rest without loosing their mobility (Vanzolini, 1951a).

The deformation, reduction and replacement of the nasal portions of the amphisbaenian chondrocranium may have primary functional implications. However, the burrowing methods used (primarily, but hardly exclusively, those of Dalophia, Leposternon and Monopeltis) indicate tremendous selective pressure on the early formation of an ossified anterior spade. This may well have forced a temporal shift in the replacement sequence of chondrocranium by osteocranium. 


\section{Cranial kinesis}

The amphisbaenian skull is mesokinetic (Versluys, 1910, 1912) with a single, often extremely convoluted, line of very limited kinetic flexure occurring between the frontals and parietals. In lizards with well developed mesokinesis the fronto-parietal suture forms a straight line (Carroll, 1977). In amphisbaenians, the fronto-parietal suture is quite rigid and shows extreme interdigitation. The extent of the interdigitation may be an adaptation to a style of burrowing in which the facial portion of the skull exerts most of the forces imposed on the parietal section (cf. Gans, 1974). However, if the initial presence of interdigitation is accepted as a primitive feature of amphisbaenians, then the limited flexure between frontals and parietals may not correspond to true mesokinesis as observed in lizards. Indeed, the interdigitations of the fronto-parietal suture would indicate that the Amphisbaenia may well have separated from the remainder of the Squamata before mesokinesis arose in lizards.

In some amphisbaenian species, movement may occur further anteriorly, namely between frontals and maxillo-nasal elements (Versluys, 1912). The variably noticeable motion is always limited; the firm connection between pterygoid and quadrate further strengthens the suspicion that kinesis is extremely reduced (Vanzolini, 1951a), at least in adults of species of amphisbaenians showing derived characteristics (Gans, 1960). However, the head of the quadrate appears to be connected to the parotic process of the cranial capsule by a connective tissue layer (Versluys, 1912; hence, it is streptostylic in the sense of Stannius, 1856), and all amphisbaenians show basipterygoid processes or angles (Vanzolini, 1951 $a, b$ ). While these are short, there is a strong M. protractor pterygoidei and an M. retractor pterygoidei, although their expression differs among species (Lakjer, 1926).

Kritzinger (1946) argues that motion among the skeletal elements of the snout, particularly the vomer and nasal septum, is needed to pump fluid into the vomeronasal ducts. Pratt's (1948) statement that there is continuous, cilia-driven flow past the mushroom body is questionable as only the ends of the duct of Jacobson's organ, but not its centre, are ciliated in squamates (Gabe \& Saint Girons, 1976).

Apparently some slight intracranial motility may occur, at least in the ontogenetically earlier stages. This motility may facilitate growth, but it is uncertain whether the motility is associated with feeding roles, as seems to be the case with the cranial kinesis of some lizards and snakes. Certainly, the directions in which forces act on the skull reverse during the role shift from feeding to excavation (Gans, 1960).

\section{Larynx, branchial arches and skeleton of middle ear}

Most amphisbaenians differ among each other only in the proportions of the ventral remnants of their branchial arches and in the nature of the hyoid arch (Camp, 1923; Fürbringer, 1919, 1922; Windischmann, 1831. For details see: Trogonophidae: Gans, 1960; Richter, 1933. Rhineura: Camp, 1923; Cope, 1900; Fürbringer, 1922. Bipes: Cope, 1900; Fürbringer, 1922. Amphisbaena: Camp, 1923; Cope, 1900; Jollie, 1960; Kesteven, 1957; Richter, 1933. Anops: Smalian, 1884. Blanus: Bedriaga, 1884. Monopeltis: Richter, 1933. Miscellaneous other reptiles: Camp, 1923; Corsy, 1933; Fürbringer, 1922; Richter, 1933). Obviously, the terms epi-, cerato- and hypo-, when referring to remnants of the visceral skeleton, only pertain to the general topography and not to clear subdivisions of the arches. 
In most members of the Amphisbaenidae, there is a cartilaginous corpus hyoideum (copula) sending anteriorly a medial processus lingualis and two lateral, anteriorly pointing cornua hyalae, which Jollie (1960) properly termed hypohyals. Along their sides attach short, posteriorly pointing ceratohyals. All authors, except Jollie, omit these, though Camp (1923: 342, 317, Fig. F) figured and described as a ceratohyal a cartilaginous nubbin proceeding posteriorly from the articulation of the corpus hyoideum with the cornu hyale of Amphisbaena caeca, and Richter $(1933: 415,419)$ noted, but considered aberrant, a short remnant of the dorsal (ceratohyal) portion of the hyoid forming a sharp angle with the hyal tip in one specimen of Amphisbaena fuliginosa. Caudad, the paired cartilaginous ceratobranchials II are continuous with the corpus and flank the trachea, as well as lying in intimate contact (ligamentous connection) with the larynx. Short, ossified ceratobranchials I, often shown with terminal cartilaginous epibranchials I, articulate with the corpus lateral to the small ceratobranchials II, but never attach to the skull as do the long horns of Tupinambis (Jollie, 1960). Fürbringer (1922) reported dorsal remnants of the second branchial arch in amphisbaenians; Richter (1933) and others never located them; de la Serna de Esteban (1959) incorrectly labelled the ceratobranchial II of Amphisbaena darwini as a posterior ramus of the hyoid.

The intimate laryngo-hyal connection, seen in Amphisbaena and apparently in amphibians, does not occur in snakes and breaks down in most adult lizards (Göppert, 1937). Göppert $(1899,1901,1937)$ also suggested that Amphisbaena fuliginosa showed the M. dilatator laryngis in the most primitive reptilian position, in that it originates from the ceratobranchials II as well as tendinously from the cricoid rather than from the cricoid only; insertion is on the arytenoid. He further noted that the laryngeal closing muscles also showed a more "primitive" dorso-ventral separation, rather than the formation of a bilateral constrictor as in lizards.

There are three fundamental exceptions to the arrangement of the hyoid skeleton described. The first occurs in the Trogonophidae, all of which lack the ceratohyal (Gans, 1960). The second exception occurs in Rhineura floridana, which lacks the ceratobranchials II (Cope, 1892b: 220, Fig. 46). The third is potentially very important, as it involves three species of Bipes (Wever \& Gans, 1972, and personal observations) and both species of Blanus (Gans \& Wever, 1975, and personal observations). These retain a dorsal portion of the hyoid (epihyal?), which continues from the anterior ceratohyal(?) tip to parallel the posterior ramus of the mandible and then reaches dorsolaterally to pass parallel to the opisthotic; it does not attach to the paroccipital process and is thus similar to the hyoids of the only microteiid examined (Richter, 1933). These five species are also unique in lacking an anteriorly developed extracolumella.

Unlike the condition in geckos and Sphenodon, in which the hyal connection first passes posteroventrally and then curves to reach the basihyal, the epihyal of Blanus and Bipes ascends directly along the side of the head and contacts neither the columellar elements nor the paroccipital process. The overall pattern is one which differs from the gekkonid condition by the retention of ceratobranchials II, but it generally indicates broad similarities with that seen in diverse lizards, especially the microteiids (Cope, $1892 b$; Richter, 1933). The hyoid of Anniella is very much more reduced and lacks both hyal processes and ceratobranchials II; it thus approaches the simple condition seen in snakes.

All amphisbaenians have a large stapes; its foot plate lies in the fenestra ovale which opens broadly into the otic capsule (Gans \& Wever, 1972; Wever \& Gans, 1973). There 
may be some variability in the relation of the columellar footplate and the cochlear recess (D. W. Hamilton, in Gans \& Lynn, 1965). In an embryo Leposternon (May, in press). as in geckonids, and juvenile (Wyeth, 1924), but not in adult Sphenodon (Gans \& Weverl 1976), the stapes is still penetrated by the stapedial artery; however, this passage is not notable in adults of most amphisbaenians (Jollie, 1960, reports passage of the vessel through a notch in the edge of the footplate, just lateral to entry of the vessel into the parabasal canal). This characteristic may be significant. Among the reptiles, only some geckos and dibamids have a perforated stapes. Other geckos, pygopodids, Sphenodon anc snakes show the artery passing anterior to the stapes, but all other lizards show it in $z$ posterior position. The shaft of the stapes projects outward for some distance, terminating in a cartilaginous connection or articulating with more external tissues.

All amphisbaenians, except the two species of Blanus and the three of Bipes, have ar. extracolumellar element, which is a well-formed, rod-shaped, flattened, cartilaginous or bony structure that is tied into dermal thickenings along the jaws. Although Camp (1923, reported and illustrated a small discrete cartilage discovered by dissection between the stapes and the "extracolumella" in one specimen of Amphisbaena caeca and correlated it with the otostapes of lizards, no such element was noted in any of the serial sections examined by me (cf. Wever \& Gans, 1973). In Blanus and Bipes, the tip of the stapedial shaft bears various irregular plates and nodules of cartilage. However, no "extracolumella" is present. Apparently this difference was first discovered by Wagner (1843), who noted that Chirotes (=Bipes) differed from Amphisbaena as it lacked the entire middle ear cavity. while Smalian (1884) remarked that Blamus lacked a "jugal". Uniquely among the Amphisbaenia, members of Bipes and Blanus retain a portion of the hyal arch (here referred to as an epihyal) that swings from its connection to the cornu hyale (ceratohyal) to pass ventrolateral to the ear and parallel to the paratympanic region, although it does not attach to the skull (Wever \& Gans, 1972). Details of "extracolumellar" structure and tissue attachments in the derived members of the family Trogonophidae and in Rhineura floridana suggest that these two groupings may have developed their "extracolumella" differently from the pattern seen in the Amphisbaenidae (Wever, in press; which see for illustrations).

The "extracolumellar" apparatus is certainly unique among the Squamata, with the exception of Typhlosaurus, but not Feylinia (Toerien, 1963; van den Heever, 1976, and pers. obs.) in which a similar anterior cartilaginous "extracolumella" just reaches the subdermal connective tissues at the level of the coronoid (much posterior to the angulus oris). It represents a significantly different condition from that seen in adults of such other reptiles as crocodilians (Frank \& Smit, 1974), in which the hyal arch, furthermore, forms a second attachment to the skull proper. In such forms, the extracolumellar system primarily shows a localized thickening and stiffening of the tympanic region; even in Sphenodon, it extends into a sheet of connective tissue involved in sound absorption (Gans \& Wever, 1976). In contrast, the amphisbaenian extracolumella always lacks cranial connection and is a more or less elongated structure that connects the stapedial shaft to regions far anterior along the face. This condition led Versluys $(1898,1903,1936)$ to speculate that the amphisbaenian "extracolumella" might represent a portion of the hyal arch connected (secondarily) to the remnant of the true extracolumella, a view accepted by Fürbringer (1919) who considered the amphisbaenians to retain the most primitive pattern known in adult reptiles. However, Camp (1923: 342-343) disagreed because his 
embryo of Amphisbaena caeca did not retain the connection to the ear but did show a short ceratohyal (probably a malformation). In Camp's opinion, the interrelations of neighbouring muscles and ligaments "would make the tie of the extracolumella to the anterior portion of hyoid unlikely"; the short, bony extracolumella of Rhineura was assumed to represent an intermediate condition, and the Amphisbaenidae was "not primitive in this respect". All such arguments to the contrary, the occurrence of one or another pattern of modified extracolumella in all those (some 130) species of amphisbaenians that lack an elongate hyal arch, and the absence of an extracolumella in only those five species that retain an elongate hyal arch, suggest that Versluys and Fürbringer were correct concerning the derivation of the extracolumella. The pattern seen in those Amphisbaenia showing an extracolumella is probably phylogenetically old, because we see no intermediate stages nor retention of a columella-hyal connection in embryos of those forms that show the derived condition (May, In press).

Actually, the amphisbaenian, indeed the saurian, stapes (perhaps not its footplate, compare Burlet, 1934; Versluys, 1903; with Kamal \& Abdeen, 1972; as well as Toerien, 1965 ) is homologous to the hyomandibular, which is also a derivative of the hyoid arch. However, in most snakes and lizards, and in Sphenodon, the stapes retains at least a short extracolumellar remnant of the hyoid arch. This arch may remain intact and pass posterodorsally to reach to the ears (Sphenodon and geckos). Alternatively, the arch may become interrupted anterior to the short extracolumellar apparatus, with the posterior part forming a connection to and a reinforcement of the tympanum. It is then significant that the apparently (on other grounds) most generalized (though otherwise quite divergent) amphisbaenians, Blanus and Bipes, (1) lack any extracolumellar connection to the stapes and (2) retain a very long, muscularly invested hyal arch that extends posteriorly far past the ear and does not attach to the skull. The unique bare condition of the distal tip of the stapes (in Blanus and Bipes) suggests that the original hyoid-stapedial connection was lost very early in the history of the group. Consequently, the fusion of the epihyal to the stapes seen in other amphisbaenians and the positional shift and liberation of the epihyal to form a new extracolumella are secondary events. Apparently the amphisbaenian "extracolumella", although derived from the hyoid arch, is not directly homologous with the structure of that name seen in the Sauria and Sphenodon.

\section{Inner ear}

The Amphisbaenia, as well as adult lizards and snakes, turtles and crocodilians, lack the paratympanic organ of Vitali (Simonetta, 1960), though the organ occurs in Sphenodon and birds.

Auditory sensitivity has been discussed by Gans \& Wever (1972) and Wever \& Gans (1973).

The amphisbaenian inner ear lacks a round window, this region being covered by the enormous stapedial footplate (Jollie, 1960). Consequently, displacements of the stapes in the oval window require displacement of fluid via the inner ear into the cranial cavity; anterior fluid shifts within the cranial cavity, moving outward again through the large Gasserian foramen, anterior to the prootic and posteriorly to the anterolateral face of the columellar footplate, thus completing the circuit. The scala tympani opens posteriorly into the perilymphatic recess and, in turn, into the cranial cavity via the foramen for the glossopharyngeal nerve. After passage via the soft tissues along the medulla, the path 
leaves the cranial cavity via the Gasserian foramen, anterior to the prootic, and then turns posteriorly to reach the lateral face of the stapedial footplate. An inward thrust on the columella then results in a continuous fluid displacement all along this route; the small quantity of fluid pushed ahead of the inner face of the footplate is restored to its outer face and vice versa. Wever (in press) discusses the membranes constraining the path and refers to a current within a body of fluid, only partially guided by firm structures. The amphisbaenian circuit is furthermore much more complex than in most other reptiles in that its route through the cranial cavity is poorly defined. Such a continuous fluid circuit occurs in snakes. In turtles, Sphenodon, and in a few divergent species of lizards the circuit is completed via a second body of fluid. However, among these forms, only in Anniella does the closed circuit traverse the cranial cavity.

The amphisbaenian saccule is approximately three times as large as the cochlear duct into which the basilar papilla faces. The periotic cistern is undivided, and the periotic sac expands within an unusual system of bony canals (Baird, 1970). The arrangement apparently reflects the unique enclosure of the anterior part of the metotic fissure and is unknown in other reptiles.

Schmidt (1964), in an analysis of a few members each of many families of lizards, suggests that the cochlea reflects phylogenetic affinities rather than habits. The cochlea of Amphisbaena alba differs from that of lizards in almost every characteristic studied. The vestibular lip arises from the anterior cartilage much farther from the basilar membrane than in lizards. The vestibular membrane is especially thin and seemingly free of secretory cells, and the secretory area, lining the margin of the posterior cartilage, is structurally closer to the mammalian stria vascularis than to the saurian condition. The anterior edge of the vestibular membrane is inserted at the posterior, rather than the anterior, edge of the anterior cartilage. Except for the probably degenerate (M. Miller, pers. comm.) structures of Chamaeleo, the basilar papilla of Amphisbaena shows the "most primitive" pattern among the lizards (Schmidt, 1964).

Miller $(1966,1968)$ has mapped the cochlear ducts of squamates and has shown that other topographic aspects of the inner ear, such as constrictions of the cochlear duct, also show a more or less divergent position for the Amphisbaenia. In snakes and amphisbaenians, and Sphenodon, an overlying tectorial plate (M. Miller, E. G. Wever, pers. comm.), rests upon the basilar papilla. Although a similar structure is present in some lizards, it is usually combined with other types of tectorial specialization (Wever, 1967a, $b$ ).

Baird (1969, 1974a, b, pers. comm.) has made ultrastructural observations on the basilar papilla in Bipes and Amphisbaena. The neuroepithelium of the receptor largely conforms to a generalized pattern characteristic of aural receptors in turtles and many infra-reptilian vertebrates (Baird, 1974b). The hair cells are broadly columnar and rather widely spaced. Their apical ciliary bundles are short and predominantly polarized in one direction. Basal synapses connect to both efferent and afferent nerve endings. The supporting cells are somewhat advanced from the generalized (i.e. testudinian) condition in that they show slight apical compression, minor reduction of cytoplasmic organelles, and scattered bundles of 15-50 cytoskeletal microtubules extending from the basal plasmalemma to the apicolateral desmosomes. Conditions in snakes differ in that additional apical compression and reduction of organelles results in somewhat closer spacing of hair cells, and the cytoskeletal microtubules are more numerous and distributed more evenly throughout the cytoplasm. 
In contrast, the saurian basilar papilla shows greater and more diverse specializations (Baird, 1969, 1974a, b, pers. comm.). With rare exceptions, only part of the saurian receptor is formed by the generalized type of neuroepithelium mentioned above. In the bulk of the papilla, slender columnar hair cells are opposingly polarized along one or two longitudinal axes, and they synapse basally with afferent nerve endings. These sensory cells are highly ordered and closely spaced, because the related supporting cells typically show great apical compression and major reduction of cytoplasmic organelles. The supporting cells usually contain extremely dense populations of cytoskeletal microtubules that are evenly spaced in the cytoplasm.

\section{Nasal system}

Following upon Fischer's detailed study of the nasal system of Trogonophis, Blanus and Amphisbaena, that of some hundreds of lepidosaurians has recently been reviewed in detail (Bellairs, 1949a; Gabe \& Saint Girons, 1976; Malan, 1946; Parsons, 1970; Pratt, 1948; Saint Girons, 1975b). All of the amphisbaenians examined show a well-developed vestibulum that enters the large and simple cavum at the level of (Blanus) or anterior to (Trogonophis, Amphisbaena, Zygaspis, Anops) the organ of Jacobson (Gabe \& Saint Girons, 1976). Except for that of Trogonophis, the amphisbaenian cavum is lined with an alveolar epithelium. Except for Amphisbaena, the cavum is large and shows a massive concha without pedicels. The concha of Amphisbaena is remarkably projecting and resembles that of the Scincidae. A well-developed olfactory epithelium lines most of the true cavum. The cavum of Sphenodon and amphisbaenians uniquely contains goblet cells or mucous glands. The choanae open from the posterior quadrant of the amphisbaenian cavum and extend posteriorly through deep, doubled nasopharyngeal fossae.

The well-developed organ of Jacobson lies rostrally, as in all lizards and, as in the Xantusiidae (Malan, 1946), the lachrymal canal opens independently of the choanae near the base of the canal of Jacobson's organ. The most derived condition is seen in the incompletely neochoanate Rhineura and Amphisbaena (Bellairs \& Boyd, 1950). Here fusion between the maxillary and vomerine processes has extended to produce a separation of the choanal groove and the duct of Jacobson's organ, a state also seen in some teiids. Trogonophis (as well as such lizards as Anguis and Anniella) shows an extensive, but circumscribed, communication of choanal groove and lachrymal duct. The external (lateral) nasal gland is enormous and mainly intraconchal; its duct is ventral or ventrolateral, rather than dorsolateral as in lizards (Parsons, 1970). The gland is formed of seromucous and mucoserous cells, while those of Trogonophis show a (poorly developed) striate zone. Blanus, Amphisbaena, Zygaspis and Anops lack even this (Gabe \& Saint Girons, 1976; Saint Girons \& Joly, 1975). Thus, most amphisbaenians appear to differ from the snakes, as well as from chameleons, anguids, anniellids and helodermatids, all of which lack these cells (Gabe \& Saint Girons, 1976). It may be that the condition reflects environmental factors, or that it is a trogonophid development.

In general, the nasal region of amphisbaenians is similar to that of lizards, but differs in numerous small details for about every characteristic examined (Fischer, 1900). Most of these differences relate to the interaction of cartilaginous and skeletal supports. As in amphibians, the olfactory region lies on an anterior prolongation of the cranial cavity; it does not, as in many lizards, enter between or beneath the anterior portion of the brain. This difference may mainly reflect the lesser volume required for the optic region. 


\section{Teeth}

The amphisbaenians all share the characteristic of an enlarged, median premaxillary tooth that may or may not be flanked by one or more pairs of generally smaller teeth on the palatal flanges of the premaxilla. The number of flanking teeth (as well as the number of maxillary and mandibular teeth) varies intragenerically. No study has yet examined individual and ontogenetic variation in tooth number and placement. No palatine or pterygoid teeth occur. There is a general trend among the Amphisbaenia toward reduction in tooth number with the specialization of the burrowing apparatus, which generally leads to shortening of the facial aspect of the skull.

The central premaxillary tooth probably represents a replacement of the true egg tooth (Smith et al., 1953; Bogert, 1964) and can only be attached after the latter is lost at term; this is an observation based upon a very few species, mainly of Amphisbaena. It also appears that the median tooth of pleurodont species is replaced. There is no indication that amphisbaenians show any trace of a doubled Anlage, either for the egg tooth or for the median premaxillary tooth (as described for some geckonids, Woerdeman, 1919; see also Schnabel, 1956), nor could either tooth be assigned to one or the other side. The median premaxillary tooth of Rhineura has been shown to be innervated by the median ethmoidal, rather than the maxillary branch of the ophthalmic nerve (first rather than second branch of the fifth cranial nerve, Smith et al., 1953; no other forms seem yet to have been checked).

The Trogonophidae show a semifused row of acrodont teeth (Gans, 1960; Woerdemann, 1921a). The members of other amphisbaenian families show a subpleurodont pattern, with the symmetrically rooted teeth arising in a partially closed groove along the lingual face of the bones while a bony ridge forms between the tooth bases (Lessmann, 1952; Woerdemann, 1921a). The amphisbaenian replacement teeth lie in an intermediate position between the bases of the fused teeth (Gans, 1957). If contrasted to the situation in those lizards that have the replacement teeth positioned at the base of each tooth, the amphisbaenian arrangement thus shows a superficial similarity to that for the Anguimorpha in the scheme of McDowell \& Bogert (1954). However, each amphisbaenian tooth is bilaterally symmetrical, being slightly compressed laterally, rather than simply conical, and the major axes (of transverse symmetry) of such teeth tend to cross the mandible at an angle of less than $90^{\circ}$. Consequently, the "intermediate" replacement teeth actually lie posteriorly on the line of this axis. It would be interesting to determine whether the acrodont teeth also differ by showing growth of bone into the primary pulp cavity, as shown by Throckmorton (1977) for some agamids. Camp (1923) suggests that pleurodonty was primitive in amphisbaenians.

\section{Tongue}

The amphisbaenian tongue is flat, covered with overlapping, plate-like papillae, bears a bifid anterior tip that emerges independently from a ventral position on the body of the tongue and has a posterior notch corresponding to the position of the glottis (Sentzen, 1796). Its pattern is more similar to that seen in lizards of the groupings Teiidae and Gymnophthalmines (Bogert, 1964; de la Serna de Esteban, 1965), Scincidae, Anguidae, Iguanidae, and Agamidae, rather than varanids and snakes (McDowell \& Bogert, 1954), but actually combines features of both. Anelytropsis and Dibamus lack the bifid anterior tips and show transverse plates and grooves (Bogert, 1964). 
Chaine (1900) noted that the exteriormost fibres of the geniohyoid, rather than the genioglossal fibres, penetrate the body of the tongue in Amphisbaena. De la Serna de Esteban (1959) suggested that the amphisbaenian tongue had more distinct muscles than do those of iguanids, gekkonids, teiids and scincids. She described two muscles, the $\mathrm{Mm}$. papillaris linguae and perientoglossus, as unique to Amphisbaena and Anops and never seen in lizards. In a later paper (1965), she described a poorly developed M. papillaris linguae in the skink Mabuya. This characteristic needs checking in members of more families.

\section{Buccal glands}

The supralabial glands of amphisbaenians are strongly developed and extend from the nostrils to the eyes. They are composed of eight hypertrophied arrangements of discrete mucous glands, each containing a distinct terminal duct; all of these exit jointly into the buccal cavity at the level of the naris (Fischer, 1900; Gabe \& Saint Girons, 1969). Fischer (1900) described a special premaxillary labial gland in Trogonophis, with a structural pattern similar to that seen in chamaeleons. The overall arrangement of supralabial glands is reminiscent of that seen in snakes (Reichel, 1883), particularly typhlopids, but has distinct structural detail. The Iguanidae also show supralabial glands; however, these glands seem to be absent in most lizards.

The purely mucous infralabial glands are well developed, particularly posteriorly, where they extend into the temporomandibular region, as do those of Typhlopidae and Leptotyphlopidae (Kochva, in press).

Amphisbaenians and snakes lack palatal glands (Fischer, 1900), otherwise found in the vast majority of lizards (except for isolated species, Gabe \& Saint Girons, 1969).

The pattern of the paired and symmetrical sublingual glands (already noted by Smalian, 1884 and Woerdemann, 1921b) is practically identical to that seen in the Scincidae. The anterior portion contains only mucoserous cells, and the posterior (except in Anops and Zygaspis where they are purely mucous) contains both mucous and mucoserous cells.

Lingual glands proper are absent, as in snakes and certain lizards.

\section{Head muscles}

The true relations of the head muscles of the Amphisbaenia remain to be worked out, as most reports are based on too few species and on too limited samples thereof, and because the innervation of these muscles has generally been determined by dissection only. The relative proportions of the muscles show major differences from those of other squamates (Haas, 1973; Lakjer, 1926; Renous-Léçuru, 1977). The M. levator anguli oris is doubled as in Sphenodon and Lanthanotus, in contrast to the condition in most lizards, and the M. adductor mandibulae externus medialis is tripled. The M. levator bulbi of snakes, Lanthanotus, and amphisbaenians has lost its connection with the eye, and functions as $\mathrm{M}$. retractor pterygoidei. The $\mathrm{M}$. pseudotemporalis is double-layered, as in most lizards, rather than single-layered as in snakes. Not until more species are sampled and innervations checked will we know whether these muscular arrangements are indeed unique, as claimed in the literature (cf. Kesteven, 1957).

The amphisbaenian mandibular adductors are very simple, but enormous; they form a thick covering over the roof of the skull (Dubecq, 1925). Their allometric growth results in a marked ontogenetic shape change of the amphisbaenian head (Gans \& Alexander, 
1962). A strong M. protractor pterygoidei and a M. retractor pterygoidei have been described (Haas, 1973; Lakjer, 1926, 1927); their occurrence suggests that elements of the palate and braincase can be moved relative to each other (Versluys, 1912). The M. protractor pterygoidei is stated to be innervated by the third branch of the trigeminal (Versluys, 1898, who also described an M. pterygoidei in Amphisbaena). The expression of these muscles varies intergenerically (Lakjer, 1926; Versluys, 1898).

The pattern of amphisbaenian throat musculature (Chaine, 1900; Zavattari, 1910) is clearly different from that in the Scincomorpha, and certain of its aspects recall the conditions in the varanids (Camp, 1923).

The M. cervicomandibulares of Bipes canaliculatus (Renous-Léçuru, 1977), of Blanus (Smalian, 1884) and other Amphisbaenidae (Camp, 1923; Zavattari, 1910) are enormous and their pattern reminds one of that in some scincomorphs, differing from that in anguimorphs (Camp, 1923). Camp (1923) noted that the amphisbaenian pattern occurred mainly in fossorial forms and that such hypertrophy, coupled with that of the deeper lying M. depressor mandibulae, might represent secondary adaptations for burrowing.

In Amphisbaenia, part of the mandibular depressors originates from the quadrate and adjacent parotic regions (Versluys, 1898). A major portion of a well-developed depressor group (see Adams, 1925) inserts onto the surface of the axial musculature along the sides of the trunk, and a much smaller portion ascends the head, just posterior to the origin of the adductors, in more nearly the position of the saurian $\mathrm{M}$. depressor mandibulae. The two heads of the depressor and the two more deeply positioned heads of the M. cervicomandibularis are innervated by the facial nerve rather than the hypoglossal (as are the depressors of snakes). This indicates that these muscles, though restructured and not originating from the quadrate, derive from an essentially saurian pattern (RenousLéçuru, 1974b). The deeper muscles of the throat are described by Richter (1933); he did not illustrate the amphisbaenian arrangement, noted mainly proportional differences among the families of lizards, and determined innervation by dissection.

\section{Vertebrae, ribs and sternal system}

Even though the amphisbaenian vertebrae are stout and solid, broad and ventrally flat, and consequently, easy to recognize, they lack any major morphological characteristic that obviously sets them off from those of lizards. They are wider anteriorly than posteriorly, are markedly constricted medially, and have an oval condyle, similar to that of Ophisaurus (Camp, 1923). The centrum is procoelous, and its anterior portion has parallel sides; the articular surface is surrounded by a flange and has a variable ventral exposure. Unlike snakes, teiids, and a miscellany of lizards (Camp, 1923; Hoffstetter \& Gasc, 1969). the Amphisbaenia lack any indication of zygosphene-zygantral articulation, but do have strong and inclined zygapophyseal processes. As in geckonids and pygopodids, as well as in a few scincomorphs, there are subcentral arterial foramina. Intercentra are lacking except on the atlanto-occipital joint, where intercentra two and three remain as part of the axis (Al-Nassar, 1976; Gans, 1960) and for a few segments thereafter. There are no discrete neural spines, but the neural arches of the anterior vertebrae may be high and ridged, particularly in the Trogonophidae (Gans, 1960), with the ridge coming to a posterior point. Rhineura generally shows longitudinal flutings of the dorsal surface of the adult neural arch, as if interfascicular connective tissues there had started to ossify. 
The number of trunk vertebrae ( 82 to about 175 ) is significantly higher in amphisbaenians than in lizards and overlaps the range of numbers seen in snakes, although the number of caudal vertebrae (fewer than 40) is lower (Broadley et al., 1976; Hoffstetter \& Gasc, 1969).

The amphisbaenian atlas consists of a (sometimes) fused pair of neural arch halves and the hypocentrum, which tends to be variously reduced or absent (Gans, 1960; Williston, 1918; Zangerl, 1945). The head joint is otherwise normal (scheme a-1; Remane, 1936), with the axis having two hypapophyses. The axis of Agamodon shows fusion of the first and second to the third centra, the second and third neural arches, and the second, third, and fourth hypocentra, apparently as part of a process of compression and stiffening of that portion of the anterior column that transmits the oscillating rotational stresses imposed by the trogonophine burrowing pattern (Gans, 1960). The anterior vertebrae have the hypapophyses fused with them in a midcentral position.

Amphisbaenians and various lizards are cited as having three cervical ribs, with six or eight being assumed to be the number in most lizards (Camp, 1923; Cope, 1892b). In Bipes, the first free rib lies on the fifth vertebra (Zangerl, 1945); in Rhineura and Trogonophis, it is on the third, and in various other trogonophids and amphisbaenids, on the fourth (Hoffstetter \& Gasc, 1969). Amphisbaenian ribs tend to be unicipital, but may have only anteroventral (Rhineuridae, Cope, 1892b) or a combination of these and posterior (other amphisbaenian families) processes. The ribs (lymphapophyses) of the sacral region fork distally in some species (Amphisbaena, but not Anops), as do those of snakes (Salle, 1880; Zangerl, 1945).

The vertebrae of the cloacal region bear haemapophyses (Hoffstetter \& Gasc, 1969; Zangerl, 1945). More posteriorly, these often unite to form caudal chevrons by distal fusion (except in Dalophia, Hoffstetter \& Gasc, 1969) and lie "intercentrally" (Camp, 1923 ; pers. obs.); this is also true for many lizards, but not for Dibamus which lacks them, and for snakes in which they never fuse distally (Underwood, 1957a). In amphisbaenians, chevrons tend to occur in the distal part of the tail, starting in the region where the integumentary annuli achieve a relation of $1: 1$ to the vertebrae. Various lizards and all snakes show the chevrons as having moved to a midcentral position and fused to the caudal vertebrae.

The Amphisbaenia are stated to differ from most lizards (including the burrowing members of the Scincomorpha; Camp, 1923) in the loss or absence of both the sternum and the parasternum; however, the amphisbaenid Blanus (Zangerl, 1945) shows some sternal remnants. Furthermore, all members of the Trogonophidae (Gans, 1960) and Bipedidae (Renous-Léçuru, 1974b) retain a fully developed cartilaginous or bony sternal plate to which the limbs or limb remnants attach. In amphisbaenians, the sternal remnants do not show a direct connection to the ventral ends of the ribs.

\section{Limb girdles and limbs}

The occurrence of some girdle rudiments in limbless amphisbaenians has been known since the descriptions of Mayer $(1826,1829)$ and Heusinger (1833). Gasc (1977) notes that the potential reduction of the girdles shows up first in the number of somites involved in the developing Anlagen. Fürbringer (1870) was the first to comment on the fact that the posterior limb girdle tended to be more reduced than the anterior in some amphisbaenians and that a similar pattern of reduction occurs in the Teiidae (cf. Presch, 1975); however, 
the anterior limb is more reduced in other lizards. This characteristic has since been emphasized by other authors (Bogert, 1964; Boulenger, 1884; Camp, 1923; Cope, 1892a, 1900; Hoffstetter \& Gasc, 1969). Unfortunately, such forms as Anguis show more reduced posterior than anterior girdle remnants (O. Müller, 1913), whereas Ophisaurus shows the opposite trend (Tiedemann, 1976). Furthermore, smaller posterior limbs and girdles occur in only two families of the order Amphisbaenia. Carlsson (1886), for instance, stresses that the pelvic plexus is better developed than the pectoral (in limbless lizards, and Amphisbaena vermicularis).

All but connective tissue traces (inscriptional traces) of the pectoral girdle have been lost, but some pelvic remnants of uncertain affinity remain in the only Recent member of the Rhineuridae (Cope, 1892a; Fürbringer, 1900; Zangerl, 1945). The same situation occurs in some members of the family Amphisbaenidae. Fürbringer (1900), M. Müller (1900), as well as Zangerl (1945), note what may be a cartilaginous sternum and an epicoracoid, a bony scapulocoracoid (or scapuloprecoracoid) and cartilaginous suprascapular remnants in Blanus and bony scapulocoracoids in Amphisbaena fuliginosa (see Fürbringer, 1900; Mayer, 1826, 1929; Rathke, 1853). Zangerl (1945; but not Fürbringer, 1900) saw a tiny remnant in Anops; Monopeltis has lost the pectoral girdle (Fürbringer, 1900), as has Leposternon (cf. Fürbringer, 1870, 1900; J. Müller, 1831; Peters, 1882; Stannius, 1856; Zangerl, 1945; however, Rathke, 1853, noted it in L. microcephalum).

In contrast, members of the families Trogonophidae (Al-Nassar, 1976; Gans, 1960) and Bipedidae retain a well-developed sternal apparatus and show much reduction of the pelvic girdle. Bipes retains a cartilaginous suprascapula, a large bony scapulocoracoid, a large medial cartilaginous "interclavicle" (this element, which shows a narrow zone of connection to the one on the opposite side, may be misidentified, as the interclavicle is presumably a dermal bone), a very reduced anterior element supposedly a cleithrum, a doubled, rod-like sternum, and the elements of the pectoral limbs (illustrations in Castañeda \& Alvarez, 1968; Fürbringer, 1870, 1900; Parker, 1868; Renous-Léçuru, 1974b; Wagner, 1841, 1843; Zangerl, 1945; the two most recent are by far the best descriptions). Embryologic and myologic correlations are still lacking and the identifications of individual elements are questionable, particularly as several of the pectoral elements named in various lizards only become separated by secondary resorption of portions of the primary cartilage plates (Bogoljubsky, 1914). All elements of the forelimb of Bipes are well developed, and the joints among the appendicular bones permit extreme bending (folding) and also the locking of the limbs when these are extended (Castañeda \& Alvarez, 1968). The pelvic elements of Bipes are much more reduced, consisting of a single central element of the girdle (either the pubis or the ischium) and the femur, with discrete epiphyses (Castañeda \& Alvarez, 1968).

The Trogonophidae show a medial cartilaginous plate, which is probably a sternum, as well as variably expressed scapulocoracoids (Gans, 1960; M. Müller, 1900; Smalian, 1884; Wagner, 1841). As far as noted, Cope's concept (1892a) that the pectoral girdle degenerates phylogenetically after the pectoral limb while the degeneration of the pelvic girdle precedes that of the pelvic limb, still holds true.

Thus variable patterns of structural retentions and reductions make it difficult to establish ordinal affinities. Obviously Camp was correct in his implication that the degree of skeletal reduction in the limbs reflects the function of the axial system. Unfortunately, the "stages" of reduction of the scapulocoracoid and "interclavicle", mentioned in the 
literature, derive from very selective choices among diverse members of different families rather than a single series.

Zangerl (1945) reported that the 3,3,3,3,3 phalangeal formula of Bipes biporus represented one of the rare cases of polyphalangy among vertebrates, differing as it did from the more normal $2,3,4,5,3$. It is interesting to note that the other two species of the genus have just been shown to have 3,3,3,3,2 (B. canaliculatus) and 0,3,3,3,2 (B. tridactylus) (Castañeda \& Alvarez, 1968). Hyperphalangy appears to reflect direct selection for tunnel widening and initial penetration (Gans \& Shaw, 1963; Gans, 1974). Among the Sauria only the geckos appear to show polyphalangy, either of digits one (Russell, 1976) or five (Haacke, 1976).

The pectoral limbs of Bipes attach more ventrally and anteriorly than do those of lizards, with the closest similarity being to the chameleons. Several of the medial elements of the girdle are cartilaginous, but the limbs are enlarged, relative to the body diameter, and clearly functional (Gans \& Shaw, 1963). This suggests that the limbs of these animals are distinct in their architecture and that those of ancestral amphisbaenians may have differed from those of lizards (Renous-Léçuru, 1974b). The carpus of Bipes is similar to that of Sphenodon and distinct from that of lizards in retaining a well-developed (rather than reduced or absent) intermedium and two (rather than one) centralia. It thus reminds one of the arrangement in primitive reptiles (Renous-Léçuru, 1973).

The shoulder and limb musculature is extremely well developed, but its plan is sufficiently distinct to make homologies difficult to determine. For instance, the dorsal bundles of the elevators of the girdle, which attach to the suprascapula in lizards, reach the clavicle in Bipes. The deltoid muscle also shows a scapular head, which is rare in squamates (RenousLéçuru, 1974b). However, Edgeworth (1935) stated that the "cucullaris" is undivided. The form of the clavicle, the occurrence of the clavicular head of the deltoid, and the division of the trapezius and sternocleidomastoid, all are much closer to the conditions seen in iguanomorphs than in scincomorph lizards (Renous-Léçuru, 1974b).

The entire distal musculature of the limb of Bipes is distinct in involving a complex ligamentous system that limits the patterns of flexure, so that the trends remind one of those in fossorial mammals (Renous-Léçuru, 1974b). One sees reductions and loss of ventral portions, fusions and shifts of insertions.

\section{Trunk muscles}

Smalian (1884), in an exemplary study of the comparative myology of Trogonophis, Amphisbaena, Anops and Blanus, characterized and illustrated the major axial muscles. Camp (1923) stressed the taxonomic value of the diverse subdivisions of the rectus musculature among the Sauria, but did note that the retention of the "superficial rectus" could be correlated with locomotor patterns in which the trunk was carried low and slid along the ground. Unfortunately the data have recently been questioned by Kluge (1976a). The problem with all such studies is that of determining homologies in a system that shows major, functionally significant modifications, particularly among animals in which the trunk has become elongate (Gasc, in press; Sukhanov, 1976).

The most recent review of the axial musculature of elongate squamates (Gasc, in press) shows that the amphisbaenian pattern is clearly distinct from that of snakes, and also is quite distinct from those in limbless lizards, including the dibamids. Characteristics in 
which the amphisbaenians are distinct are listed as: (1) The inner layer of the M. transversospinalis shows a plurisegmental M. interarticularis superior. (2) The M. spinalis is linked with the $\mathbf{M}$. interarticularis superior, and is completely free from the M. semispinalis. (3) The bundles of the M. longissimus lack a cranial bifurcate tendon. (4) The long bundles of the M. iliocostalis lack tendinous segmentation. (5) The medial hypaxial layer is clearly divided into dorsal and ventral portions. (6) The lateral layer is differentiated proximally, depending upon its local relation to vertebrae and ribs, into an $\mathrm{M}$. tuberculocostalis or an M. levator costae. (7) The M. obliquus externus forms long supracostal bundles that fill the space between the lateral limits of the $\mathrm{Mm}$. iliocostalis and intercostales ventrales. (8) The subvertebral muscles are restricted to the neck region.

The nuchal muscles, which hold the head and rotate it about the head joint, as well as those that bend the anterior portion of the vertebral column, are more or less dark red in Leposternon (Kaiser, 1955), Rhineura (Gans, 1960) and other species. In contrast, the more posterior, true axial musculature is white. This pattern presumably reflects a functional dichotomy similar to that seen in uropeltid snakes (Gans, 1976; Gans, Dessauer \& Baic, 1978).

The integument of the amphisbaenids is connected to the axial mass by three sets of muscles for each segment (generally corresponding to at least two integumentary annuli; Kaiser, 1955; Smalian, 1884). These are the muscles variously called Mm. scalares or divisions of the rectus musculature. The ventral tip of a rib and the vertebrocostal junction provide the origin for inferior costocutaneous and vertebrocutaneous muscles inserting anteriorly on the skin, whereas the superior costocutaneous muscle originating on the middle of each rib inserts more caudally. Smalian (1884) considered the vertebrocutaneous muscle to be unique to the Amphisbaenia and the other two as possibly homologous to those in snakes.

\section{Tail and caudal autotomy}

Amphisbaenian tails, whether autotomized or not, show a change in segmentation within the first ten annuli posterior to the cloaca. Here the ratio of annuli to vertebrae changes from $2: 1$ to $1: 1$ (Alexander \& Gans, 1966).

In spite of a few, mainly African species of the genera Cynisca (Loveridge, 1941) and Dalophia (Broadley, Gans \& Visser, 1976) which have more than 30 vertebrae to the tail, the vast majority of amphisbaenians have very short tails. In this, they resemble the burrowing snakes (Typhlopidae, Leptotyphlopidae, Uropeltidae, Aniliidae) and differ from most snakes and burrowing lizards. While the autotomizing portion of the amphisbaenian tail has a diameter almost equivalent to that of the trunk, it does not appear to participate in force transmission during undulatory locomotion. This represents a fundamental difference from the patterns seen in snakes and many lizards.

Many amphisbaenians show caudal autotomy; the Trogonophidae are the only family in which it is always lacking. As far as known, autotomy always occurs at a single site on the tail, with the external indication being a narrowed, shortened, diversely pigmented, autotomy annulus (Gans \& Alexander, 1962). Autotomized tails do not regenerate, and the caudal stump heals cleanly, which accounts for some descriptions of "short-tailed" species.

The autotomy vertebra shows a single intravertebral plane, located toward the anterior end and crossing both centrum and neural arch. The centrum shows a well-developed 
double lip fringing the cleft (Alexander, 1966b), much as in lizards (Sheppard \& Bellairs, 1972; A. d'A. Bellairs, pers. comm.) and Sphenodon (Ali, 1941, 1949), except that all of these differ from the Amphisbaenia in showing at least some regeneration. More peripherally, the cleft zigzags between the layers of muscle and fat and reaches the external surface between two annuli of the integument. Certain geckos also have but a single intravertebral fracture plane; however, all of them appear to be capable of regeneration. As far as known, snakes generally do not autotomize their tail (Hoffstetter \& Gasc, 1969). Occasional fractures may be intervertebral and do not regenerate.

Even though few extensive studies appear to have been carried out, it is noteworthy that the fat layers of the tail, which in lizards and possibly in Sphenodon (Ali, 1941) lie immediately perivertebrally and are ensheathed by the longitudinal and transverse muscle layers, are perimuscular in amphisbaenians. The tail contains two ventral, and sometimes two more dorsal, rods of fatty tissue, each of which may or may not be segmented, and all of which lie immediately beneath the thin sheath of a more properly cutaneous musculature (A. d'A. Bellairs, pers. comm.; Smalian, 1884). The trogonophid amphisbaenians lack fat layers in their conical, downward-pointed tails, as do various lizards that do not autotomize the tail. Sheppard \& Bellairs (1972) suggest that the fat may facilitate autotomy, but these layers may rather provide the bulk for storage (Bustard, 1967) or in order to increase the caudal diameter; as the tail often has a major role in locomotion in these stout-tailed lizards (Gans, 1975; C. Leonard, pers. comm.).

\section{Hypophysis}

In the Amphisbaenia, as in other burrowing squamates, the hypophysis is generally dorsoventrally flattened. It lies posterior to the pars distalis as it does in the Feyliniidae and Typhlopidae. A small pars intermedia of the hypophysis remains in Trogonophis and a vestigial one in Blanus, as well as in Amphisbaena, Anops and Zygaspis; it is completely absent in the snakes Typhlops and Leptotyphlops (Saint Girons, 1961, 1968, 1970). In limbless lizards, Anguis (Anguidae) and Lialis (Pygopodidae), the pars intermedia remains well developed; its reduction has been associated with a burrowing existence, rather than mere cryptive behaviour. No microteiids appear to have been studied. The recessus infundibularis generally penetrates the neurohypophysis, as in all reptiles except the snakes. The cytology of the pars distalis of Trogonophis is distinct from that of the other amphisbaenian studied thus far (Blanus, Saint Girons, 1968, 1970), but amphisbaenians differ generally from other burrowers except for a common reduction in cell size (Saint Girons, 1970). Many of the differences among the amphisbaenians and other squamates are thus ascribable to their subterranean existence. The differences are shared with diverse burrowers, but there is no single trend of modification.

\section{Adrenal glands}

The amphisbaenian adrenals are spindle-shaped and lie adherent to the efferent renal veins in the urogenital mesentery, just medial to the gonads, with the right adrenal slightly anterior to the left (Crook \& Parsons, in press). The position of the organs is thus similar to that of other squamates with but minor differences in shape.

Gabe \& Martoja (1961, 1962; also Gabe et al., 1964; cf. Gabe, 1970) have described and compared the histology of the adrenal glands of Blanus cinereus and Trogonophis wiegmanni to those of several species of each of some 14 families of lizards, and of most 
families of snakes. They state, on the basis of these two species, that the dorsal layer of cells is most highly developed in amphisbaenians; here the layer sends multiple, long. finger-like processes into the organ, so that parasagittal sections yield the impression of a complete interpenetration of tissues, such as exists in crocodilians and birds. Dendritic melanocytes are rare in the parenchyma of lizards; these cells are completely lacking in amphisbaenians and snakes. Otherwise, there are no histological characteristics distinguishing the Amphisbaenia from other squamates (Gabe, 1970; Saint Girons, pers. comm.).

\section{Pancreas}

The amphisbaenian pancreas is generally a pyramidal organ, concentrated in the vicinity of the pylorus or to the right side of the gut just posterior to it, a condition otherwise seen only in some varanids (Crook \& Parsons, In press; Miller \& Lagios, 1970; Underwood, 1957b). Hill (1926) notes that "limbless lizards" have an elongate pancreas located in the mesentery, whereas lizards show triradiate, ribbon-shaped glands and snakes a very diverse, sometimes more condensed, mass of glandular tissue. The islands of Langerhans are small to medium-sized and, as in reptiles generally, tend to be most common in the tip of the organ. About $70 \%$ of the secretory cells are $\beta$ and the rest $\alpha$, which makes the Amphisbaenia unique among the Lepidosauria, as snakes and lizards show the opposite frequency (Saint Girons, 1968).

\section{Thyroid and parathyroid}

The thyroid glands of lizards exhibit numerous intrafamilial variations in shape and arrangement (Lynn \& Walsh, 1957). Those of the Scincomorpha are generally unpaired, though feyliniids and teiids show bilobed forms. Simon (1844) was wrong when he stated that the thyroids of the Amphisbaenia were like those of snakes, as amphisbaenians generally have bilobed glands while those of snakes are single and median (Lynn, 1970). Actually, the pattern is one of paired and discrete, compact to ovoid structures in the Bipedidae and the Amphisbaenidae. In the Rhineuridae, the posterior ends of the two glands are connected by a narrow isthmus (Lynn \& Komorowski, 1957). This pattern also appears in the generalized trogonophid genus Trogonophis, while the derived genera of the Trogonophidae show only a left thyroid (Gans \& Lynn, 1965).

The amphisbaenian thyroid lies in the throat, near the angle of the jaws (Bedriaga, 1884) but, of course, far from the heart. This is unlike the position seen in lizards, where the thyroids remain close to the pericardium, while the thyroid of snakes generally lies far posterior to the head and close to the heart (Saint Girons, 1968).

No amphisbaenians have been checked for the presence of parathyroid glands (Senior, 1974).

\section{Thymus}

In lizards, the thymus bodies are derived from visceral pouches II and III and lie anteriorly, even in elongate species (Varanus, Anguis, Pygopus, Delma, Aprasia, Lialis, Adams, 1953; Bockman, 1970; Underwood, 1967). In snakes, the thymus bodies derive from visceral pouches IV and $\mathrm{V}$ and lie more posteriorly, just anteriorly to the heart (Bedriaga, 1884; Pischinger, 1937; Smalian, 1884). The embryology of the amphisbaenian thymus remains to be studied. While the number and shape of lobules is variable, the 
thymus of snakes and lizards is always paired. In Amphisbaena, the thymus is Y-shaped, although one or another limb may become lost, giving rise to an azygous structure (Pischinger, 1937; Simon, 1844).

\section{Heart, major vessels and blood}

The hearts of Amphisbaena and Agamodon are generally reptilian (Francis, 1977). Like those of snakes, they lie back of the first quarter of the trunk, thus reflecting elongation of the neck (Rathke, 1857, 1863). They thereby contrast to the condition in limbless lizards, in which the heart tends not to shift as far posteriorly. The atria (the right the larger) are large and elongate, and the triangular ventricle is less elongate than that of snakes. Seven longitudinal septa run down the long axis of the ventricle from the apex to the base of the heart. The plane of the principal "vertical" septum coincides with that of the interatrial septum and restricts the variably proportioned, common ventricular chamber.

The base of the pulmonary and aortic arches forms a bulbus cordis, with its muscles extending to the semilunar valves. A helicoid septum crosses the dorsal wall of the bulbus. The sinus venosus forms a substantial and nearly spherical chamber. The sinuatrial opening in the dorsal wall of the right atrium is oblique and contains a membranous valve, the cranial cusp of which overlaps the caudal. Muscular bands radiate from each end of the opening.

The pulmonary vein enters the left atrium near the septum at the level of the septal end of the sinuatrial opening, which is guarded by an internal valvular flap. The free border of the thin, imperforate interatrial septum holds the two large septal cusps of the atrioventricular valve. The cusps may contact the free edge of the interventricular septum, the free borders of which are anchored by chordae tendinae.

The left systemic arch of the Amphisbaenia is considerably larger and thicker than the right (Beddard, 1905; Francis, 1977; Rathke, 1857; van der Merwe, 1940). Both aortae travel anteriorly a considerable distance before arching around the esophagus. The right arch extends further anteriorly than the left and first gives off coronary arteries. It then gives off a single vessel that immediately splits (Rathke, 1857) or a pair of vessels that supply the vertebral column and the head and may represent either the lateral aortae or carotids (Francis, 1977; Rathke, 1857). Rathke (1857) describes the separation of a second pair of "anterior vertebrals" (subclavians, per Beddard, 1905), which leave the arch beyond the bend and then supply the large muscles of the neck. Minor intercostals leave the right aorta before it fuses with the left into a common dorsal aorta. The amphisbaenians, in this view, would be unique among the Recent reptiles in that the left (which does not give off any major branches) is the dominant aortic arch. Amphisbaenians also lack the ductus Botalli (arteriosus).

Amphisbaenia (Rathke, 1857) and all snakes investigated (G. Underwood, pers. comm.) as well as the Chamaeleonidae, Helodermatidae, and Varanidae (among the lizards), lack the ductus caroticus (Adams, 1953; Underwood, 1957a; van der Merwe, 1940). In general, the equally paired appearance of the carotids is similar to that in some snakes and the varanids (Rathke, 1857). The pulmonary artery swings right dorsally to the left aorta, then turns dorsally to join the pulmonary vein and the trachea. Though Bedriaga (1884) stated that neither pulmonary artery nor vein bifurcates before ramifying amid the pulmonary tissues, Brongersma (1951) illustrated such separation in Trogonophis and 
Monopeltis. The internal carotid passes ventral to the stapes and enters the skull with the branches of the facial nerves (Rathke, 1857; Versluys, 1898). (Note the pattern of the stapedial artery noted in section on Larynx, branchial arches and skeleton of middle ear.)

The internal jugular disappears in Sphenodon, adult lizards, and snakes, but persists in adult amphisbaenians, in which it leaves the skull jointly with nerves IX and X (Underwood, 1957a; Versluys, 1898 (which see for account of intracranial vessels), 1936). Subequal, paired external jugulars receive the drainage from the body wall and the subvertebral muscles of the neck to form the precavals, which enter the right side of the sinus venosus, as does the large postcaval vein (Francis, 1977).

In Amphisbaenia and other Lepidosauria reported on, the arteries, supplying the digestive tract, branch off from the dorsal aorta rather than the left aortic arch (as in turtles and crocodilians; Rathke, 1863; von Hofsten, 1941). The coeliac trunk leaves the aorta on the left side, as does that of most lizards (Rathke, 1863). The gastric artery of the Amphisbaenia branches off the coeliac trunk and runs posteriorly along the right side of the stomach; the gastric vein enters the hepatic portal vein (Crook \& Parsons, In press).

The posterior vena cava reminds one of the saurian pattern (Bedriaga, 1884). Unlike lizards, amphisbaenians may have a remnant of a small posterior cardinal (or vena deferentialis, Hochstetter, 1898) between the kidneys and testes (Beddard, 1905).

The intercostal arteries of Amphisbaena and Bronia are paired and of equal size and leave regularly from the ventral surface of the aorta in the saurian pattern (Beddard. 1905; Rathke, 1857), while those of Blanus (cf. Bedriaga, 1884) show the more irregular pattern characteristic of higher snakes and some lizards (Rathke, 1857).

The nature of the mesenteries and of the vessels passing through them deserves further attention. In the amphisbaenids Bronia and Leposternon, most or all of the veins from the oesophagus and the anterior part of the stomach run in the right hepatic ligament (Beddard, 1905). In the most primitive amphisbaenid, Blanus cinereus, some of the veins run in the right and some in the median hepatic ligament, whereas only in the Trogonophidae (Pachycalamus and Trogonophis) do the veins lie in the median mesentery as in all other vertebrates (Butler, 1895). Hochstetter (1898) considered the pattern of gastric vessels of the Amphisbaenia closest to that of anguids among the lizards. The number of gastric vessels varies between one and nine without any phylogenetically obvious pattern.

The passage of parieto-hepatic veins along the whole length of the liver is a characteristic that is similar to the condition in snakes (Beddard, 1905; van der Merwe, 1940). In the Sauria, the gastrohepatic veins enter the liver separately; at the most, one or two fuse before joining the hepatic blood sinuses (Beddard, 1904, 1905). In Sphenodon, as in the Amphisbaenia, an anterior prolongation of the hepatic portal vein (incorporating the anterior abdominal) passes within the gastrohepatic ligament. The vein receives blood from the stomach and gives off branches to the liver; otherwise, the condition is not similar to that in the Amphisbaenia. In snakes, the hepatic portal vein not only passes branches from the stomach to the liver but is also in contact with the venous system of the dorsal body wall, as it is joined by the parietohepatic veins (Beddard, 1905).

Large lymph hearts lie between the split lymphapophyses, lateral to the tail, and send their drainage to the lateral lymphatic trunks (Salle, 1880; Smalian, 1884).

The proportions of the different types of amphisbaenian erythrocytes are overlapped by those of the lizards and snakes thus far examined (M. C. Saint Girons, 1970; Saint Girons \& Saint Girons, 1969). 
Lungs

The Amphisbaenia are unique "among pulmonate vertebrates in having the right [rather than the left] lung completely or partially suppressed". (Butler, 1895; based on independent dissections but including a review of the very confused earlier literature). Reduction of the left lung occurs in Caecilia, as well as in snakes and almost all elongate lizards insofar as these show reduction at all. The Amphisbaenia show a gradual reduction in the relative length of the right lung in parallel with increased burrowing modification. The trend appears to have occurred independently in several families (Gans, 1960, 1969). Cope (1900) notes that the lungs of Amphisbaenia and Anniella lie dorsad, rather than ventrad, to the alimentary canal, thus differing from those of most lizards including the teiids.

Although Butler did not dissect Bipes, his observations were soon confirmed for that genus as well (Cope, 1896a), and it shows a right lung only about $20 \%$ the length of the left (Gans, 1960). In the Trogonophidae, the left lung is always longer than the right, and the gradual reduction of the latter parallels the increase in burrowing specialization demonstrated by the four genera, even though the family shows a simultaneous reversal of the trend toward a more elongate trunk (Gans, 1969, 1974).

Wiedersheim's (1886) illustration of the viscera of a reptile, which includes a tracheal lung and is labelled Amphisbaena fuliginosa, must be that of a snake, as indicated, for instance, by the posteriorly placed gall bladder. Meckel (1818) was correct in his report that Amphisbaena lacks a tracheal lung.

Crook \& Parsons (in press), in a recent report, note the possibility that the "reduced right" lung of many species may only be a diverticulum of the remaining lung; according to this view, only a single lung remains in any amphisbaenian, and the second side represents a neomorph. Their suggestion is based on the confirmation of Bedriaga's (1884), Cope's (1900), and Smalian's (1884) observations that the trachea does not bifurcate but passes between the two anterior pulmonary lobes, ultimately entering the left one. The remaining amphisbaenian lung lies on the left side of the body cavity, and its relations to the various median blood vessels suggest that the lung is clearly the left. The evidence of separate (Brongersma, 1951) right and left pulmonary arteries (in Trogonophis and Monopeltis) does lend support to the view that the right portion represents the remnant of a lung. Crook \& Parsons (in press) are correct in indicating that embryological evidence would be highly desirable for resolving these questions.

\section{Alimentary canal and adnexae}

The amphisbaenian alimentary canal is a fairly straight muscular tube; normally the anterior portion of the hindgut (the small intestine) shows some folding. A few specimens show folds of the oesophagus or of otherwise straight sections of the intestine, and assorted variants of the curvature pattern have been described in the literature (cf. Crook \& Parsons, in press, for a review; also Al-Nassar, 1976; Kostanecki, 1926). The division of foregut and hindgut is indicated by a muscular pyloric sphincter (Pernkopf \& Lehner, 1937), which is often followed by a duodenal caecum (Lönnberg, 1902 for Rhineura). Posterior to the small intestine, there tends to be a colonic caecum (Cope, 1900; Crook \& Parsons, in press; Meckel, 1829), which may be very small or even absent as in Rhineura and the derived trogonophids, Diplometopon and Agamodon (Cope, 1900; Crook \& 
Parsons, in press; Jacobshagen, 1937; Lönnberg, 1902) and clearly shows interspecific differences in shape (Bedriaga, 1884).

Various degrees of fringes (Bipes) and regular zig-zag projections (diverse amphisbaenids) form a raised internal relief along the inside in the small intestine (cf. Parsons \& Cameron, 1977). Parsons \& Cameron (1977) and Jacobshagen $(1920,1937)$ suggest a phylogeny in which the Amphisbaenia plus anguids and teiids show generalized conditions from which those of other lizards derive, whereas Sphenodon and snakes (except for typhlopids) represent distinct patterns. Unfortunately the degrees of internal relief and the degree of intestinal curvature are markedly affected by the filling of the gut and the time of fixation (cf. Jacobshagen, 1920). The contraction state of both the axial and the intrinsic musculature of the gut and the condition of the genital system also affect these parameters. Presumably standardized relaxation and perfusion techniques (Bergmann, 1962; and earlier references) will have to be employed before one may make meaningful comparisons.

The fundic glands of amphisbaenians share two cell types (erythrophile and cyanophile respectively) with Sphenodon and all lizards except for the Anguimorpha. The latter group and the Boidae and Colubroidea show a second glandular pattern and the typhlopids and leptotyphlopids a third (Gabe \& Saint Girons, 1965, 1972). Otherwise, the surface epithelium and the pattern of pyloric glands is the general reptilian one. Neither histology nor pattern of layering distinguish the amphisbaenian alimentary canal from that of lizards (Al-Nassar, 1976).

The internal cloacal glands are polystomatic and generally agree with those of Sphenodon and Sauria (Whiting, 1967, 1969), rather than with the monostomatic glands of snakes (Gabe \& Saint Girons, 1965). Diverse amphisbaenians show two dorsal and two ventral polystomatic (many ducted) cloacal glands (Zygaspis), two dorsal glands and one ventral gland (Blanus and Anops), and two dorsal glands only (Amphisbaena and Trogonophis; Gabe \& Saint Girons, 1965).

Unlike snakes, amphisbaenians lack anal glands and anal sacs (Gabe \& Saint Girons, 1965). The proctodeum of amphisbaenians is fairly short; in females the urodeum is long and more or less bifurcate anteriorly. The genital tubercles emerge from the dorsolateral wall at the level of the anal sphincter. The ureter emerges from the posterior aspect of the genital tubercle. The urogenital papillae of males are smaller than those of females.

In lizards, the foramen Winslowi (= the epiploic foramen that opens into the lesser omental bursa) increases in size ontogenetically, while it becomes gradually smaller in the Amphisbaenidae and finally closes completely (Broman, 1937; Butler, 1889b).

A single mesenteric pattern appears common to all amphisbaenians (Crook \& Parsons, In press; also Butler, 1889a). The falciform or umbilical ligament and its connections run as a single sheet of midventral mesentery from the ventral surface of the heart along the lung, liver, gall bladder, and the fat body (posterior to the left lobe of the liver). Dorsally, the esophageal mesentery, mesentery proper, and mesocolon form a continuous sheet. In some species, the layers of the esophageal mesentery remain unfused, and the right hand sheet attaches to the lateral body wall. Diverse and complex sheets interconnect the anterior viscera.

The urogenital mesenteries run from the gonads to the kidneys, first as folds off the gut and then as a pair of separate sheets deriving from the middorsal body wall (Crook \& Parsons, in press). 
Liver and bile ducts

The amphisbaenian liver is elongate and may be completely and variably lobate (Beddard, 1905; Bedriaga, 1884; Crook \& Parsons, in press); this appears to be a general condition in elongate burrowers. The liver provides attachment for about five mesenteric ligaments (de Carlo, 1957); the pattern shows some intergeneric variation (cf. Cope, 1896a; Crook \& Parsons, in press), although it is generally saurian (Beddard, 1905). Two gastrohepatic mesenteries occur in Amphisbaena and only one in Rhineura (Cope, 1896a); One of the key problems, possibly involved in interpreting the different patterns, is the known seasonal (and even diurnal) variability of liver mass, as described, for instance, for frogs (March, 1937), lizards (Dessauer \& Fox, 1959), and birds (Fisher \& Bartlett, 1957).

All reptiles have a gall bladder (Gorham \& Ivy, 1938). That of amphisbaenians, as in lizards, lies in a notch of the liver, not separate and posteriorly as in snakes (Stannius, 1856; Underwood, 1967). The multiple hepatic ducts and the parallel cystic duct only fuse to form a common bile duct just before they enter the muscular wall of the duodenum, where they also receive the pancreatic ducts (Bedriaga, 1884; de Carlo, 1957).

Tauricholic acid, the principal bile acid of many lizards and snakes, also predominates in the bile of Agamodon anguliceps, the only amphisbaenian examined (Haslewood, 1967; Tammar, 1974; Skoczylas, in press).

\section{Spleen}

The spleen of amphisbaenians generally is a globular structure that lies in the mesentery, slightly dorsal to the apex of or embedded in the right side of the pancreas, near the pylorus (Duvernoy, 1833; Bedriaga, 1884; Crook \& Parsons, in press). The spleen of Agamodon and Trogonophis is elongated and U-shaped. In snakes, the spleen lies at the level of the pancreas; in most lizards, it lies near the stomach, on the right side.

\section{Fat bodies}

A small group of fat bodies lies just anterior to the heart (Cope, 1900). A large, ventral fat body, formed of secondarily lobulated left and right strips, runs from the liver to just anterior to the level of the cloaca (Bedriaga, 1884; Butler, 1889b; Crook \& Parsons, in press). The anterior abdominal vein runs down the centre of the trunk; it drains the fat bodies and connects posteriorly to the kidneys and anteriorly, via the pancreas, to the anterior mesenteric vein which enters the hepatic portal vein. Anteriorly, these bodies project into the coelomic cavity; however, the transverse sections of Butler (1889b: pl. 59, figs 1-7) show the fat bodies adherent to the ventral musculature in the posterior region, so that the peritoneum passes dorsal to them. Otherwise, the general arrangement of the fat bodies is described as similar to that in snakes and elongate lizards (Butler, 1889b; Stannius, 1856).

\section{Kidney and bladder}

The elongate amphisbaenian kidneys lie adjacent to each other at the extreme posterior end of the coelom. They are unique among those of the Squamata in the degree of freedom with which they hang into the coelomic cavity (Butler, 1889b, 1892; Crook \& Parsons, in press). The kidneys of Bipes canaliculatus appear to be unique among those of the Amphisbaenia, because of their relatively close attachment to the dorsal body wall; those 
of Rhineura have a narrow mesentery, while the organs project freely in the species of Amphisbaena, Leposternon and Pachycalamus thus far examined (Butler, 1892; Crook \& Parsons, in press).

Lepidosaurians appear unique in possessing a sexual segment of their kidney; in some snakes, this is apparently involved in the production of a coagulant secretion. The secretion hardens, blocking the cloaca of the female after copulation and producing a sperm plug (Devine, 1975). In snakes and Varanus, the sexual segment includes only the mid-part of the nephron. In other squamates, it is primarily composed of collecting tubes. In the Amphisbaenia and some chamaeleons, the segment only reaches to the ureter, while most lizards seem to have it connected to the cloaca (Saint Girons, 1972). In amphisbaenians. most lizards and some snakes, the segment shows but a weak histochemical differentiation. whereas in anguid lizards and some snakes it shows strong modification with some seasonal variation. Seasonal variation is also notable in Amphisbaenia and Sphenodon (Gabe \& Saint Girons, 1965).

Jacobshagen (1937) disagreed with Cope (1900) and claimed that amphisbaenians lack a urinary bladder; however, Crook \& Parsons (in press) found a bladder in a trogonophid (Trogonophis, confirming Gabe \& Saint Girons, 1965) but not in the advanced Diplometopon and Agamodon. They also found a bladder in the Rhineuridae (where it is distinct by being attached by a relatively wide ventral mesentery), in the Bipedidae and in some Amphisbaenidae (in Amphisbaena, also Fink, 1817; Stannius, 1856; Leposternon, also Stannius, 1856; Monopeltis, also van der Merwe, 1940; and Zygaspis; but not in the very small species of Chirindia and Cynisca). Bedriaga (1884) and Gabe \& Saint Girons (1965) noted it in Blanus. Lizards (except teiids, Cope, 1900, varanids, and some Gekkota and Iguania, Gabe \& Saint Girons, 1965) and Sphenodon generally have a bladder, and snakes always lack it (Jacobshagen, 1937). Consequently, most (or all) amphisbaenians appear to retain a generalized state.

\section{Gonads}

In the Amphisbaenia, the right testis tends to be slightly longer than and always anterior to the left. Both are flattened ovoids (Bons \& Saint Girons, 1963; Crook \& Parsons, in press, pers. obs.). The testes are freely suspended from the middorsal line by the mesorchial portion of the urogenital mesentery, up which pass the series of seminiferous tubules that fuse more medially to form the Wolffian duct. This duct travels caudad in a characteristically coiled pattern within the more laterally attached posterior continuation of the mesorchium; it then shifts to the ventral surface of the kidney before terminating in the urodeum. The duct and presumably the testicular size show marked seasonal variation (Bons \& Saint Girons, 1963; pers. obs.). Both Blanus and Trogonophis (the only forms examined) have a testicular histology intermediate between those of lizards and snakes. particularly in the manner in which the seminiferous tubules and the epididymis are connected (Bons \& Saint Girons, 1963).

The basic plan of the female gonads is very similar to that of the male. Except during pregnancy, the right ovary is usually much longer than and commences anterior to the left. It may be clumped but is generally strung out along the narrow mesovarium, starting at a species-specific site slightly posterior to midbody (Crook \& Parsons, in press). The ova are stated to be clumped only in the posterior portion of the ovary, but strung out in 
a series in the anterior portion (as in snakes, Stannius, 1856). Both oviducts are functional; amphisbaenians do not show a vestigial right one, as does Anniella. The oviducts run from a level near the pylorus or posterior end of the liver, but are freely suspended from the dorsal midline of the coelom by the wide mesotubarium. Past the level of the ovary, each oviduct is characteristically pleated (this and the coiling of the Wolffian duct provide the easiest means for sexing mature specimens through a small incision of the body wall). During maturation, the ovaries elongate enormously, and there may be significant displacement of other organs (Bons \& Saint Girons, 1963; Crook \& Parsons, in press). Trogonophis, Blanus, and Amphisbaena show a typically saurian pattern of histology for the female gonads.

Little is known about the temporal relation between insemination and fertilization in Amphisbaenia. In Blanus cinereus and Trogonophis, insemination only briefly precedes fertilization (Bons \& Saint Girons, 1953). These species lack the seminal crypts, present in chameleons and certain iguanids, that there allow the spermatozoa to survive between cycles. Apparently, the sperm of these lizards may survive for many months in the lumen or the folded wall of the vaginal tube. This seems also to occur in many snakes of temperate zones. Not untii just before ovulation do the spermatozoa migrate to the seminal receptacles in the tuba and there begin to mature. Apparently the expression of crypts and receptacles is seasonal, so that routine examination of museum specimens might not disclose their occurrence (Saint Girons, 1975a). However, studies of Trogonophis and Blanus throughout the sexual cycle (Bons \& Saint Girons, 1963) show no crypts, nor do crypts seem to occur in turtles and Sphenodon (Saint Girons, 1975a). This suggests that if the several sets of crypts are indeed homologous they probably represent a specialization that arose within the line leading to the Sauria and Serpentes.

\section{Hemipenes}

Hemipenes have been described for members of the amphisbaenian genera Rhineura (Gans \& Rosenberg, In prep.), Bipes (Gans \& Rosenberg, In prep.), Blanus (Bedriaga, 1884), Amphisbaena (Rosenberg, 1967; Thomas, 1965), Chirindia (Rosenberg, 1967), Leposternon (Rosenberg, 1967), Dalophia (Broadley et al., 1976), and Monopeltis (Broadley et al., 1976; Cope, 1896b, 1900). Most of these characterizations were based on light microscopy or histology (Rosenberg, 1967), while recent studies have checked surface texture by scanning microscopy (Gans \& Rosenberg, In prep.). All amphisbaenian hemipenes are retractile and have a central retractor muscle. A tubular gland occurs at the apex of the retracted hemipenis in some species and may be homologous to the Penisdrüse of Anguis (Whiting, 1967).

The short hemipenes are generally bilobed and have centrifugal sulci, although the bifurcation of head and sulcus is limited or absent, so that each hemipenis is simple in Bipes, Rhineura and Blanus. The two tips may bear folds or tiny non-keratinized processes. In contrast to most snakes, most Lacertidae (Klemmer, 1957), and Gymnophthalmines (Dixon, 1974; Uzzell, 1973), the amphisbaenian hemipenes are diversely flounced, but lack any calcified or keratinized spines. It is unclear from extant descriptions whether such spines occur in other lizards, such as Anniella in which Cope (1896b) reported only transverse flounces. In a few forms (Anops, Chirindia), each lobe of the hemipenis bears an accessory projection. 


\section{Brain}

The external topography of the amphisbaenian brain has been described for Blanus (Bedriaga, 1884). The simple and superficially unpaired and smooth midbrain is relatively small, though small midbrains are common in some burrowing snakes and lizards. More anteriorly lie the two hemispheres of the telencephalon and the sharply defined sessile (directly connected) olfactory bulbs. Such sessile bulbs occur not only in amphisbaenians, but characterize all turtles and snakes, as well as many lizards. The midbrain roof and cerebellum cover most of the medulla, which is invisible in dorsal view.

On plots of brain weight to body weight, amphisbaenians show low values, paralleled among lizards only by the Gymnopthalmines (R. Platel, pers. comm.). All other lizards thus far examined show relative brain weights greater by a factor of two. The amphisbaenian values fall in the zone otherwise occupied by the snakes. The index of encephalization (brain weight for zero body weight, or Y-intercept) for the trogonophids is near 40 , while the (limbless) anguid lizards and the snakes show values at or near 50. A few skinks are in the 60's and most lizards near 75 and higher, whereas the varanids and teiids are highest.

The choroid plexuses of Trogonophis are the only ones thus far reported on (Leblanc, 1920). The posterior one completely roofs the fourth ventricle. However, this apparent elongation of the vascularized portion may result from the shortening of the medulla in amphisbaenians, compared to those of chameleons, geckos, agamids, iguanids and skinks studied for comparison, so that this difference may mainly reflect the proportions of the brain stem.

While serial sections of the brains of various amphisbaenians have been prepared, their analysis has only recently started, and what follows is only an assemblage of random data gleaned from individual reports. In general, the brains of the Amphisbaenia are unique among those of the Squamata in showing fewer but longer cells per unit area (R. G. Northcutt, pers. comm.).

A very limited sample (comparing Monopeltis guentheri with Lacerta and Chamaeleo) suggests that in this amphisbaenian the lateral area of the cerebral cortex is very small (Beckers et al., 1972).

A study of the amphibian and reptilian thalamus was based in part on sections of the brains of five species of Amphisbaena, plus those of Blanus, Rhineura, Trogonophis and Diplometopon (Senn, 1974). The report only suggested that the Amphisbaenia (1) definitely showed the reptilian-avian, rather than the amphibian, pattern, and (2) as special patterns are defined, for instance, for Anniella, Sphenodon, and snakes, but not for amphisbaenians, that the latter generally fit a lizard pattern.

\section{Cranial nerves}

Nerves III, IV and VI are stated to be lacking in the Amphisbaenia (Jollie, 1960); however, forms retaining remnants of eye muscles (Bonin, 1965) have not been checked for these. The facial ganglion lies within a bony canal, and the branches of the facial and trigeminal nerves exit through the single large foramen (in which lies the Gasserian or trigeminal ganglion (May, in press) just anterior to the occipito-sphenoid junction (see Versluys, 1898, for details and illustrations of the condition in Trogonophis and Amphisbaenia fuliginosa). In Amphisbaenia, as in gekkonids, the chorda tympani (a posttrematic ramus of the facial nerve) descends across the anterior face of the tympanic chamber, 
anterior to the stapes, and directly to the lower jaw (Kritzinger, 1946; Underwood, 1957b), while the main branch of the facial nerve passes first dorsal to the stapes and then swings antero-ventrally after supplying the M. depressor mandibulae. Versluys $(1898,1903)$ interprets the divergent path of the chorda tympani as an indirect result of the loss of the middle ear cavity. The branching of the palatine portion of the facial nerve uniquely occurs within the bone in Amphisbaenia; however, its subdivisions otherwise do not differ from those in lizards.

The amphisbaenian ophthalmic nerve passes extracranially as in lizards, thus providing a major difference from the condition seen in snakes (Bellairs, 1949b). The glossopharyngeal (IX) nerve leaves the skull via the apertura lateralis recessus scalae tympani in lizards, but not in Sphenodon, the Amphisbaenia, and the snakes, in which it and the vagus $(\mathrm{X})$ nerve use the jugular foramen (Bendz, 1843; Bischoff, 1832; Fischer, 1852; Underwood, 1957a; Versluys, 1898, 1936). The nerves are fused in snakes and Amphisbaena (Versluys, 1898; Vogt, 1840) and distinct in Monopeltis (Kritzinger, 1946); the vagus and sympathicus lack a throat ganglion (Vogt, 1840). The entire hypoglossal (XII) complement leaves the skull through the external aperture of the combined jugular and condylar foramen (Bahl, 1937) in chameleons, varanids and Lanthanotus, as well as in the amphisbaenians (Versluys, 1936; Jollie, 1960). The common exit of all of these nerves occurs by fusion of the canals internal to the bony wall; they enter it separately (Versluys, 1936). All of these paths should be checked with experimental techniques.

\section{Appendicular plexuses}

One basic question in establishing homologies among the spinal roots of squamates is the length of the nuchal zone and the potential for confusion between cervical and pectoral plexi. The plexi of Trogonophis wiegmanni and Amphisbaena alba (Fürbringer, 1900) and of $A$. vermicularis (Carlsson, 1886) are formed of the second to fourth spinal nerves, whereas limbless anguids form them from the fourth to sixth thoracics, and other lizards (including limbed anguids) from the sixth to tenth. Only in Enygrus, among the snakes investigated, did a plexus (the cervical?) involve the second spinal nerve; in most snakes, it started with the third, fourth, or fifth nerves (Carlsson, 1886). More recent studies (Renous-Léçuru, 1974a) show three, four or five pectoral roots in lizards, with the plexus of chameleons starting at the fourth, that of Lanthanotus and varanids on the seventh, and that of all other lizards on the sixth.

The plexus of Bipes derives from roots four to seven. It differs from those of all lizards, except the chameleons, by its anterior position and small size. Furthermore, it is unique in the distribution of its roots; thus the great dorsal nerve derives from root seven rather than eight and nine (Sphenodon) or seven and eight (lizards), while the radial nerve derives from four to six, in contrast to six to nine (Sphenodon) and seven and eight in lizards (Renous-Léçuru, 1974a). Consequently, Bipes shows more than a mere migration of the plexus; rather, its output is organized differently than that of lizards.

Snakes and Amphisbaena (vermicularis, the only species examined for this) combine three nerves in the pelvic plexus, while lizards, including the limbless Anguis, generally retain five, as do crocodilians and turtles (Carlsson, 1886). The anteriormost derivative nerve passes to the integument, while the two posterior ones innervate the rudimentary M. ischio-coccygeus. 


\section{Parietal and pineal organs}

The interchangeable usage of the terms parietal and pineal has caused a certain amount of confusion in the literature (cf. Eakin, 1973). In theory, vertebrates may have two internal organs, an anterior paraphysis or parietal and a more posterior epiphysis or pineal. The parietal organ of reptiles is the one often involving photoreceptors (hence parietal eyes), yet the literature incorrectly refers to pineal eyes.

Parietal eye spots (integumentary modifications) are externally noticeable in Sphenodon, in many lizards of the families Xantusiidae, Cordylidae, Varanidae, Anniellidae, Anguidae, Xenosauridae, and Chamaeleonidae, as well as in most members of the families Scincidae, Lacertidae, Iguanidae and Agamidae. Parietal spots are lacking in most snakes and in lizards of the familes Pygopodidae, Dibamidae (incl. Anelytropsis), Helodermatidae, Lanthanotidae, Gekkonidae, and almost all Teiidae, as well as in the Amphisbaenia (Gundy \& Wurst, 1976; pers. obs.). A parietal organ (or parietal eye) apparently occurs in all species of lizards that show parietal eye spots (Camp, 1923). In all lizards, except Gerrhosaurus and Anniella, the loss of a parietal (not pineal) foramen is claimed to be correlated with loss of the underlying parietal eye (Schmidt, 1909). Eye spots, pariental eyes and paraphyseal foramina are absent in the Amphisbaenia (Taylor, 1951). Only in some species of Monopeltis (note Kritzinger, 1946), but not in any other (including African) amphisbaenian genus checked by me, does the parietal have a median perforation or parietal foramen. However, all reptiles have a pineal gland (Eakin, 1973).

The anterior exposure of the cartilaginous edge of the supraoccipital (processus ascendens tecti synotici) may be incompletely overlapped by the medially notched parietal of certain amphisbaenians. "Cleaned" skulls may show a hole here, but this is not a pineal foramen.

\section{Eyes}

The eyes of the amphisbaenians examined (Trogonophis: Fischer, 1900; RochonDuvigneaud, 1943; Underwood, 1957b; Verrier, 1932, 1933. Agamodon: Bonin, 1965. Blanus: Fischer, 1900; Hanke, 1913; Menacho, 1915; Rochon-Duvigneaud, 1943. Cadea: Payne, 1906. Amphisbaena: Birabén, 1954; Fischer, 1900; Underwood, 1957b, 1977. Anops: Birabén, 1954. Rhineura: Eigenmann, 1902) resemble those of lizards and are subject to reduction of the visual system (Franz, 1934; Underwood, 1970, 1977, and literature therein; Verrier, 1932; Walls, 1942).

The subbrillar space (deep to the fusion of the integument over the eye), most clearly seen in Trogonophis, is considered a subpalpebral space, and the covering of the eye is hence a tertiary spectacle (Walls, 1942), equivalent to that in other fossorial squamates (Bellairs \& Boyd, 1947; who also comment on Rhineura, Amphisbaena, and Blanus). Walls (1942) notes that such a spectacle would have to arise, presumably as a protective device, prior to eye reduction. In most species (with the possible exception of some of the derived species of genera such as Dalophia and Monopeltis), the skin immediately over the eye curves outward convexly, and is thinned and certainly translucent when examined from the inside (pers. obs.).

Agamodon (Bonin, 1965), as well as Trogonophis and Diplometopon (Al-Nassar \& Bellairs, pers. comm.), are unique in possessing remnants of eye muscles, lost in the other amphisbaenians that have been examined (Hanke, 1913). Sphenodon and most lizards show an arrangement of scleral ossicles. Amphisbaenians (except for Rhineura, Underwood, 1957b) 
have either traces thereof or remnants of connective tissue and/or cartilage, neither of which appears in snakes (Bellairs \& Boyd, 1947, 1950; Birabén, 1954).

The Harderian gland fills the orbit and is much larger than in lizards of equivalent size; unlike that of snakes, it does not project posteriorly beyond the orbit (H. Saint Girons, pers. comm.). Remnants of a lens and a more or less developed retina are always present. The retina is never vascularized, and the cells appear as variably-sized cones with oil droplets and paraboloids (Underwood, 1970; in 1957b, he noted that the visual cells do not develop in Rhineura).

The dilation of the anterior lachrymal duct, and its passage from the anterior part of the subbrillar space directly into the palatal region, is similar to the condition in snakes rather than that in lizards (Bellairs \& Boyd, 1947; Kritzinger's, 1946, statements about the condition in Monopeltis need to be checked). However, amphisbaenians do not appear to share the special modifications that make the snake eye unique. Amphisbaenian eyes lack a conus, as do those of Dibamus and Anelytropsis, though Anniella still shows this as well as moveable lids rather than a spectacle (Walls, 1942).

Otherwise the amphisbaenian eye shows no particular modifications that resemble those of any particular group of lizards. Although the eyes are reduced, they have been shown still to perceive light and shapes (Gans \& Bonin, 1963; L. Ireland, pers. comm.), though behavioural responses had earlier been denied (Underwood, 1957b; Verrier, 1932) or ascribed to the effect of heat (Menacho, 1915).

\section{Mast cells}

The connective tissues of lizards, snakes and amphisbaenians are stated to have amphoteric mast cells containing acidophilic granules (Sottovia-Filho, 1974); earlier reports of differences between the cells of these groups (Sottovia-Filho \& Junqueira, 1972; SottoviaFilho et al., 1972, 1973) were apparently in error.

\section{Karyotypes}

Matthey (1954 and earlier) examined the chromosomes of the two species Trogonophis wiegmanni and Rhineura floridana and used them as evidence that the acrodont and pleurodont amphisbaenians were each derived from a distinct family of lizards. The karyotypes of some 30 forms of 14 genera are now available (cf. Huang \& Gans, 1971; Beçak et al., 1971a, b; C. J. Cole, pers. comm.; Table II). Gorman (1973), referring only to part of this series, notes that 12 macrochromosomes and 24 microchromosomes $(n=36)$, which is the count seen in many families of lizards (and not a single snake), represents the basic pattern in the "family" Amphisbaenia and concludes that "this argues for strong saurian affinity even if one chooses to raise the Amphisbaenia to ordinal level." Paull et al. (1976) accept this argument and extend it by noting that the occurrence of the basic pattern in members of numerous families suggests that it is primitive in lizards.

There is some evidence for this view, as the "basic pattern" occurs in all trogonophids and in eight species of Amphisbaena, as well as both species of Zygaspis. Furthermore, 20 out of 30 forms examined have 12 macrochromosomes, while 10 out of 30 have 24 microchromosomes, and 8 out of 30 have $2 n=36$. One species shows significant polymorphism (Beçak et al., 1971b). However, the Recent members of the Rhineuridae $(2 n=24+20)$ and 
TABLE II

The chromosomes of amphisbaenians

(modified after Huang \& Gans, 1971)

\begin{tabular}{|c|c|c|c|c|c|c|}
\hline \multirow[b]{2}{*}{ Species } & \multirow[b]{2}{*}{$\mathbf{M}$} & \multicolumn{2}{|c|}{ Chromosome number $(2 n)^{1}$} & \multicolumn{3}{|c|}{ No. of chromosome arms ${ }^{1}$} \\
\hline & & $\mathrm{m}$ & Total & M & $\mathrm{m}$ & Ref. \\
\hline \multicolumn{7}{|l|}{ Trogonophidae } \\
\hline Diplometopon zartudnyi & 12 & 24 & 36 & 24 & 28 & \\
\hline Trogonophis wiegmanni & 12 & 24 & 36 & 24 & 24 & \\
\hline \multicolumn{7}{|l|}{ Bipedidae } \\
\hline Bipes biportus & 20 & 22 & 42 & 40 & 26 & 5 \\
\hline B. canaliculatus & $20+$ & $16+$ & $36+$ & & & 5 \\
\hline B. tridactylus & 22 & 24 & 46 & & & 5 \\
\hline \multicolumn{7}{|l|}{ Amphisbaenidae } \\
\hline Amphisbaena angustifrons & 12 & 18 & 30 & 24 & 18 & \\
\hline A. darwini & 12 & 18 & 30 & 24 & 22 & \\
\hline A. trachura & 12 & 18 & 30 & 24 & 22 & \\
\hline A. heterozonata & 12 & 18 & 30 & 24 & 22 & \\
\hline A. manni & 12 & 24 & 36 & 24 & $?$ & \\
\hline A. fenestrata & 12 & 24 & 36 & 22 & $28-32$ & \\
\hline A. caeca & 12 & 24 & 36 & 24 & 24 & \\
\hline A. dubia & $12-15[14]$ & $10-16[12]$ & $25-28[26]$ & 26 & 12 & 3,4 \\
\hline A. xera & 12 & 24 & 36 & 24 & 24 & \\
\hline A. alba & 22 & 16 & 38 & 36 & 28 & Also 2 \\
\hline A. fuliginosa & 22 & 26 & 48 & 28 & $30-32$ & \\
\hline A. camura & 24 & 20 & 44 & $28 ?$ & $20-22$ & \\
\hline A. vermicularis & 22 & 22 & 44 & 24 & 20 & 2,4 \\
\hline A. innocens & 22 & 28 & 50 & 30 & $?$ & \\
\hline Anops kingi & 12 & 14 & 26 & 24 & $?$ & \\
\hline Blanus cinereus & 12 & 20 & 32 & 24 & 20 & \\
\hline B. strauchi & 12 & 20 & 32 & 24 & 20 & \\
\hline Chirindia langi & 12 & $18-22$ & $30-34$ & 24 & $?$ & \\
\hline C. swynnertoni & 12 & $18-20$ & $30-32$ & 24 & $22-26$ & \\
\hline Cynisca leucura & 12 & $18-20$ & $30-32$ & 24 & $?$ & \\
\hline Geocalamus acutus & 14 & 24 & 38 & 24 & $?$ & \\
\hline Leposternon microcephalum & 12 & $20-22$ & $32-34$ & 24 & $20-22$ & Plus 2, 4 \\
\hline Monopeltis capensis & 12 & 22 & 34 & 24 & 38 & \\
\hline M. sphenorhynchus & & & & & & 6 \\
\hline Zygaspis quadrifrons & 12 & 24 & 36 & 24 & 48 & \\
\hline Z. violacea & 12 & 24 & 36 & 24 & $?$ & \\
\hline \multicolumn{7}{|l|}{ Rhineuridae } \\
\hline Rhineura floridana & 24 & 20 & 44 & 30 & $24-26$ & \\
\hline
\end{tabular}

${ }^{1} \mathrm{M}=$ macrochromosomes; $\mathrm{m}=$ microchromosomes.

2 Becac et al., 1971a.

${ }^{3}$ Becac et al., 1971b, 1972.

${ }^{ \pm}$Benirshke \& Hsu, 1973.

${ }^{5} \mathrm{C}$. J. Cole, pers. comm.

${ }^{6}$ M. C. Branch, pers. comm. 
Bipedidae ( $B$. biporus $2 n=20+22 ; B$. tridactylus $2 n=22+24 ;$ B. canaliculatus $2 n=20+$ $+16+$; C. J. Cole, pers. comm.) have much higher counts, and the two species of Blanus, probably the most primitive living species, have lower ones $(12,20)$. Also the variation within the genus Amphisbaena is as great as that within the entire group. Consequently, there is substantial uncertainty about this characteristic; perhaps, the application of other techniques, such as band identification, would be desirable.

\section{Discussion}

The preceding analysis has shown that the Amphisbaenia are squamate reptiles and that they appear to be unique within the Squamata in at least the following characteristics ( $A=$ a state presumed to be ancestral or primitive; $D=$ a state presumed to be derived): In the possession of an enlarged median premaxillary tooth $(D)$, in the enormous (fused) orbitosphenoid-pleurosphenoid plate $(D)$, in (advanced members only) the capture of the epihyal as a new extracolumellar unit $(D)$, in the development of an unusual pattern of flow for the fluid of the inner ear $(D)$, in the retention (in the hand of Bipes) of a welldeveloped intermedium and two centralia $(A)$, in the hypertrophy (in the hand of Bipes) of the phalangeal formula $(D)$, in the pattern of autotomy combined with the lack of caudal regeneration (though the fracture plane is intravertebral) $(D)$, in the arrangement of muscles around the caudal axis $(D)$, in the structure of the supralabial glands $(D)$, in the relative cell frequencies of their endocrine pancreas $(D)$, in the occurrence (or retention from the embryo) of an internal jugular vein in adults $(A$ ?), in that the left aortic arch is dominant $(D)$, in the retention of a left rather than a right lung $(D)$, in the connections of their testes to the epidydimis and portions of the sexual segment $(D)$, and in (except for Bipes) the occurrence of kidneys suspended freely in the coelom $(D)$.

The Amphisbaenia are similar to snakes, rather than lizards, in the loss of the lateral arcades of the skull ( $D$, shared by some lizards), and of the epipterygoid ( $D$, except for Trogonophis shared by some lizards), in modification of the M. levator bulbi into an $M$. retractor pterygoidei $(D)$, in the superficial arrangement of their supralabial glands $(D)$, in the pattern of the sensory cells of their inner ear $(D)$, in the path of the glossopharyngeal nerve $(A)$, and in the architecture of their hepatic portal vessels $(D)$. Various characteristics, such as the pattern of the infralabial glands $(D)$ and the pituitary arrangement $(D)$, suggest similarity only to the Typhlopidae and sometimes the Leptotyphlopidae.

The amphisbaenians are closer to the general saurian condition than to that seen in snakes in another suite of characteristics, among which are: infundibular recess entering into the neurohypophysis $(D)$; vestibulum well specialized $(A)$; organ of Jacobson rostrally placed $(A)$; nasopharyngeal ducts not closed $(A)$; the external nasal gland sometimes with striate (salt secreting) cells (?); labial glands purely mucous $(A)$; architecture of sublingual glands (?); mixture of two cell types in the fundic glands of the stomach (?); ribbon-like shape of the pancreas $(D)$; occurrence of a urinary bladder and of multiple cloacal glands embracing the proctodeum $(A)$; lack of anal glands $(A)$; occurrence of precloacal epidermal glands or pores $(A)$; retention of scleral ossicles or cartilages $(A)$, and perhaps their karyotypes $(A)$. The closest resemblance is not with one group only, but various organ systems show (sometimes in one amphisbaenian family only) primary similarity to systems in such diverse groups as the gekkonids and pygopodids (facial artery perforates stapes, hyoid arch to vicinity of paroccipital, subcentral arterial foramina on the vertebrae), iguanomorphs (shoulder girdle and its muscles), chameleons 
(loss of epipterygoid, position of brachial plexus), Anniella (cranial details, fluid path in otic region, position of lung), the dibamids (head muscles), the gymnophthalmines (integumentary annulation, trend toward loss of epipterygoid; scaly tongue, reduction of posterior before anterior girdle (in two amphisbaenian families), precloacal pores, hyoid pattern), Lanthanotus (head muscles), and various skinks. What conclusions does this permit?

(1) The major differences seen suggest that the Amphisbaenia are distinct from the snakes and from the lizards in multiple, generally derived, character states.

(2) The Amphisbaenia are clearly more similar to lizards than to snakes. When there is a departure from the general squamate condition, it rarely appears to be in "the direction" of snakes; hence, amphisbaenians cannot be considered intermediate between snakes and lizards. The similarities to typhlopids and leptotyphlopids are of characteristics involved in specialization of these groups to a subterranean existence, rather than to the specializations of snakes as a group.

(3) The issue of slight and varying affinities to diverse groups of saurians has already been mentioned. Mostly, the similarity appears to be one of retention of generalized characteristics, as indicated by the observation that many of them are shared by Sphenodon as well. However, where derived characters are involved, they generally reflect limited parallels coupled with numerous differences; one thus appears to see the result of convergences of individual character systems. Hence, the Amphisbaenia may be considered to be a sister group of the Sauria (and Serpentes), rather than of any component saurian sub-group. The Amphisbaenia would seem to have separated within the lepidosaurian stock before the Sauria divided into major groupings. The many similarities to lizards are then to be seen as remnants of a general common ancestry, or of coincidental convergences affecting various characteristics, rather than indications that the Amphisbaenia are derived from one or another group of lizards.

(4) The amphisbaenians differ almost as much from burrowing squamates as from non-burrowers. Certain "derived amphisbaenian characteristics are shared with diverse burrowing lizards and snakes. In all such species, the pars nervosa of the hypophysis lies on the same horizontal level as the pars distalis, and the pars intermedia is atrophied. The parietal eye and the parietal foramen are lost or reduced. All burrowers have nasopharyngeal ducts and an excellently developed chemical sense (but reduced vision), particularly the olfactory and vomeronasal epithelia. It is probable that these characteristics are the result of parallelism or convergence to the subterranean ecotone.

In this context, it is perhaps most significant that the Amphisbaenia differ substantially, distinctly and individually from each of the lines of lizards that have started or undergone reduction of limbs; note, for instance, their lack of alveolar cells in the hinge regions of their cephalic integument. This suggests that the Amphisbaenia do not represent remnants of a past trend for the reduction of limbs, away from a surviving stock of limbed lizards, such as is suggested by the situation between limbed and limbless cordylids, between geckos and pygopodids, and within the scincid-Feylinia assemblage. The lack of intermediate forms, furthermore, shows a fundamental difference between the amphisbaenianlizard assembly and the pattern exhibited by the agamid/chamaeleonid transition. The latter groups show a suite of common characteristics, and certain agamids bridge the gap for many of the seemingly distinct chamaeleonid character states. In contrast, the amphisbaenians lack an equivalent group within the Sauria. 
The functional patterns that led to anguids and anniellids clearly have a different structural base from that leading to the Amphisbaenia. The greatest similarity may exist between the Amphisbaenia and some gymnophthalmines on the one hand and dibamids on the other, but major differences separate them as well. Unfortunately, we still have least evidence on these two groups, and the differences very much outweigh the similiarities.

(5) It may be assumed that the earliest squamates were tetrapodous and broadly similar to one or another kind of surviving lizards. The precursors of amphisbaenians and snakes presumably separated from this lepidosaurian offshoot during the Jurassic (Carroll \& Galton, 1977). The few amphisbaenian fossils are from much later periods, There clearly show amphisbaenian derived states, and their assignment to the Amphisbaenia poses few problems; none of these fossils suggests any useful intermediacy to other groups, fossil or Recent. Nothing we have seen in the present analysis as yet permits a decision regarding the relative time that the amphisbaenians separated from the remainder of the Squamata.

(6) The snakes are clearly more successful than the Amphisbaenia; they are represented by 2300 rather than 150 species and occupy a far wider area of the globe and many more biotopes. Their characteristics more obviously differ from those of the basic "lizard stock", perhaps making it more "plausible" to recognize them as a distinct order, while the Amphisbaenia show more subtle differences from the remaining Squamata. The "obvious" specializations of snakes are, of course, not restricted to the head, but affect vertebral column and viscera. It has been suggested that the passage of snakes through a subterranean adaptive mode may be documented by their character states (Gans, 1975; Walls, 1942). Many of the adaptive trends may well have been supplementary modifications in further development of the initial specializations for elongation of the trunk, thus the capacity for swallowing their prey whole, and for moving at varying speeds over complex surfaces. Selection in some groups appears to have been for increased size and for reorganization of their viscera and visceral attachments (to permit constriction and tight bending), their feeding and locomotive systems, and their sensory apparatus.

In contrast, the modifications of amphisbaenians suggest that they entered the subterranean environment early and continued its development and exploitation. Their specializations appear to have been toward locating and feeding on variably sized prey by cutting pieces out of it, and toward more effective burrowing and travel in tunnels (Gans, 1975). Witness the reorganization of the skull, and of the ear, as well as the triple sets of scalares (Mm. costo- and vertebro-cutanei). Also note the modification of the forelimbs in Bipes. Whereas almost every organ system shows some difference from the condition in most lizards, there seem to have been fewer clearly function-associated modifications of visceral topography. Obviously amphisbaenian viscera are more rarely stressed by pressure changes, as the animals do not constrict their prey. Apparently none of the amphisbaenian specializations represented protoadaptations for unoccupied niches on the surface, and we see no evidence of successful re-emergence in any amphisbaenian line, past or present.

I do not wish to treat the question of ordinal, as opposed to subordinal, status for the Amphisbaenia. If the Squamata are considered to be an order, then the present analysis would suggest that the Amphisbaenia, Sauria and Serpentes should at most be treated as suborders; if the Squamata are treated as a superorder, as here, then any of the other groups could be treated as an order. However, assignment of ordinal or subordinal status to these groups must logically proceed as part of a re-evaluation of all the orders of reptiles, a task that is beyond the scope of the present analysis. 
It is my hope that this interim summary will lead to further review and reconsideration. There remains substantial uncertainty about the distribution of the states of many of the characteristics here mentioned, both within the Amphisbaenia and among other squamate groupings. For these reasons I desist from proposing any scheme that would require the naming of more higher categories at this time. Rather than attempts at reorganization of these data to fit some other classification, the situation needs analysis to test whether the differences are real and whether the shared and the distinct character states, apparently indicating similarity or difference, have been properly characterized. Re-examination should evaluate whether the reported similarities result from parallelism (development of a similar derived phenotypic state in two populations initially sharing similar [ancestral] genotypes) or from convergence (development of a similar derived phenotypic state in two populations initially possessed of quite dissimilar [ancestral] genotypes). In other words, one needs to determine whether the similarity is due to homology or homoplasy. Beyond this, there is an obvious need to check for the occurrence of these characteristics in a more nearly adequate sample of amphisbaenians and other groups of squamates. Ultimately the predictive and explanatory value of an evaluation, such as the one here initiated, depends primarily upon the quality of the data on which it is based.

\section{REFERENCES}

Adams, L. A. (1925). Correlations of the musculature and the movements of the skull in Natrix, with some suggestions of homology in the lacertilians. J. Morph. 41:159-181.

Adams, W. E. (1953). The carotid arch in lizards with particular reference to the origin of the internal carotid artery. J. Morph. 92: 115-155.

AleXANDER, A. A. (1966a). Taxonomy and variation of Blanus strauchi, with comments on the nature of its meristic variation. Copeia 1966: 205-224.

Alexander, A. A. (1966b). Problems involving vertebral segmentations in amphisbaenids and primitive snakes. Thesis, State Univ. N.Y.

AleXANDER, A. A. \& GANS, C. (1966). The pattern of dermal-vertebral correlation in snakes and amphisbaenians. Zool. Meded., Leiden 41 (11): 171-190.

ALI, S. M. (1941). Studies on the comparative anatomy of the tail in Sauria and Rhynchocephalia. 1. Sphenodon punctatus Gray. Proc. Indian Acad. Sci. 13B: 171-192.

ALI, S. M. (1949). Studies on the anatomy of the tail in Sauria and Rhynchocephalia. Part III. Varanus monitor (Linné). Proc. Indian Acad. Sci. 30B: 155-167.

AL-NASSAR, N. A. (1976). Anatomical studies. Osteology and gut histology of the amphisbaenian Diplometopon zarudnyi inhabiting Kuwait. Thesis M.S. Zool., Univ. Kuwait.

BaHL, K. N. (1937). Skull of Varanus monitor (Linn.). Rec. Indian Mus. 39: 133-174.

BAIRD, I. L. (1969). Some findings of comparative fine structural studies of the basilar papilla in certain reptiles. Anat. Rec. 163: 149 .

BAIRD, I. L. (1970). The anatomy of the reptilian ear. In Biology of the Reptilia 2: 193-275. Gans, C. \& Parsons, T. S. (Eds). London: Academic Press.

BAIRD, I. L. (1974a). Some aspects of the comparative anatomy and evolution of the inner ear in submammalian vertebrates. Brain, Behavior, Evolution 10: 11-36.

BAIRD, I. L. (1974b). Anatomical features of the inner ear in submammalian vertebrates. In Handbook of sensory physiology. Auditory system. Anatomy, Physiology (Ear). V/1 (6): 159-212. Keidel, W. D. \& Neff, W. D. (Eds). Springer: Berlin, Heidelberg \& New York.

BAKKer, R. T. \& GALTON, P. M. (1974). Dinosaur monophyly and a new class of vertebrates. Nature, Lond. 248: $168-172$.

Baur, G. (1894). The relationship of the lacertilian genus Anniella Gray. Proc. U.S. natn. Mus. 17: 345-351.

BeÇAK, M. L., BeÇAK, W. \& Denaro, L. (1971a). Cariologia comparada em oito especies de lacertilios. Cienc. Cult. (Supl.) 23: 124. 
BeÇaK, M. L., BeÇAK, W. \& Denaro, L. (1971b). Polimorfismo cromossomico intraindividual Amphisbaena dubia (Sauria). Cienc. Cult. (Supl.) 23: 125.

BeÇAK, M. L., BEŞAK, W. \& DenARo, L. (1972). Chromosome polymorphism, geographical variation and karyotypes of Sauria. Caryologia 25: 313-326.

Beckers, H. J. A., Platel, R. \& Nifuwenhuys, R. (1972). Les aires corticales de quelques reptiles squamates. (Lacerta viridis, Chamaeleo lateralis, Monopeltis guentheri). Acta Morph. Nèerl. scand. 9: 337-364.

Beddard, F. E. (1904). Contributions to the anatomy of the Lacertilia. (2) On some points in the structure of Ttipinambis. Proc. zool. Soc. Lond. 1904: 465-470.

BEDDARD, F. E. (1905). Some additions to the knowledge of the anatomy, principally of the vascular system, of Hatteria, Crocodilus, and certain Lacertilia. Proc. zool. Soc. Lond. 1905: 461-489.

Bedriaga, J. V. (1884). Amphisbaena cinerea Vand. und A. strauchi v. Bedr. Erster Beitrag zur Kenntniss der Doppeischleichen. Arch. Naturgesch. 50 (1): 23-77.

Bellairs, A. D'A. (1949a). Observations on the snout of Varanus, and a comparison with that of other lizards and snakes. J. Anat. 83: 116-146.

BeLlairs, A. D'A. (1949b). The anterior brain-case and interorbital septum of Sauropsida, with a consideration of the origin of snakes. J. Limn. Soc. Lond. (Zool.) 41: 482-512.

BellaIRS, A. D'A. (1950). Observations of the cranial anatomy of Anniella, and a comparison with that of other burrowing lizards. Proc. zool. Soc. Lond. 119: 887-904.

Bellairs, A. D’A. (1957). Reptiles. London: Hutchinson Univ. Libr.

Bellairs, A. D'A. \& AtTridge, J. (1975). Reptiles. Fourth (revised) edition. London: Hutchinson Univ. Libr.

Bellairs, A. D'A. \& BoyD, J. D. (1947). The lachrymal apparatus in lizards and snakes. 1. The brifle, the orbital glands, lachrymal canaliculi and origin of the lachrymal duct. Proc. zool. Soc. Lond. 117: 81-108.

BelLairs, A. D'A. \& Boyd, J. D. (1950). The lachrymal apparatus in lizarđs and snakes. II. The anterior part of the lachrymal duct and its relationship with the palate and the nasal and vomeronasal organs. Proc. zool. Soc. Lond. 120: 269-310.

BENDZ, H. (1843). Bidrag til den sammenlignende anatomie af Nervus glossopharyngeus, vagus, accessorius Willisii og hypoglossus hos reptilierne. $K$. danske Vidensk. selsk. Skr. 10:113-152.

BenirschKe, K. \& Hsu, T. C. (1973). Chromosome Atlas: Fish, amphibians, reptiles and birds. 2. Berlin, New York, Heidelberg: Springer Verlag.

Bergman, R. A. M. (1962). Die Anatomie der Elapinae. Z. wiss. Zool. 167: 291-337.

BERMAN, D. (1972). Hyporhina tertia, new species (Reptilia: Amphisbaenia), from the Early Oligocene (Chadronian) White River formation of Wyoming. Ann. Carneg. Mus. 44: 1-10.

Berman, D. (1973). Apathorhynchus fossorium, a middle Eocene amphisbaenian (Reptilia) from Wyoming. Copeia 1973: 704-721.

Berman, D. (1976). A new amphisbaenian (Reptilia: Amphisbaenia) from the Oligocene-Miocene John Day formation, Oregon. J. Paleont. 50: 165-174.

Berman, D. (1977). Spatorhynchus natronius, a new species of rhineurid amphisbaenian (reptile) from the Early Oligocene of Wyoming. J. Paleont. 51: 986-991.

Brrabén, M. (1954). El ojo anópsico de anfisbénidos argentinos. Physis, B. Aires 20: 390-396.

Bischoff, L. W. T. (1832). Nervi Accessorii Willisii. Anatomia et Physiologia. Commentatio. Darmstadt: C. W. Leske.

Bockman, D. E. (1970). The thymus. In Biology of the Reptilia 3: 111-133. Gans, C. \& Parsons, T. S. (Eds). London: Academic Press.

BogerT, C. M. (1964). Little snake with hands: amphisbaenids are a taxonomic enigma. Nat. Hist., N.Y. 73 (7): $18-25$.

Bogert, C. M. \& Cowles, R. B. (1947). Results of the Archbold expeditions. No. 58. Moisture loss in relation to habitat selection in some Floridian reptiles. Am. Mus. Novit. No. 1358: 1-34.

Bogoljubsky, S. (1914). Brustbein- und Schultergürtelentwicklung bei einigen Lacertilien. Z. wiss. Zool. 110: 620-666.

BONAPARTE, C. L. (1839). Amphibia Europaea. Ad systema nostrum vertebratorum ordinata. Typographica regia. Memorie Accad. Sci. Torino (2) 2: 385-456.

BonaParTe, C. L. (1840). Prodromus systematis herpetologiae. Nouv. Ann. Sci. nat. Bologna 4: 90-101.

Bonaparte, C. L. (1845). Specchio generale dei Sistemi Erpetologico, Anfibiologico ed Ittiologico. Milano: Luigi di Giacomo Pirola. 
Bonaparte, C. L. (1850). Conspectus systematicum herpetologicae et amphiologicae. Editio altera reformata. Batavorum: Daban Lugduni. (1 sheet).

Bonin, J. J. (1965). The eye of Agamodon anguliceps Peters (Reptilia, Amphisbaenia). Copeia 1965: 324-331.

Bons, J. \& Saint Girons, H. (1963). Ecologie et cycle sexuel des amphisbéniens du Maroc. Bull. Soc. Sci. nat. phys. Maroc 43: 117-170.

Boulenger, G. A. (1878). Description d'un genre nouveau et d'un espèce nouvelle de la famille des amphisbénides. Bull. Soc. zool. Fr. 3: 300-303.

Boulenger, G. A. (1884). Synopsis of the families of existing Lacertilia. Ann. Mag. nat. Hist. (5) 14: 117-122.

Boulenger, G. A. (1885). Catalogue of the lizards in the British Museum (Natural History). Second edition. London.

Broadley, D. G. \& Gans, C. (1978a). Southern forms of Chirindia (Amphisbaenia, Reptilia. Ann. Carneg. Mus. 47 (3): 29-51.

BROADlEY, D. G. \& GaNS, C. (1978b). Distribution, variation and systematic status of Zygaspis violacea (Peters) (Amphisbaenia, Reptilia), endemic to southeastern Africa. Ann. Carneg. Mus. 47 (4): 319-334.

BroAdley, D. G., GANS, C. \& VISSER, J. (1976). Studies on amphisbaenians (Amphisbaenia, Reptilia). 6. The genera Monopeltis and Dalophia in southern Africa. Bull. Am. Mus. nat. Hist. 157: 313-485.

BRock, G. T. (1941). The skull of Acontias meleagris, with a study of the affinities between lizards and snakes. J. Linn. Soc. Lond. (Zool.) 41: 71-88.

Broman, I. (1937). Cölom. In Handbuch der vergleichenden Anatomie der Wirbeltiere: 3: 989-1018. Bolk, L., Göppert, E., Kallius, E. \& Lubosch, W. (Eds). Berlin and Wien: Urban und Schwarzenberg.

BrongerSMA, L. D. (1951). Some remarks on the pulmonary artery in snakes with two lungs. Zool. Verh., Leiden No. 14: 1-36.

BRÜHL, C. B. (1886). Zootomie aller Tierklassen für Lernende nach Autopsien, skizziert. (40 pts). part 38, p. 1 CL1 and text.

BURLET, M. H. DE (1934). Höhere Sinnesorgane. 2. Vergleichende Anatomie des stato-akustischen Organs. b. Die mittlere Ohrsphäre. In Handbuch der vergleichenden Anatomie der Wirbeltiere 2 (part 2): 1381-1432. Bolk, L., Göppert, E., Kallius, E. \& Lubosch, W. (Eds). Berlin and Wien: Urban und Schwarzenberg.

BustaRD, H. R. (1967). Gekkonid lizards adapt fat storage to desert environments. Science, N.Y. 158: 1197-1198.

Butler, G. W. (1889a). On the subdivisions of the body cavity in lizards, crocodiles, and birds. Proc. zool. Soc. Lond. 1889: 452-474.

Butler, G. W. (1889b). On the relations of the fat bodies of the Sauropsida. Proc. zool. Soc. Lond. 1889: 602-613.

Butler, G. W. (1892). On the subdivision of the body-cavity in snakes. Proc. zool. Soc. Lond. 1892: 477-498.

BUTLER, G. W. (1895). On the complete or partial suppression of the right lung in the Amphisbaenidae and of the left lung in snakes and snake-like lizards and amphibians. Proc. zool. Soc. Lond. 1895: 691-712.

CAmp, C. L. (1923). Classification of the lizards. Bull. Am. Mus. nat. Hist. 48: 289-481. (Reprinted 1971. Soc. Stud. Amphib. Reptiles).

CARLsson, A. (1886). Untersuchungen über Gliedmassen-Reste bei Schlangen. Bih. K. svenska VetenskAkad. Handl. 11 (11): 1-38.

CARR, A. (1949). Notes on eggs and young of the lizard Rhineura floridana. Copeia 1949: 77.

CARroll, R. L. (1977). The origin of lizards. In Problems in vertebrate evolution. Andrews, S. M., Miles, R. S. \& Walker, A. D. (Eds). (Linn. Soc. London Symp. No. 4: 359-396.) London: Academic Press.

Carroll, R. L. \& Galton, P. M. (1977). "Modern" lizard from the Upper Triassic of China. Nature, Lond. 266: 252-255.

Castañeda, M. R. \& Alvarez, T. (1968). Contribucion al conocimiento de la osteologia apendicular de Bipes (Reptilia: Amphisbaenia). An. Esc. nac. Cienc. biol., Méx. 17: 189-206.

ChaIne, J. (1900). Anatomie comparée des certains muscles sus-hyoidiens. Thèse, Fac. Sci. Paris.

Charig, A. J. (1976). "Dinosaur monophyly and a new class of vertebrates"; a critical review. In Morphology and biology of reptiles: 191-204. Bellairs, A. d’A. \& Cox, C. B. (Eds). (Linn. Soc. Lond. Symp. No. 3.) London: Academic Press.

Charig, A. J. \& Gans, C. (In press). Two new amphisbaenians from the Lower Miocene of Kenya. Bull. Br. Mus. nat. Hist. (Geol.).

Coe, W. R. \& Kunkel, B. W. (1906). Studies on the California limbless lizard, Anniella. Trans. Conn. Acad. Arts Sci. 12: 349-403.

Cole, C. J. (1966). Femoral glands of the lizard, Crotaphytus collaris. J. Morph. 118: 119-135. 
COPE, E. D. (1864). On the characters of the higher groups of Reptilia Squamata-and especially of the Diploglossa. Proc. Acad. nat. Sci. Philad. 16: 224-231.

COPE, E. D. (1871). On the homologies of some of the cranial bones of the Reptilia, and on the systematic arrangement of the class. Proc. Am. Ass. Advmt Sci. 19: 194-247.

Cope, E. D. (1892a). On the degenerative types of scapular and pelvic arches in the Lacertilia. J. Morph. 7:223-242.

Cope, E. D. (1892b). The osteology of Lacertilia. Proc. Am. phil. Soc. 30 (138): 185-221. [See substitute pages in number 139.]

Cope, E. D. (1894). On the genera and species of Euchirotidae. Am. Nat. $28: 436-437$.

Cope, E. D. (1896a). The mesenteries of the Sauria. Proc. Acad. nat. Sci. Philad. 48: 308-314.

Cope, E. D. (1896b). On the hemipenes of the Sauria. Proc. Acad. nat. Sci. Philad. 48: 461-467.

Cope, E. D. (1900). The crocodilians, lizards and snakes of North America. Rep. U.S. natn. Mus. 1898: 153-1270.

CORSY, F. (1933). Evolution de l'appareil hyo-branchial. Marseilles: P. Ciarfa.

Crook, J. M. \& PARsons, T. S. (In press). Visceral anatomy of the Amphisbaenia. J. Morph.

Cuvier, G. (1817). Le règne animal distribué d'après son organisation, pour servir de base à l'histoire naturelle des animaux et d'introduction à l'anatomie comparée: 2. Paris: Ch. Deterville.

DE BEER, G. R. (1937). The development of the vertebrate skull. Oxford: University Press.

De Carlo, J. M. (1957). Consideraciones anatomo-histologicas sobre el higado y vias biliares de Amphisbaena darwinii D. у B. Revta Mus. argent. Cien. nat. Bernardino Rivadavia (Zool.) 3: 155-186.

De la Serna de Esteban, C. J. (1959). Anatomia miscroscopica de la lengua de Amphisbaena vermicularis darwini (D. y B.). Actas Trab. Primer Congr. Sulamer. Zool. 5: 143-150.

De la Serna de Esteban, C. J. (1965). Anatomia microscopica comparada de la lengua de algunos saurios Argentinos. Anais Segundo Congr. Latinoamer. Zool. 2: 235-245.

Dessauer, H. C. \& Fox, W. (1959). Changes in ovarian follicle composition with plasma levels of snakes during estrus. Am. J. Physiol. 197: 360-366.

Devine, M. C. (1975). Copulatory plugs in snakes: enforced chastity. Science, N.Y. 187: 844-845.

Drxon, J. R. (1974). Systematic review of the microteiid genus Iphisa. Herpetologia 30: 133-139.

Dowling, H. G. (1975). A classification of reptiles. Yearbook of Herpetology (Herp. Inform. Search Systems, N.Y.) 1: 163-166.

DubecQ, J. (1925). Morphologie comparative de quelques muscles élévateurs de la mandibule chez les vertébrés. P. v. Séanc. Soc. Sci. phys. nat. Bordeaux 1925: 1-188.

DuméRIL, A. (1852). Mémoire sur un nouveau genre de reptile saurien, de la famille des Chalcidiens (le Lépidophyme), et sur le rang que les Amphisbéniens doivent occuper dans la classe des reptiles. C.r. hebd. Séanc. Acad. Sci., Paris 35: 395-397.

Duméril, A. M. C, \& Bibron, G. (1839). Erpétologie Générale ou Histoire Naturelle Complète des Reptiles. 5. Paris: Libr. Roret.

Duvernoy, G. L. (1833). Fragmens d'anatomie sur l'organisation des serpens. Annls Sci. nat. 30: 1-32.

EakIN, R. M. (1973). The third eye. Berkeley: Univ. California Press.

EDGEWORTH, F. H. (1935). The cranial muscles of vertebrates. Cambridge: Univ. Press.

Eigenmann, C. H. (1902). The eyes of Rhineura floridana. Proc. Wash. Acad. Sci. 4: 533-548.

Essex, R. (1927). Studies in reptilian degeneration. Proc. zool. Soc. Lond. 1927: 879-945.

Estes, R. (1965). Notes on some Paleocene lizards. Copeia 1965: 104-106.

EsTes, R. (1970). Origin of the Recent North American lower vertebrate fauna: An inquiry into the fossil record. Forma functio 3: 139-163.

Estes, R. (1975). Lower vertebrates from the Fort Union Formation, Late Paleocene, Bighorn Basin, Wyoming. Herpetologica 31: 365-385.

FINK, T. F. (1817). De amphibiorum systemate uropoetico. Dissertatio Inauguralis . . . in Medicina et Chirugia Honores. Halae: Grunerti \& Sohn.

Fiorin, P. (1962). Der Eizahn und die Eischwiele der Reptilien. Eine zusammenfassende Darstellung. Acta Anat. 49: $328-366$.

FisCHER, E. (1900). Beiträge zur Kenntniss der Nasenhöhle und des Thränennasenganges der Amphisbaeniden. Arch. mikr. Anat. 55: 441-478.

FisCHER, J. G. (1852). Die Gehirnnerven der Saurier anatomisch untersucht. Abh. Geb. Naturw., Hamburg 1852: 109-212.

Fisher, H. I. \& BartLett, L. M. (1957). Diurnal cycles in liver weights in birds. Condor 59: 364-372. 
FITZINGER, L. J. (1826). Neue Classification der Reptilien nach ihren natürlichen Verwandschaften nebst einer Verwandschafts-Tafel und einem Verzeichnisse der Reptilien-Sammlung des $k$. $k$. zoologischen Museum's zu Wien. Vienna: J. G. Heubner.

FitzInger, L. J. (1843). Systema reptilum. Fasciculus primus. Amblyglossae. Vienna: Braumüller and Seidel.

FLEMING, J. (1822). The philosophy of zoology or a general view of the structure, finctions and classification of animals. Edinburgh: A. Constable \& Co.

Fox, H. (1977). The urinogenital system. In Biology of the Reptilia 6: 1-157. Gans, C. \& Parsons, T. S. (Eds). London: Academic Press.

Francis, E. T. B. (1977). Amphisbaenia. Heart and arterial arches. Br. J. Herp. 5: 607-610.

FRANK, G. H. \& SMIT, A. L. (1974). The early ontogeny of the columella auris of Crocodilus niloticus and its bearing on problems concerning the upper end of the reptilian hyoid arch. Zool. Afr. 9 (1): 59-88.

Franz, V. (1934). Höhere Sinnesorgane. 1. Vergleichende Anatomie des Wirbeltierauges. In Handbuch der vergleichenden Anatomie der Wirbeltiere: 2: 989-1292. Bolk, L., Göppert, E., Kallius, E. \& Lobosch, W. (Eds). Berlin and Wien: Urban and Schwarzenberg.

FüRBRINGER, M. (1870). Die Knochen und Muskeln der Extremitäten bei den schlangenähnlichen Sauriern. Vergleichend-anatomische Abhandlung. Leipzig: W. Engelmann.

FÜRBRINGER, M. (1900). Zur vergleichenden Anatomie des Brustschulterapparates und der Schultermuskeln. Jena. Z. Naturw. 34: 215-718.

Fürbringer, M. (1919). Über das Zungenbein der Reptilien. Bijd. Dierk. 21: 195-212.

FÜ̈RRINGER, M. (1922). Das Zungenbein der Wirbeltiere insbesondere der Reptilien und Vögel. Abh. heidelb. Akad. Wiss. (math. naturwiss, Klasse sect. B.) 11: 1-164.

GABE, M. (1970). The adrenal. In Biology of the Reptilia: 3: 263-318. Gans, C. \& Parsons, T. S. (Eds). London: Academic Press.

Gabe, M. \& Martoja, M. (1961). Contribution à l'histologie de la glande surrénale des Squamata. Archs anat. microsc. Morph. exp. 50: 1-34.

Gabe, M. \& Martoja, M. (1962). Contribution à l'histologie de la glande surrénale des Squamata. Archs anat. microsc. Morph. exp. 51: 107-128.

Gabe, M., Martoja, M. \& SaINT Girons, H. (1964). État actuel des connaissances sur la glande surrénale des reptiles. Année biol. (4) 3: 303-376.

Gabe, M. \& SAINT GiRons, H. (1965). Contribution à la morphologie comparée du cloaque et des glandes épidermoides de la région cloacale chez les lépidosauriens. Mém. Mus, natn. Hist, nat., Paris (n.s., ser. A, Zool.) 33: 149-292.

Gabe, M. \& SAINT Girons, H. (1967). Données histologiques sur le tégument et les glandes épidermoides céphaliques des lépidosauriens. Acta anat. 67: 571-594.

Gabe, M. \& SAInt Girons. H. (1969) Données histologiques sur les glandes salivaires des lépidosauriens. Mém. Mus. natn. Hist. nat., Paris (n.s., ser. A, Zool.) 58: 1-112.

Gabe, M. \& SaInt Girons, H. (1972). Contribution à l'histologie de l'estomac des lépidosauriens (Reptiles). Zool. Jb. (Anat.) 89: 579-599.

Gabe, M. \& SAINt Girons, H. (1976). Contribution à la morphologie comparée des fosses nasales et de leurs annexes chez les lépidosoriens. Mém. Mus. natn. Hist. nat., Paris (n.s., ser. A, Zool.) 98: 1-87.

GaNs, C. (1957). "Anguimorph" tooth replacement in Amphisbaena alba Linnaeus, 1758, and Amphisbaena fuliginosa Linnaeus, 1758. (Reptilia: Amphisbaenidae). Breviora No. 70: 1-12.

Gans, C. (1960). Studies on amphisbaenids (Amphisbaenia, Reptilia). 1. A taxonomic revision of the Trogonophinae and a functional interpretation of the amphisbaenid adaptive pattern. Bull. Am. Mus. nat. Hist. 119: 129-204.

Gans, C. (1966). Studies on amphisbaenids (Amphisbaenia, Reptilia). 3. The small species from southern South America commonly identified as Amphisbaena darwini. Bull. Am. Mus. nat. Hist. 134: 185-260.

Gans, C. (1967a). A check list of Recent amphisbaenians (Amphisbaenia, Reptilia), Bull. Am. Mus. nat. Hist. 135: 61-106.

GaNs, C. (1967b). Rhineura. In Catalogue of American amphibians and reptiles: 42. Am. Soc. Ichthyol. Herpetol.

GANs, C. $(1967$ c). Rhineura floridana. In Catalogue of American amphibians and reptiles: 43. Am. Soc. Ichthyol. Herpetol.

Gans, C. (1968). Relative success of divergent pathways in amphisbaenian specialization. Am. Nat. 102: $345-362$.

GANs, C. (1969). Amphisbaenians-reptiles specialized for a burrowing existence. Endeavour 28: 146-151. 
GaNs, C. (1971). Studies on amphisbaenians (Amphisbaenia, Reptilia). 4. A review of the amphisbaenid genus Leposternon. Bull. Am. Mus. nat. Hist. 144: 379-464.

GANs, C. (1973). Uropeltid snakes-survivors in a changing world. Endeavour 32: 60-65.

Gans, C. (1974). Biomechanics: Approach to vertebrate biology. Philadelphia: J. P. Lippincott.

Gans, C. (1975). Tetrapod limblessness: Evolution and functional corollaries. Am. Zool. 15: 455-467.

GaNs, C. (1976). Aspects of the biology of uropeltid snakes. In Morphology and biology of reptiles: 191-204. Bellairs, A. d'A. \& Cox, C. B. (Eds). [Linn. Soc. London, Symp. No. 3]. London: Academic Press.

Gans, C. \& Alexander, A. A. (1962). Studies on amphisbaenids (Amphisbaenia, Reptilia). 2. On the amphisbaenids of the Antilles. Bull. Mus. comp. Zool. Harv. 128: 65-158.

GANs, C. \& BaIC, D. (1977). Regional specialization of reptilian scale surfaces: Relation of texture and biologic role. Science, Wash. 195: 1348-1350.

Gans, C. \& Bonin, J. (1963). Acoustic activity recorder for burrowing animals. Science. N.Y. 140: 398.

Gans, C., Dessauter, H. C. \& Baic, D. (1978). Axial differences in the musculature of uropeltid snakes: The freight train approach to burrowing. Science, Wash. 199: 189-192.

Gans, C. \& Kochva, E. (1966). A systematic review on Ancylocranium (Amphisbaenia: Reptilia). Notes on amphisbaenids 22. Israel J. Zool. 14: 87-121.

Gans, C. \& Lehman, G. C. (1973). Studies on amphisbaenians (Amphisbaenia: Reptilia). 5. The species of Monopeltis from north of the River Zaire. Occas. Pap. Mus. Zool. Univ. Mich. No. 669: 1-34.

GaNs, C. \& LYNN, W. G. (1965). Comments on the thyroid structure of some acrodont amphisbaenians, with remarks on their systematic status. Herpetologica 21: 23-26.

Gans, C. \& Rosenberg, H. I. (In prep.). More on amphisbaenian hemipenes.

Gans, C. \& Shaw, C. E. (1963). The locomotion of Bipes biporus Cope. Proc. A. Meet. Am. Soc. Ichth. Herp., Vancouver 50: 38.

Gans, C. \& Wever, E. G. (1972). The ear and hearing in Amphisbaenia (Reptilia). J. exp. Zool. 179: $17-34$.

GANS, C. \& WeVER, E. G. (1972). The amphisbaenian ear: Blanus cinereus and Diplometopon zarudnyi. Proc. natn. Acad. Sci. U.S.A. 72: 1487-1490.

Gans, C. \& Wever, E. G. (1976). Ear and hearing in Sphenodon punctatus. Proc. natn. Acad. Sci. U.S.A. 73: 4244-4246.

GaSC, J. P. (1977). Corrélations anatomiques dans le squelette et la musculature des reptiles serpentiformes. In Mécanismes de la rudimentation des organes chez les embryons de vertébrés. Coll. Int. C.N.R.S. Paris No. 266: 341-352.

GASC, J. P. (In press). Axial musculature. In Biology of the Reptilia 11. Gans, C. \& Parsons, T. S. (Eds). London: Academic Press.

Gervais, P. (1853). Recherches sur l'ostéologie de plusieurs espèces d'amphisbenes, et remarques sur la classification de ces reptiles. Annls Sci. nat. (3) 20: 293-312.

Gilmore, C. W. (1943). Fossil lizards of Mongolia. Bull. Am. Mus. nat. Hist. 81: 361-384.

GoELDI, E. A. (1897). Die Eier von 13 brasilianischen Reptilien, nebst Bemerkunge nüber Lebens- und Fortpflanzungsweise letzterer. Beobachtungen aus den Jahren 1884-1897. Zool. Jb. (Syst.) 10: 640-676.

GöPperT, E. (1899). Der Kehlkopf der Amphibien und Reptilien. 11. Theil. Reptilien. Morph. Jb. 28: 1-27.

GöPPERT, E. (1901). Beiträge zur vergleichenden Anatomie des Kehlkopfes und seiner Umgebung mit besonderer Berücksichtigung der Monotremen. Denkschr. med-wiss. Ges. Jena 6: 533-634.

GöPPERT, E. (1937). Atmungssystem (Organe der Luftatmung). 1. Kehlkopf und Trachea. In Handbuch der vergleichenden Anatomie der Wirbeltiere 3: 797-866. Bolk, L., Göppert, E., Kallius, E. \& Lubosch, W. (Eds). Berlin and Wien: Urban and Schwarzenberg.

Gorham, F. W. \& Ivy, A. C. (1938). General function of the gall bladder from the evolutionary standpoint. Publs Field Mus. nat. Hist. Zool. Ser. 22: 159-213.

Gorman, G. C. (1973). The chromosomes of the Reptilia, a cytotaxonomic interpretation. In Cytotaxonomy and vertebrate evolution 12: 349-424. Chiarelli, A. B. \& Capanna, E. (Eds). New York: Academic Press.

Gray, J. E. (1825). A synopsis of the genera of reptiles and Amphibia, with a description of some new species. Thomson Ann. Phil. (2) 10 (B25): 193-217.

Gray, J. E. (1844). Catalogue of the tortoises, crocodiles and amphisbaenians, in the collection of the British Museum. London: British Museum.

Gray, J. E. (1845). Catalogue of the specimens of lizards in the collection of the British Museum. London: British Museum. 
GRAY, J. E. (1865). A revision of the genera and species of amphisbaenians with the descriptions of some new species now in the collection of the British Museum. Proc. zool. Soc. Lond. 1865: 442-455.

GraY, J. E. (1872). Catalogue of shield reptiles in the collection of the British Museum. Part 11. Emydosaurians, Rhynchocephalia, and Amphisbaenians. London: British Museum.

GrAY, J. E. (1873). Handlist of the specimens of shield reptiles in the British Museum. London: British Museum.

Gundy, G. C. \& WURST, G. Z. (1976). The occurrence of parietal eyes in Recent Lacertilia (Reptilia). J. Herpet. 10: $113-121$.

HAACKE, W. D. (1976). The burrowing geckos of southern Africa, 5 (Reptilia: Gekkonidae). Ann. Transv. Mus. 30: $71-89$.

HAAS, G. (1973). Muscles of the jaws and associated structures in the Rhynchocephalia and Squamata. In Biology of the Reptilia: 4: 285-490. Gans, C. \& Parsons, T .S. (Eds). London: Academic Press.

Halstead TaRio, L. B. (1968). An outline classification of the squamates. Br. J. Herpet. 4: 32-35.

Hanke, V. (1913). Die rudimentären Sehorgane einiger Amphibien und Reptilien. Arch. vergl. Opthalmol. 3: 323-342.

HASLEWOOD, G. A. D. (1967). Bile salts. London: Methuen.

Hediger, H. (1935). Herpetologische Beobachtungen in Marokko. Verh. naturf. Ges. Basel 46: 1-49.

HEUSINGER, C. F. (1833). Untersuchungen über die Extremitäten der Ophidier, nebst Bemerkungen über die Extremitätenentwicklung im Allgemeinen. $Z$. org. Physik 3: 481-523, 653-654.

HILL, W. C. O. (1926). A comparative study of the pancreas. 1. Proc. zool. Soc. Lond. 1926: 581-631.

HochstetTer, F. (1898). Über die Arterien des Darmkanals der Saurier. Morph. Jb. 26: 213-273.

HoffSTETTER, R. \& GASC, J. P. (1969). Vertebrae and ribs of modern reptiles. In Biology of the Reptilia 1: 210-310. Gans, C., Bellairs, A. d'A. \& Parsons, T. S. (Eds). London: Academic Press.

HuAng, C. C. \& Gans, C. (1971). The chromosomes of 14 species of amphisbaenians (Amphisbaenia, Reptilia). Cytogenetics 10: 10-22.

JACKSON, M. K. \& RENO, H. W. (1975). Comparative skin structure of some fossorial leptotyphlopid and colubrid snakes. Herpetologica 31 : $350-359$.

JACOBSHAGEN, E. (1920). Zur Morphologie des Oberflächenreliefs der Rumpfdarmschleimhaut der Reptilien. Jena. Z. Naturw. 56: 361-430.

JACOBSHAGEN, E. (1937). IV. Mittel- und Enddarm (Rumpfdarm). In Handbuch der vergleichenden Anatomie der Wirbeltiere 3: 563-724. Bolk, L., Göppert, E., Kallius, E. \& Lubosch, W. (Eds). Berlin and Wien: Urban and Schwarzenberg.

Jollie, M. T. (1960). The head skeleton of the lizard. Acta zool., Stockh. 41: 1-64.

JoNes, G. M. \& Spelis, K. E. (1963). A theoretical and comparative study of the functional dependence of the semicircular canal upon its physical dimensions. Proc. R. Soc. (B) 157: 403-419.

KAISER, P. (1955). Über die Fortbewegungsweise der Doppelschleichen. Beobachtungen an Leposternon microcephalus (Wagl.). Zool, Anz. 154: 61-69.

Kamal, A. M. \& ABdeEN, A. M. (1972). The development of the chondrocranium of the lacertid lizard, Acanthodactylus boskiana. J. Morph. 137: 289-334.

KeRfoOT, W. C. (1970). The effect of functional changes upon the variability of lizard and snake body scales. Copeia 1970: 252-260.

Kesteven, H. L. (1957). Notes on the skull and cephalic muscles of Amphisbaenia. Proc. Linn. Soc. N.S.W. 82: $109-116$.

Kim, Y. J., Gorman, G. C., Papenfuss, T. \& Roychoudhury, A. K. (1976). Genetic relationships and genetic variation in the amphisbaenian genus Bipes. Copeia 1976: 120-124.

KLemmer, K. (1957). Untersuchungen zur Osteologie und Taxionomie der europäischen Mauereidechsen. Abh. senckenb. naturf. Ges. No. 496: 1-56.

KLUGE, A. G. (1976a). A reinvestigation of the abdominal musculature of gekkonoid lizards and its bearing on their phylogenetic relationship. Herpetologica 32: 295-298.

KLUGE, A. G. (1976b). Phylogenetic relationships in the lizard family Pygopodidae: an evaluation of theory, methods and data. Misc. Publs Mus. zool. Univ. Mich. No. 152: 1-72.

Kochva, E. (In press). Oral glands of the Reptilia. In Biology of the Reptilia 8. Gans, C. \& Gans, K. A. (Eds). London: Academic Press.

KOSTANECKI, K. (1926). Le caccum des vertébrés (y compris l'appendice vermiculaire). Morphologie et signification fonctionelle. Bull. int. Acad. pol. Sci. Lett. (Math.-Nat.) 1926 Suppl. 1-295. 
Krakauer, T., Gans, C. \& Paganelei, C. V. (1968). Ecological correlation of water loss in burrowing reptiles. Nature, Lond. 218: 659-660.

KRItZINGER, C. C. (1946). The cranial anatomy and kinesis of the South African amphisbaenid Monopeltis capensis Smith. S. Afr. J. Sci. 42: 175-204.

KuHN, O. (1961). Reptilia. Suppl. 1. Fossilium Catalogus 1: Animalia 98: 1-47.

LACÉPÈDE, B. G. E. DE LA VILlE (1788, 1789). Histoire natuelle des quadrupedes ovipares et des serpens. Paris: Academie royale des Sciences.

LAKJER, T. (1926). Studien ïber die Trigeminus-versorgte Kaumuskulatur der Satropsiden. Copenhagen: C. A. Reitzel.

LAKJER, T. (1927). Studien über die Gaumenregion bei Sauriern im Vergleich mit Anamniern und primitiven Sauropsiden. Zool. Jb. (Anat.) 49: 57-356.

Laurent, R. F. (1947). Note sur les Amphisbaenidae d'Afrique. Revue Zool. Bot. afr. 40: $52-63$.

Leblanc, E. (1920). Recherches sur les plexus choroides des reptiles (Anatomie-histologie-embryologie). Thèse Fac. Sci. Paris.

Lessmann, M. H. (1952). Zur labialen Pleurodontie an Lacertilier-Gebissen. Anat. Anz. 99: 35-67.

LINNÉ, C. v. (1758). Systema naturae per regna tria naturae. Editio decima, reformata. Holmiae: Laurenti Salvii.

LöNNBERG, E. (1902). On some points of relation between the morphological structure of the intestine and the diet of reptiles. Bih. K. svenska Vetensk Akad. Handl. 28 (4) (8): 1-51.

LOVERIDGE, A. (1920). Notes of East African lizards collected 1915-1919, with description of a new genus and species of skink and a new subspecies of gecko. Proc. zool. Soc. Lond. 1920: 131-167.

Loveridge, A. (1941). Revision of the African lizards of the family Amphisbaenidae. Bull. Mus. comp. zool. Harv. 87: $351-451$.

LoveridGe, A. (1955). On a second collection of reptiles and amphibians taken in Tanganyika Territory by C. J. P. Ionides, Esq. Jl E. Afr. nat. Hist. Soc. 22: 168-198.

LyNN, W. G. (1970). The thyroid. In Biology of the Reptilia 3: 201-234. Gans, C. \& Parsons, T. S. (Eds). London: Academic Press.

LyNN, W. G. \& Komorowski, L. A. (1957). The morphology of the thyroid gland in lizards of the families Pygopodidae and Amphisbaenidae. Herpetologica 13: 163-173.

LyNN, W. G. \& WALSH, G. A. (1957). The morphology of the thyroid gland in the Lacertilia. Herpetologica 13: $157-162$.

MacDonald, J. R. (1970). Review of the Miocene Wounded Knee faunas of southwestern South Dakota. Bull. Los Ang. Cty Mus. (Sci.) No. 8: 1-82.

MacLean, W. P. (1974). Feeding and locomotor mechanisms of teiid lizards: functional morphology and evolution. Papéis avuls. Zool. S. Paulo 27: 179-213.

Malan, M. E. (1946). Contributions to the comparative anatomy of the nasal capsule and the organ of Jacobson of the Lacertilia. Annale Univ. Stellenbosch 24(A): 60-137.

March, F. (1937). Relative growth in Amphibia. Proc, zool. Soc. Lond. (A) 1937: $415-469$.

MAtThey, R. (1931). Les chromosomes des amphisbéniens acrodontes (Trogonophis wiegmanni Kaup). Bull. Soc. vaud. Sci. nat. 57: 313.

Matthey, R. (1932a). Les chromosomes de l'amphisbénien acrodont Trogonophis wiegmanni Kaup. Archs Zool. exp. gen. 74: 193-203.

Matrhey, R. (1932b). Chromosomes de sauriens: Geckonidae, Eublepharidae, Gerrhosauridae, Amphisbaenidae pleurodontes. C. r. Séanc. Soc. Biol. 110: 273.

Matthey, R. (1932c). Nouvelle contribution à l'étude des chromosomes chez les sauriens. Bull. Soc. vaud. Sci. nat. 57: $587-588$.

Matthey, R. (1933). Nouvelle contribution à l'étude des chromosomes chez les sauriens. Revue suisse Zool. 40: 281-283.

MatThey, R. (1949). Les chromosomes des vertébrés. Lausanne: Librairie de l'Université.

Matthey, R. (1951a). The chromosomes of vertebrates. Adv. Genet. 4: 159-180.

Matthey, R. (1951 b). Systématique et critères cytologiques. Les chromosomes de Blanus cinereus Vand. (Lacertilia-Amphisbaenidae) et la méiose de Leucophaea maderae Brun. (Blattaria-Blaberidae). Bull. Soc. vaud. Sci. nat. 65: 111-120.

Matthey, R. (1954). Les chromosomes des vertébrés. Généralités. In Traité de Zoologie 2: 1044-1063. Grassé, P. P. (Ed.). Paris: Masson et Cie. 
MAY, E. (In press). Ein Beitrag zur Entwicklung des Schädels von Lepidosternon microcephalum Gray, 1845 (Reptilia-Amphisbaenia, Gray 1844). Senckenb. biol.

MAYer, C. (1826). Sur les membres postérieurs des ophidiens. Annls Sci. nat. 7: 170-191.

MAYER, C. (1829). Über die hintere Extremität der Ophidier. Nova Acta physico-med. 12: 821-842.

MCDowelt, S. B. \& Bogert, C. M. (1954). The systematic position of Lanthanotus and the affinities of the anguinomorphan lizards. Bull. Am. Mus. nat. Hist. 105: 1-142.

Meckel, J. F. (1818). Ueber das Respirationssystem der Reptilien. Dt. Arch. Physiol. 4: 60-89.

Meckel, J. F. (1829). System der vergleichenden Anatomie. Vierter Theil. Halle: Renger.

Menacho, A. (1915). El ojo anópsico del Blanus cinereus. Trab. Mus. nac. Cienc. Nat. Madr. (Zool.) No. 21: $1-50$.

Merrem, B. (1820). Versuch eines Systems der Amphibien. Tentamen Systematis Amphibiorum. Marburg: J. C. Krieger.

Miller, M. R. (1966). The cochlear duct of lizards. Proc. Calif. Acad. Sci. 33: 255-359.

Miller, M. R. (1968). The cochlear duct of snakes. Proc. Calif. Acad. Sci. 35: 425-476.

Miller, M. R. \& Lagtos, M. (1970). The pancreas. In Biology of the Reptilia 3: 319-346. Gans, C. \& Parsons, T. S. (Eds). London: Academic Press.

Müller, J. (1831). Beiträge zur Anatomie und Naturgeschichte der Amphibien. Z. Physiol. 4: 190-275.

MülleR, M. (1900). Die Reduktion des Brustschultergürtels bis zum völligen Verluste desselben. Inaug. Diss., Hesse und Becker, Leipzig.

MÜller, O. (1913). Neue Untersuchungen über die Extermitätengürtel von Anguis fragilis. Inaug. Diss., Bern, M. Dreschsel, Bern.

Oppes, M. (1811). Die Ordnungen, Familien und Gattungen der Reptilien als Prodrom einer Naturgeschichte derselben. München: Lindauer.

Ostrom, J. H. (1974). Archaeopteryx and the origin of flight. Q. Rev. Biol. 49: $27-47$.

Ostrom, J. H. (1975). The origin of birds. A. Rev. Earth Plan. Sci. 3: 55-77.

OWEN, R. (1840-1845). Odontography; or a treatise on the comparative anatomy of the teeth; their physiological relations, mode of development, and microscopic structure, in the vertebrate animals. 1 \& 2. London: Longmans Green.

OWen, R. (1866). On the anatomy of vertebrates. 1. Fishes and Reptiles. London: Longmans Green.

PARKer, H. W. (1942). The lizards of British Somaliland. Bull. Mus. comp. Zool. Harv. 91: 3-101.

PARKER, W. K. (1868). A monograph on the structure and development of the shoulder-girdle in the Vertebrata. London: Ray Soc.

Parsons, T. S. (1959). Nasal anatomy and the phylogeny of reptiles. Evolution 13: 175-187.

Parsons, T. S. (1970). The nose and Jacobson's organ. In Biology of the Reptilia 2: 99-191. Gans, C. \& Parsons, T. S. (Eds). London: Academic Press.

Parsons, T. S. \& CAMERon, J. E. (1977). Internal relief of the digestive tract. In Biology of the Reptilia 6: 159-223. Gans, C. \& Parsons, T. S. (Eds). London: Academic Press.

Paull, D., Williams, E. E. \& Hall, W. P. (1976). Lizard karyotypes from the Galapagos islands: Chromosomes in phylogeny and evolution. Breviora No. 441: 1-31.

PAYNE, F. (1906). The eyes of the blind vertebrates of North America. VII. The eyes of Amphisbaena punctata (Bell), a blind lizard from Cuba. Biol. Bull. mar. biol. Lab., Woods Hole 11: 60-70.

PernKopf, E. \& LeHner, J. (1937). 111. Vorderdarm. A. Vergleichende Beschreibung des Vorderdarmes bei den einzelnen Klassen der Kranioten. In Handbuch der vergleichenden Anatomie der Wirbeltiere 3: 349-476. Bolk, L., Göppert, E., Kallius, E. \& Lubosch, W. (Eds). Berlin and Wien: Urban and Schwarzenberg.

Peters, W. C. A. (1882). Über eine neue Art und Gattung der Amphisbaenoiden, Agamodon anguliceps, mit eingewachsenen Zähnen, aus Barava (Ostafrica) und über die zu den Trogonophides gehörigen Gattungen. Sber. preuss. Akad. Wiss. 1882: 579-584.

Pischinger, A. (1937). Kiemenanlage und ihre Schicksale bei Amnioten-Schilddrüse und epitheliale Organe der Pharynxwand bei Tetrapoden. In Handbuch der vergleichenden Anatomie der Wirbeltiere 3: 279-348. Bolk, L., Göppert, E., Kallius, E. \& Lubosch, W. (Eds). Berlin and Wien: Urban and Schwarzenberg.

Pratt, C. W. McE. (1948). The morphology of the ethmoidal region of Sphenodon and lizards. Proc. zool. Soc. Lond. 118: 171-201.

Presch, W. (1975). The evolution of limb reduction in the teiid lizard genus Bachia. Bull. S. Calif. Acad. Sci. 74: $113-121$.

Rathke, H. (1853). Ueber den Bau und die Entwicklung des Brustbeins der Saurier. Königsberg: E. J. Dalkowski. 
RathKe, H. (1857). Untersuchungen über die Aortenwurzeln und die von ihnen ausgehenden Arterien der Saurier. Denkschr. k. Akad. Wiss. Wien. (math. -naturwiss. Cl.) 13: 51-142.

RathKe, H. (1863). Untersuchungen über die Arterien der Verdauungswerkzeuge der Saurier. Abh. bayer. Akad. Wiss. 9: 125-183.

ReicheL, P. (1883). Beitrag zur Morphologie der Mundhöhlendrüsen der Wirbeltiere. Gegenbaur's morph.Jb.7:1-72. ReIG, O. A. (1967). Archosaurian reptiles: A new hypothesis on their origins. Science, N. Y. 157: 565-568.

Remane, A. (1936). Skelettsystem. 1. Wirbelsäule und ihre Abkömmlinge. In Handbuch der vergleichenden Anatomie der Wirbeltiere 4: 1-206. Bolk, L., Göppert, E., Kallius, E. \& Lubosch, W. (Eds). Berlin and Wien: Urban und Schwarzenberg.

Renous-LÉçuRU, S. (1973). Morphologie comparée du carpe chez les Lepidosauriens actuels (Rhynchocéphales, Lacertiliens, Amphisbéniens). Gegenbaurs morph. Jb. 119: 727-766.

RENous-LÉçURU, S. (1974a). Place des lépidosauriens actuels dans l'évolution des transformations constitutionnelles du plexus brachial des tétrapodes. Gegenbaurs morph. Jb. 120: 777-790.

ReNOUs-LÉçURU, S. (1974b). La musculature du membre antérieur de Bipes canaliculatus (Amphisbénidés, Reptiles). Bull. Mus. natn. Hist. nat., Paris (3) No. 248 (Zool.): 1262-1282.

Renous-LÉçuRu, S. (1977). Musculature of the buccal floor of Bipes canaliculatus (Reptilia, Amphisbaenidae). Copeia 1977: 464-471.

Richter, H. (1933). Das Zungenbein und seine Muskulatur bei den Lacertilia vera. Jena. Z. Naturwiss. 66: 395-480.

Rochon-Duvigneaud, A. (1943). Les yeux et la vision des vertébrés. Paris: Masson et Cie.

ROMER, A. S. (1956). Osteology of the reptiles. Chicago: Chicago Univ. Press.

RosenberG, H. I. (1967). Hemipenial morphology of some amphisbaenids (Amphisbaenia: Reptilia). Copeia 1967: 349-361.

Russell, A. P. (1976). Some comments concerning interrelationships amongst gekkonine geckos. In Morphology and biology of reptiles: 217-259. Bellairs, A. d'A. \& Cox, C. B. (Eds). [Linn. Soc. London, Symp. No. 3.] London: Academic Press.

SaINT Grons, H. (1961). Particularités anatomiques et histologiques de l'hypophyse chez les Squamata. Archs Biol., Paris 72: 211-299.

SaINT Girons, H. (1968). La morphologie comparée des glandes endocrines et la phylogenie des reptiles. Bijdr. Dierk. 37: 61-79.

Saint Girons, H. (1970). The pituitary gland. In Biology of the Reptilia 3: 135-199. Gans, C. \& Parsons, T. S. (Eds). London: Academic Press.

Saint Girons, H. (1972). Morphologie comparée du segment sexuel du rein des squamates (Reptilia). Archs Anat. microsc. morph. expér. $61: 243-266$.

SaINT Girons, H. (1975a). Sperm survival and transport in the female genital tract of reptiles. In The Biology of Spermatozoa: 105-113. Hafez, E. S. E. \& Thibault, C. G. (Eds). Basel: S. Karger.

SaINT Girons, H. (1975b). Développement respectif de l'épithelium sensoriel du cavum et de l'organe de Jacobson. chez les Lépidosauriens. C.r. hebd. Séanc. Acad. Sci., Paris (D) 280: 721-724.

SaINT Girons, H. \& Joly, J. (1975). Histologie et ultrastructure de la glande nasale externe du lacertilien Lacerta muralis et de l'amphisbenien Trogonophis wiegmanni (Reptilia, Lacertidae et Trogonophidae). Archs Biol. (Bruxelles) 86: 97-126.

SAINT Girons, M. C. (1970). Morphology of the circulating blood cells. In Biology of the Reptilia 3: 73-91. Gans, C. \& Parsons, T. S. (Eds). London: Academic Press.

SaINT Girons, M. C. \& Saint Girons, H. (1969). Contribution à la morphologie comparée des érythrocytes chez les reptiles. Br.J. Herpet. 4: 67-82.

SALLE, O. (1880). Untersuchungen über die Lymphapophysen der Schlangen und schlangenähnlichen Sauriern. Diss. inaug., Göttingen Univ., Leipzig.

Schmidt, R. S. (1964). Phylogenetic significance of lizard cochlea. Copeia 1964: 542-549.

SCHMid, W. J. (1909). Beiträge zur Kenntniss der Parietalorgane der Saurier. Z. wiss. Zool. 92: 359-426.

SCHNABEL, R. (1956). Beitrag über die frühen Entwicklungsstadien des Eizahns und das Abortivgebiss des Zwischenkiefers bei Natrix natrix. Z. mikrosk.-anat. Forsch. 62: 40-50.

SCHrEIBER, E. (1875). Herpetologia Europaea. Eine systematische Bearbeitung der Amphibien und Reptilien, welche in Europa aufgefunden sind. Braunschweig: Vieweg und Sohn.

SENIOR, W. (1974). Parathyroid gland structure in some tropical lizards. J. Morph. 142: 91-103.

SENN, D. G. (1974). Notes on the amphibian and reptilian thalamus. Acta anat. 87: 555-596.

SentZen, U. J. (1796). Ophiologische Fragmente. In Zoologisches Archiv, part 2. Leipzig: F. A. A. Meyer. 
Sheppard, L. \& Bellairs, A. d'A. (1972). The mechanism of autotomy in Lacerta. Br. J. Herpet. 4: 276-286.

Simon, J. (1844). On the comparative anatomy of the thyroid gland. Phil. Trans. R. Soc. 134: 295-303.

SimonetTA, A. M. (1960). Distribuzione e significato dell'organo paratimpanico del Vitali. Atti Soc. tosc. Sci. nat. (B) 66: 39-55.

Skoczylas, R. (In press). Physiology of the digestive tract. In Biology of the Reptilia 8. Gans, C. \& Gans, K. A. (Eds). London: Academic Press.

Smalian, C. (1884). Beiträge zur Anatomie der Amphisbaeniden. Z. wiss. Zool. 42: 126-202.

Smith, M. A., Beilairs, A. d'A. \& Miles, A. E. W. (1953). Observations on the premaxillary dentition of snakes with reference to the egg-tooth. J. Linn. Soc. (Zool.) 42: 260-261.

Sonnini, C. S. \& LATReille, P. A. (1802). Histoire naturelle des reptiles, avec figures dessinées d'après nature. 4 vols. Paris: Deterville.

Sottovia-Filho, D. (1974). Morphology and histochemistry of the Mast cells of snakes. J. Morph 142: 109-116.

Sottovia-Filho, D. \& Junqueira, L. C. U. (1972). Studies on the connective tissue of the snake Xenodon merremii (Wagler, 1824). Arch. hist, japon. 34: 143-154.

Sottovia-Filho, D., Leite-Ribeiro, M. C., Junqueira, L. C. U. \& Carneiro, J. (1972). Studies on granular acidophilic cells in the connective tissue of the snake Xenodon merremii (Wagler, 1824). Revta bras. Biol. 32: $127-132$.

Sottovia-Filho, D., Leite-Ribeiro, M. C. \& Junqueira, L. C. U. (1973). An amphoteric character in mast cell granules of Amphisbaena filliginosa, a snake like lizard. Arch. hist. japon. 35: 249-254.

Stannius, H. (1856). Die Wirbelthiere. Zootomie der Amphibien. In Handbuch der Zootomie. 2nd ed. von Siebold, Ph.-F. \& Stannius, H. (Eds). Berlin: Veit and Co.

Strauch, A. (1881). Bemerkungen über die Eidechsenfamilie der Amphisbaeniden. Mélang. Biol. Acad. Imp. Sci. St. Pétérsb. 11: 355-479. [Repr. Bull. Acad. Sci. St. Pétérsb. 28: 45-131.]

SukHanov, V. B. (1961). Some problems of the phylogeny and systematics of Lacertilia. Smithson. Herp. Inf. Serv. No. 38: 1-15. [In Russian.]

TAMMAR, A. R. (1974). Bile salts of reptilia. In Chemical zoology: 9: 337-351. Florkin, M. and Scheer, B. T. (Eds). New York: Academic Press.

TAYLOR, E. H. (1951). Concerning Oligocene amphisbaenid reptiles. Kans. Univ. Sci. Bull. 34: 521-579.

ThomAs, R. (1965). Two new subspecies of Amphisbaena (Amphisbaenia, Reptilia) from the Barahona peninsula of Hispaniola. Breviora No. 215: 1-14.

THROCKMORTON, G. S. (1977). The structure of the "periodontal tissues" in the agamid lizard Uromastix aegyptitls. Anat. Rec. 187: 730 .

Thulborn, R. A. (1975). Dinosaur monophyly and the classification of archosaurs and birds. Austr. J. Zool. 23: 249-270.

THurber, J. (1933). My life and hard times. New York: Harper and Row.

TiedemanN, F. (1976). Vergleichend anatomische Untersuchungen an Muskeln und Knochen des Beckengürtels von Ophisaurus harti Blgr., Ophisaurus apodus Pall. und Ophisaurus koellikeri Gthr. Annln naturh. Mus. Wien 80: 325-335.

ToErien, M. J. (1963). The sound conducting system of lizards without tympanic membranes. Evolution, Lancaster, Pa. 17: 540-547.

Toerien, M. J. (1965). An experimental approach to the development of the ear capsule in the turtle, Chelydra serpentina. J. Embryol. exp. Morph. 13: 141-149.

UNDERwOOD, G. (1957a). Lanthanotus and the anguinomorphan lizards: A critical review. Copeia 1957: $20-30$.

UNDERwood, G. (1957b). Lizards of the family Pygopodidae. A contribution to the morphology and phylogeny of the Squamata. J. Morph. 100: 207-268.

UNDERWOOD, G. (1967). A contribution to the classification of snakes. London: British Museum (Natural History).

Underwood, G. (1970). The eye. In Biology of the Reptilia 2: 1-97. Gans, C. \& Parsons, T. S. (Eds). London: Academic Press.

UNDERwood, G. (1971). A modern appreciation of Camp's "Classification of the Lizards". [In C. Camp's Classification of the lizards.] Misc. Publs Soc. Study Amphibians Reptiles: pp. vii-xvii.

UNDERwOOD, G. (1977). Simplification and degeneration in the course of evolution of squamate reptiles. In Mécanismes de la Rudimentation des Organes chez les Embryons de Vertébrés: 341-352. Raynaud, A. (Ed.). Col. Int. C.N.R.S. Paris No. 266.

Uzzell, T. (1973). A revision of lizards of the genus Prionodactylus, with a new genus for P. leucostictus and notes on the genus Euspondylus (Sauria, Teiidae). Postilla No. 159: 1-67. 
VAN DeN HeEver, J. A. (1976). The cranial and cervical muscles of the South African limbless lizard Typhlosaurus aurantiacus aurantiacus Peters (Reptilia, Sauria). Ann. S. Afi. Mus. 69: 169-214.

VAn der Merwe, N. J. (1940). Die liggamsvate van Monopeltis capensis Smith sp. Tydskr. Wet. Kuns 1: 201-207.

Vanzolini, P. E. (1951a). Evolution, adaptation and distribution of the amphisbaenid lizards (Sauria: Amphisbaenidae). Thesis, Harvard Univ.

Vanzolini, P. E. (1951b). A systematic arrangement of the family Amphisbaenidae (Sauria). Herpetologica 1: 113-123.

VERRIER, M.-L. (1932). Sur les rapports entre la structure des yeux et le comportement. Indications fourniers par l'étude des reptiles (Note preliminaire). Archs Zool. exp. gén. 74: 307-316.

VERRIER, M.-L. (1933). Recherches sur la vision des reptiles. Étude comparée de la morphologie des cellules visuelles et du pouvoir séparateur de la rétine. Bull. biol. Fr. Belg. 67: 351-369.

VersLuYs, J., JR (1898). Die mittlere und äussere Ohrsphäre der Lacertilia und Rhynchocephalia. Zool. Jb. (Anat.) 12: $161-406$.

VersLuYs, J., JR (1903). Entwicklung der Columella auris bei den Lacertiliern. Ein Beitrag zur Kenntniss der schalleitended Apparate und des Zungenbeinbogens bei den Sauropsiden. Zool. Jb. (Anat.) 18: 107-188.

VERSLUYS, J., JR (1910). Streptostylie bei Dinosauriern, nebst Bemerkungen über die Verwandschaft der Vögel und Dinosaurier. Zool. Jb. (Anat.) 30: 175-260.

VersluYs, J., JR (1912). Das Streptostylie-Problem und die Bewegungen im Schädel bei Sauropsiden. Zool. Jb. (Suppl.) 15: 545-716.

Versluys, J., JR (1936). Kranium und Visceralskelett der Sauropsiden. 1. Reptilien. In Handbuch der vergleichenden Anatomie der Wirbeltiere 4(D): 699-808. Bolk, L., Göppert, E., Kallius, E. \& Lubosch, W. (Eds). Berlin: and Wien Urban und Schwarzenberg.

VISSER, J. (1967). First report of ovoviviparity in a Southern African amphisbaenid, Monopeltis c. capensis. Zool. afr. 3: 111-113.

VoGT, C. (1840). Beiträge zur Neurologie der Repttlien. Neuchâtel.

Von Hofsten, N. (1941). On the phylogeny of the Reptilia. Zool. Bidr. Upps. 20: 501-521.

WAGLer, J. (1830). Natürliches System der Amphibien. Munich, Stuttgart, Tübingen: J. G. Cotta.

WAGNER, R. (1841). Icones zootomicae. Handatlas zur vergleichenden Anatomie. Leipzig.

WAGNER, R. (1843). Lehrbuch der Zootomie ... Erster Theil. Anatomie der Wirbelthiere. Leipzig: Voss.

WALLS, G. L. (1942). The vertebrate eye and its adaptive radiation. Bull. Cranbrook Inst. Sci. No. 19: 1-785.

WeVER, E. G. (1967a). The tectorial membrane of the lizard ear: Types of structure. J. Morph. 122: 307-320.

Wever, E. G. (1967b). The tectorial membrane of the lizard ear: Species variation. J. Morph. 123: 355-372.

WeVER, E. G. (In press). The reptilian ear. Princeton, New Jersey: Princeton University Press.

Wever, E. G. \& Gans, C. (1972). The ear and hearing in Bipes biportus. Proc. natn. Acad. Sci. U.S.A. 69: 2714-2716.

WeVER, E. G. \& Gans, C. (1973). The ear in Amphisbaenia (Reptilia): further anatomical observations. J. Zool., Lond. 171: 189-206.

Whiting, A. M. (1967). Amphisbaenian cloacal glands. Am. Zool. 7: 302.

Whiting, A. M. (1969). Squamate cloacal glands: morphology, histology and histochemistry. PhD diss. Pa State Univ.

WiedemanN, E. (1932). Zur Ortsbewegung der Schlangen und Schleichen. Zool. Jb. (Zool.) 50: 557-596.

Wiedersheim, R. (1886). Lehrbuch der vergleichenden Anatomie der Wirbelthiere. 2nd ed. Jena: Gustav Fischer.

Wiegmann, A. F. A. (1834). Herpetologia mexicana, seu descriptio amphibiorum novae hispaniae. Pars prima, saurortum species. Berlin: Lüderitz.

Willtams, E. E. (1959). Gadow's arcualia and the development of tetrapod vertebrae. Q. Rev. Biol. 34: 1-32.

Williston, S. W. (1917). The phylogeny and classification of reptiles. J. Geol., Chicago 25: 411-421.

Williston, S. W. (1918). The evolution of vertebrae. Contr. Walker Mus. 2: 75-85.

WiLliston, S. W. (1925). Osteology of reptiles. Cambridge: Harvard University Press.

Windischmann, C. J. (1831) De Penitiori Auris in Amphibiis Structura. Dissertatio Inauguralis Anatomica. Univ. Frid. Wilhelm, Thormannianus, Bonn. [One of the first mentions of the columella-extracolumella story.]

Wofrdeman, M. W. (1919). Beiträge zur Entwicklungsgeschichte von Zähnen und Gebiss der Reptilien. Beitrag III. Über den Eizahn. Arch. mikrosk. Anat. 92: 104-244.

WoErdeman, M. W. (1921a). Beiträge zur Entwicklungsgechichte von Zähnen und Gebiss der Reptilien. Beitrag IV. Über die Anlage und Entwicklung der Zähne. Arch. mikrosk. Anat. 95: 265-395. 


\section{GANS}

WOERDEMAN, M. W. (1921b). Beiträge zur Entwicklungsgeschichte von Zähnen und Gebiss der Reptilien. Beitrag V. Über die Beziehungen der Mundhöhlendrüsen zum Zahngarten. Arch. mikrosk. Anat. 95: 396-413.

WYETH, F. J. (1924). The development of the auditory apparatus in Sphenodon punctatus, with an account of the visceral pouches, aortic arches and other accessory structures. Phil. Trans. R. Soc. (B) 212: 259-368.

YatKolA, D. A. (1976). Mid-Miocene lizards from western Nebraska. Copeia 1976: 645-654.

Young, C. (1961). On two new fossil lizards of China. Vertebr. palasiat. 2: 115-120.

ZANGere, R. (1944). Contributions to the osteology of the skull of the Amphisbaenidae. Am. Midl. Nat. 31: 417-454.

ZANGERL, R. (1945). Contributions to the osteology of the post-cranial skeleton of the Amphisbaenidac. Am. Midl. Nat. 33: 764-780.

ZAVATTARI, E. (1910). I muscoli ioidei dei Sauri in rapporto con i muscoli ioidei degli altri vertebrati. Richerche morphologiche. Part 1. Memorie Accad. Sci. Torino (2) 60: 351-392. Part 2. (2) 61: 55-134. 